University of Louisville

ThinkIR: The University of Louisville's Institutional Repository

Electronic Theses and Dissertations

$12-2007$

\title{
Gene therapy and cellular transplantation : towards a combination strategy for spinal cord injury repair.
}

Ahmed Abdelzaher Abdellatif

University of Louisville

Follow this and additional works at: https://ir.library.louisville.edu/etd

Part of the Neuroscience and Neurobiology Commons

\section{Recommended Citation}

Abdellatif, Ahmed Abdelzaher, "Gene therapy and cellular transplantation : towards a combination strategy for spinal cord injury repair." (2007). Electronic Theses and Dissertations. Paper 2.

https://doi.org/10.18297/etd/2

This Doctoral Dissertation is brought to you for free and open access by ThinkIR: The University of Louisville's Institutional Repository. It has been accepted for inclusion in Electronic Theses and Dissertations by an authorized administrator of ThinkIR: The University of Louisville's Institutional Repository. This title appears here courtesy of the author, who has retained all other copyrights. For more information, please contact thinkir@louisville.edu. 


\title{
GENE THERAPY AND CELLULAR TRANSPLANTATION; TOWARDS A COMBINATION STRATEGY FOR SPINAL CORD INJURY REPAIR
}

\author{
By \\ Ahmed Abdelzaher Abdellatif \\ M.D., Alexandria University, Egypt 1990 \\ M.Sc., Alexandria University, Egypt 1997 \\ M.S., University of Louisville, 2004
}

A Dissertation Submitted to the Faculty of the Graduate School of the University of Louisville in Partial Fulfillment of the Requirements for the Degree of

Doctor of Philosophy

Department of Anatomical Sciences and Neurobiology

University of Louisville

School of Medicine

Louisville, Kentucky

December, 2007 
GENE THERAPY AND CELLULAR TRANSPLANTATION: TOWARDS A

COMBINATION STRATEGY FOR SPINAL CORD INJURY REPAIR

By

Ahmed Abdelzaher Abdellatif

M.D., Alexandria University, Egypt 1990

M.Sc., Alexandria University, Egypt 1997

M.S., University of Louisville, 2004

A Dissertation Approved on

November $30^{\text {th }}, 2007$

By the Following Dissertation Committee

Scott R. Whittemore Ph.D. (Thesis Director)

Xiao-Ming Xu M.D., Ph.D. (Thesis Co-Director)

Theo Hagg M.D., Ph.D.

Fred J. Roisen, Ph.D. 


\section{DEDICATION}

This thesis is dedicated to

My parents for dedicating their life to the prosperity of their children. 


\section{ACKNOWLEDGMENTS}

I would like to thank my dissertation advisors and mentors, Dr. Scott R. Whittemore, and Dr. Xiao-Ming Xu, for their guidance, valuable support, and patience. I would also like to thank my other committee members, Dr. Theo Hagg, Dr. Stephen Onifer and Dr. Fred Roisen, for their valuable support and guidance throughout my training. I am indebted to Jennifer Pelt, Russ Howard and Dr. Richard Benton for their valuable assistance and constructive advice. I also would like to thank all Whittemore laboratory members, and all Xu laboratory members for their friendship and support. I am also deeply indebted to all member of KSCIRC for their support during my training.

Finally, I would like to thank my wife Salwa, and kids Omar, Rana, Faris and Momen for their love, and support. 


\title{
ABSTRAC'T \\ GENE THERAPY AND CELLULAR TRANSPLANTATION: TOWARDS A COMBINATION STRATEGY FOR SPINAL CORD INJURY REPAIR
}

\author{
Ahmed A. Abdellatif \\ November, 302007
}

The combination of viral mediated gene delivery, tissue engineering, and Schwann cell (SC) transplantation offer a promising strategy to enhance axonal regeneration and functional recovery following spinal cord injury (SCI). The rationale and feasibility of using such combination has been extensively reviewed in Chapter 1 .

The study presented in Chapter 2 showed that lentiviral vectors are most suitable in situations where stable long term transgene expression is needed, while adenovirus and retrovirus are more suited for transient gene delivery.

Tissue engineering combined with Schwann cell (SC) transplantation is a promising method to enhance regeneration and remyelination of axons following a thoracic spinal cord injury (SCI). Previously, SCs in semi-permeable guidance channels madle of polyacrylonitrile and polyvinylchloride (PAN/PVC) copolymers were shown to promote the growth of axons into the graft environment. In Chapter 3, we test whether different PAN/PVC mini-channel geometries affects axonal regeneration, we compared three types of channels, i.e. channels with smooth inner wall, channels with grooved 
inner wall, and channels filled with filaments using this model. Our results showed that grooving of the channel inner wall along the axis of the channel resulted in a significantly higher number (730.66 \pm 252.76$)$ of myelinated axons at the channel mid-point, compared to the channels with smooth inner wall $(539.4 \pm 287.63 ; \mathrm{p}<0.01)$, indicating an enhancement of axonal regeneration when grooves are provided within the channel. In contrast, channels filled with filaments had a significantly lower number of myelinated axons $(163.54 \pm 76.04)$ than both the grooved and smooth inner wall channels $(\mathrm{p}<0.001)$, indicating that densely-packed filaments prohibited axonal growth into the channel. This type of channels may need to be modified to incorporate growth-promoting molecules on filament surface and/or decrease the number of filaments inside the channel to provide attractiveness and/or space for more axons to grow. We conclude that the use of channels with grooved inner wall, combination with seeded SCs, is more suitable for axonal regeneration and myelination following $\mathrm{SCI}$ than the other two channel types. This combination can be used in further studies with the addition of regeneration enhancing factors such as neurotrophins.

In Chapter 4, we examined axonal regeneration following transplantation of PAN/PVC mini-channel seeded with SCs that were infected with 3 viral vectors, i.e. retroviral, adenoviral, and lentiviral vectors. Although, animals in LZRS-D15A SCs group had a significantly lower number of myelinated axons compared to lentiD15A group they showed significant improvement in grid walking test. We conclude that different patterns of transgene expression may enhance regeneration and myelination of different populations of regenerating axons following thoracic SCI. 
In conclusion, combination strategies for $\mathrm{SCI}$ using different transgene expression patterns and different channel inner wall geometry enhance axonal regeneration and myelination. Functional recovery however, may be the result of reorganization of spinal cord circuitry rather than successful axonal regeneration. 



\section{TABLE OF CONTENTS}

PAGE

ACKNOWLEDGMENT

ABSTRACT

IV

LIST OF FIGURES

CHAPTER 1

1

INTRODUCTION

Anatomy of the Spinal Cord

Pathology of Spinal Cord

Injury

Experimental models for SCI

Neurotrophic factors

D15A Neurotrophin Molecule

The Schwann Cell

Tissue engineering for spinal

cord injury repair

Combination strategies for

SCI repair

CHAPTER 2.

Gene therapy for spinal cord injury: a comparison between lentiviral, adenoviral, 
and retroviral vector delivery systems.

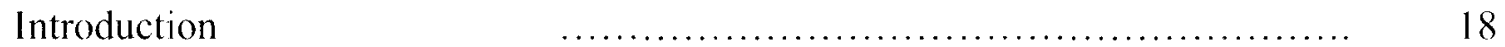

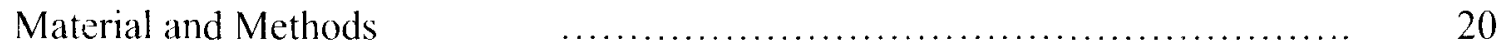

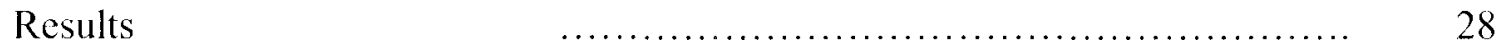

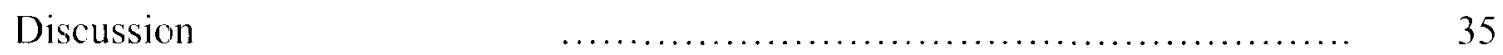

CHAPTER 3

Axonal regeneration into Schwann cell-seeded PAN/PVC guidance channels

following a mid-thoracic spinal cord hemisection: A comparison between 3 types of channel geometry.

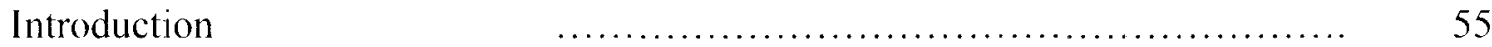

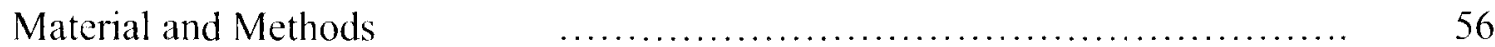

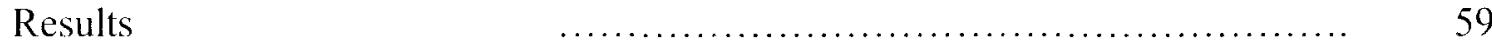

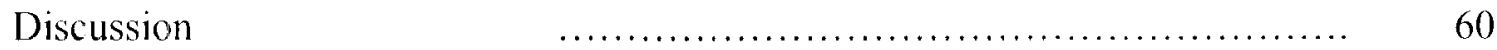

CHAPTER 4

Axonal regeneration into guidance channels sceded with neurotrophin-secreting $\quad 65$

Schwann cells following a mid-thoracic spinal cord hemisection: effects of altered temporal expression.

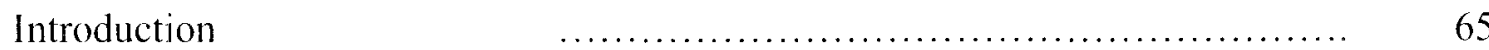

Material and Methods $\quad$............................................ 67

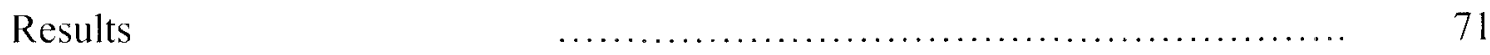

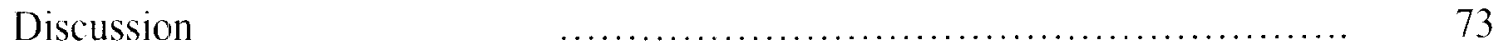

CHAPTER 5: Discussion $\quad$.......................................... 83 
References

Appendix.

Curriculum Vitae 


\section{LIST OF FIGURES}

FIGURE

PAGE

1.1 The Edwin Smith surgical papyrus

2.1 Schwann cells infection and biological activity of D15A

2.2 Temporal expression of D15A in the spinal cord after ex vivo gene delivery using lentivirus, adenovirus, EGFP, and retrovirus

2.3 D15A protein expression is dependent on viral titer

2.4 Inflammatory response and cell-specific infection by low titer

lentiviral and adenoviral vectors in the spinal cord

2.5 Identification of cell types infected with high titer lentivirus and adenovirus

2.6 Temporall expression of D15A in the spinal cord after in vivo gene delivery

2.7 Induction of D15A expression using doxycycline (Dox) in vitro and in vivo

3.1 Comparison between three types of channels

4.1 Stereological assessment of myelinated axons, cable area and blood vessels

4.2 Grid walk and Hargraeve's Behavioral testing

4.3 Relative density of $\mathrm{EDI}^{+}$staining and $\mathrm{GFAP}^{+}$staining 


\section{CHAPTER 1}

\section{INTRODUCTION}

The earliest recorded evidence of spinal cord injury (SCI) is from an Egyptian text (Fig 1.1) written in 2500 B.C. (Breasted 1980) "When you examine a man with a dislocation of a vertebra of his neck, and you find him unable to move his arms, and his legs...Then you have to say: a disease one cannot treat" (Case and Tessier-Lavigne 2005).

The first evidence of regenerative capacity in the spinal cord came in the early 1900s when Ramón y Cajal described "the cone of growth" in the injured spinal cord and suggested that the absence of guiding factors is the reason behind their failure to regenerate (Ramón y Cajal, 1952). An early recorded attempt at tissue transplantation to treat human SCI came in 1944 when a St. Louis surgeon transplanted a piece of formalin fixed cadaver spinal cord into the injured spinal cord of a 16y old male; he died three months postoperative without any functional improvement (Woolsey 1944). To date, spinal cord injured patients do not have a cure to their disability. Scientists at the Kentucky Spinal Cord Injury Research Center (KSCIRC) as well as other researchers worldwide are making steady steps towards the goal of bringing a cure to these patients. 
Every year approximately 11,000 new cases of SCI are reported in the U.S. $82 \%$ of which are males. The highest per capita rate of injury occurs between the ages of 1630 (National Spinal Cord Injury Association, and the National Spinal Cord Injury Statistical Center, Birmingham, Alabama, http://www.spinalcord.org/html/factsheets/spinstat.php). Currently, 200,000-400,000 people in the U.S. are living with SCI. These patients suffer from the consequences of their injury resulting in dysfunction and loss of sensory, motor and autonomic function. Patients with high level cervical injuries suffer more serious complications including fatal respiratory and pressure ulcers. The work presented here focuses mainly on providing axonal regeneration in a thoracic SCI in rat.

\section{Anatomy of the Spinal Cord}

The spinal cord develops from the caudal two thirds of the neural tube and extends through the neural canal of the vertebral column. Its rostral end continues into the medulla through the foramen magnum and the caudal end terminates in the conus medullaris. The spinal cord has two enlargements: the cervical from C5 to T1 and the lumbar from $\mathrm{L} 1$ to $\mathrm{S} 2$. These enlargements are caused by the higher motor innervation density for the limbs.

The spinal cord is arranged so that the central H-shaped gray matter is surrounded by the spinal white matter comprised of the ascending and descending fibers of the spinal tracts. The gray matter is grossly divided into dorsal horns, and ventral horns.

Histologically, it is divided into 9 Rexed laminae from dorsal to ventral, with the 10th lamina surrounding the central canal of the spinal cord. Damage to the cervical 
enlargements and less commonly the lumbar enlargements also contributes to the deficit that follows spinal cord injury.

The white matter is subdivided into three major funiculi: dorsal, ventral and lateral. Spinal tracts are grouped into ascending sensory tracts: the posterior dorsal column (gracile, and cuneate fasciculi), the anterolateral system (spinothalamic, spinoreticular, spinomesencephalic, and spinotectal tracts), and the spinocerebellar system (anterior, posterior and cuneo- cerebellar tracts). The descending motor system is divided into: corticospinal, rubrospinal, tectospinal, reticulospinal and vestibulospinal tracts. The disruption of these ascending and descending tracts as well as gray matter leads to much of the disability encountered following SCI.

The spinal cord is supplied by longitudinal arterial trunks that receive segmental arteries. Each segmental artery divides outside the spinal canal into 3 branches: the anterior and posterior spinal canal arteries as well as the radicular artery which continues along the nerve roots and divides into anterior and posterior radicular arteries. After penetrating the dura mater, the anterior and posterior radicular arteries join the anterior median longitudinal and the right and left posterolateral longitudinal spinal arteries. Numerous anastomoses exist between these arteries forming the pial plexus (Mautes, Weinzierl et al. 2000). Central arteries from the anterior median longitudinal arteries and arterioles from the pial plexus form the intrinsic blood supply of the spinal cord. Large anterior and posterior central veins collect venous blood and drain to the anterior and posterior radicular veins. 


\section{Pathology of Spinal Cord Injury}

Trauma to the vertebral column results in distortion of the neural arch and sudden narrowing of the vertebral canal. This results in compression, contusion and/or tearing of the meninges and spinal cord tissue, with disruption of the blood supply and breaching of the blood - spinal cord barrier (BSCB). The loss of sympathetic control over the vascular system results in the life threatening "spinal shock" (Black and Rossitch. 1995). Care for acute SCI patients is mainly directed at resuscitation, stabilization of spinal fractures, and the control of spinal shock stage. Neurological defects following SCI result primarily from damage of spinal tracts, disruption of vascular supply and electrolyte imbalance (Tator 1998). Reports available on the pathology of human SCI suggest that the rat contusion lesion (Metz, Curt et al. 2000) is similar to a large number of human SCI (Kakulas 1988; Bunge, Puckett et al. 1993).

\section{Experimental models for SCI.}

To replicate human SCI, researchers have developed multiple experimental SCI models. The consensus is that these models have to be reliable, and reproducible, which make it possible to predict outcomes and test possible therapeutic measures. These models include contusion (Allen, D'Angelo et al. 1974; Basso, Beattie et al. 1996), compression (Guth, Zhang et al. 1994), ischemia (Kanellopoulos, Kato et al. 1997), and crush (Zhang and Guth 1997; Zhang, Krebs et al. 1997) injuries, which generate controlled injuries that mimic some, but not all, clinical aspects of the mechanical damage and posttraumatic ischemia that occur following human SCI. The transection (Noble and Wrathall 1989) hemisection (Xu, Guenard et al. 1995; Xu, Chen et al. 1997; 
Xu, Zhang et al. 1999) model provides a controlled injury for unequivocally evaluating axonal regeneration strategies. Hemisection provides an additional internal control in the non-injured side of the cord. However, these later injuries share little pathological relevance to the majority of human SCI.

The immediate events following traumatic contusion/compression experimental SCI models are intraparenchymal hemorrhage and vasospasm of spinal arteries, which start in the most vulnerable spinal gray matter (Ducker and Hamit 1969). The disruption of blood vessels following trauma leads to loss of the $\mathrm{BSCB}$ with resulting edema, infiltration of monocytes and macrophages, and release of cytokines leading to a decrease of spinal tissue perfusion. This ischemia triggers cell death and excitotoxicity. Necrosis and phagocytosis of dead spinal tissue typically leads to cavity formation and axonal degeneration and demyelination. Recent data (Johnson, Taylor et al. 1995; Crowe, Bresnahan et al. 1997; Liu, Xu et al. 1997; Beattie, Li et al. 2000; Beattie, Hermann et al. 2002; Beattie 2004) suggest that apoptosis of both neurons and glia also plays a important role in the final pathologic picture.

Spinal cord injury research is geared towards reducing secondary injury following an initial trauma including neuroprotection to preserve the intact spinal tissue and preventing neuronal cell loss, as well as enhancing regeneration and myelination of injured axons by particularly modifying the non-permissive environment at the injury site.

Neurotrophic factors

Neurotrophic factors (NTFs) are molecules that have evolved in several gene families and are important factors that influence the development, maintenance, function 
and plasticity of the nervous system. NTFs are made in the targets of dependant cells at the time of innervation. The synthesis of these molecules is controlled such that the transcription of mRNA is regulated during development and can be altered in adult animals by injury and changes in neural activity (Heumann 1987; Lindholm 1994; Lindholm, Castren et al. 1994; Lindholm, da Penha Berzaghi et al. 1994; Lindholm, Harikka et al. 1994; Lewin and Barde 1996). The survival of different neurons appears to be dependent on multiple factors from the same family or from multiple families that can be required sequentially or simultaneously (Oppenheim and Haverkamp 1988;

Oppenheim, Prevette et al. 1991; Oppenheim, Yin et al. 1992; Oppenheim, Prevette et al. 1993; Snider 1994; Oppenheim, Houenou et al. 2000). Some neurons appear to change either their dependency from one factor to another during development (Davies 1994) or their response to the same factor during different developmental stages. These changes are due to receptor modification as well as changes in their downstream signaling pathways. In neonatal (postnatal days $\mathrm{P} 3$ to P10) rats the spinal cord expresses higher levels of nerve growth factor (NGF), brain derived neurotrophic factors (BDNF), neurotrophin-3 (NT-3) and glial derived neurotrophic factor (GDNF) mRNA expression and a lower level of ciliary neurotrophic factor (CNTF) when compared with the adult normal spinal cord. In P10-P17 neonatal rats, levels of NGF, BDNF, NT-3 decreased with a significant increase in CNTF mRNA levels. This shift of NTFs expression in the developing neonatal spinal cord indicates changing dependency (Nakamura and Bregman 2001). NTFs are believed to be retrogradely, as well as anterogradely transported along axons (Fawcett et al. 2000). This transport may mediate local effects at synaptic sites, and regulate dendritic growth, neuronal cytoarchitecture, and phenotypes (Altar, Cai et al. 
1997; Fawcett 2002). The transport of NT-3 for example has been found to be dependent on extracellular sodium, intact microtubules and microfilaments, and requires the release of calcium from intracellular stores (Wang, Reece et al. 2002)

The neurotrophins (NGF, BDNF, NT-3, NT-4/5 and NT-6) bind, dimerize and activate protein tyrosine kinases which subsequently act on substrates and signaling pathways shared with other growth and differentiation factors. NGF binds TrkA, BDNF and NT-4 bind TrkB, and NT-3 binds TrkC. These neurotrophins also bind to the low affinity neurotrophin receptor $\mathrm{p} 75^{\mathrm{NTR}}$ that is closely related to the tumor necrosis factor (TNF) receptor family (Bothwell 1995; Kaplan and Miller 1997). NT-3 gene ablation in mice was found to cause a more severe phenotype than deletion of its receptor TrkC, indicating that NT3 also acts through other receptors (Coppola, Kucera et al. 2001) including TrkA, TrkB and the $\mathrm{p} 75^{\mathrm{NTR}}$.

Neurotrophins regulate axon growth in vitro (Levi-Montalcini 1987) and target tissue innervation in vivo (Tsoulfas, Soppet et al. 1993). Importantly they were found to have protective effects on neurons in the CNS. NT-3 and BDNF play important roles in the spinal cord both during development and post-SCI. BDNF promotes axonal regeneration of spinal axons including local motor, sensory, and cerulospinal axons. NT3 enhances growth and sprouting of ascending sensory axons (Oudega and Hagg 1999). Table 1.1 (Lu and Tuszynski 2007) shows the Sensitivity of spinal cord axons to different growth factors. This information is very important in design of experiments targeting specific axons following SCI. In our design we are using D15A a molecule with BDNF and NT-3 activities, based on previous evidence we expect dorsal column sensory axons, 
rubrospinal axons, reticulospinal axons, vestibulospinal axons and local motor as well as sensory axons to be responsive to D15A neurotrophic activity.

Changes in NTFs levels have been shown following SCI both in the neonate and adult spinal cords. As assessed by ribonuclease protection assay following $\mathrm{SCI}$ in the adult rat, NGF and CNTF mRNA increased between 1-4 days, while BDNF and GDNF transiently increased at 1 day post-injury. When compared to expression levels following SCI injury in neonatal rats, BDNF mRNA was significantly lower and CNTF mRNA significantly higher in adult rats indicating an important role of higher levels of BDNF in axonal regeneration following SCI in the early neonatal period (Nakamura and Bregman 2001). Following SCI, NT-3 were shown to influence collateral sprouting (Schnell, Schneider et al. 1994; Weaver, Marsh et al. 2006).

Delivery of neurotrophins to the CNS has been studied using both ex vivo and in vivo viral approaches. Genetically modified fibroblasts (Tuszynski, Grill et al. 2003), astrocytes (Smith, Hale et al. 1996), stem cells (Falk, Holmstrom et al. 2002), SCs (Menei, Montero-Menei et al. 1998; Tuszynski, Weidner et al. 1998), and olfactory ensheathing cells (Ruitenberg, Plant et al. 2002; 2003) were transplanted into the spinal cord to support axonal growth and regeneration. These studies have demonstrated the great potential of combining gene therapy with cellular grafts to enhance neuroprotection and regeneration following $\mathrm{SCI}$.

\section{D15A Neurotrophin Molecule.}

Mutational analysis of the interaction of Human NT-3 with its receptors TrkC and p75 and the study of amino acid residues located on the surface of NT-3 using alanine 
scanning mutagenesis defined the surface interaction of NT-3 with TrkC and p75

(McDonald and Blundell 1991; Urfer, Tsoulfas et al. 1994). D15A, one of the NT-3 mutants developed by Urfer and colleagues (Urfer, Tsoulfas et al. 1994) was tested for binding to TrkA, TrkB, and TrkC and found to bind firmly to TrkB, TrkC as well as the p75 receptor. Further testing showed that D15A induced auto-phosphorylation on PC12/TrkB cells that was similar to that achieved by BDNF. This indicated that D15A had both NT-3 and BDNF activities.

\section{The Schwann Cell}

Peripheral nerves are composed of an outer epineurium of connective tissue, fibroblasts and blood vessels, a perineurium of flattened cells surrounding nerve fascicles and an endoneurium containing supporting cells and extracellular matrix molecules that surround nerve fibers. The supporting tissue of the nerve includes SCs. Mature SCs are elongated cells that extend longitudinally along axons of peripheral nerves, with a centrally located oval nucleus. Two types of SCs exist. Myelinating SCs myelinate one segment of an axon and ensheathing SCs surround and separate one or many unmyelinated axons in longitudinal indentations along their surfaces. Each ensheathing $\mathrm{SC}$ is associated with 5-20 axons, extending processes that create longitudinal furrows that surround the axons' surface.

Peripheral nerve myelin is synthesized by SCs. Protein zero $\left(\mathrm{P}_{0}\right)$, a member of immunoglobulin gene family forms $80 \%$ of peripheral nerve myelin(Brunden, Windebank et al. 1990). In peripheral nerve myelin, compaction of membrane surfaces without intervening cytoplasm is accomplished solely by $\mathrm{P}_{0}-\mathrm{P}_{0}$ interaction at both 
extracellular and intracellular surfaces (Giese, Martini et al. 1992). In the CNS, DM-20 and proteolipid protein (PLP) serve a similar compaction function in the CNS (Agrawal and Agrawal).

The analysis of early stages of migration of SCs and the formation of peripheral nerves have lead to two hypotheses. The first one suggests that SC migration may precede axonal elongation by up to $100 \mu \mathrm{m}$ (Noakes and Bennett 1987). The second hypothesis based on studies in chick limb innervation, suggests that motor axons pioneer their pathway based on interactions with local cues and SCs follow immediately (Dahm and Landmesser 1988; Carpenter and Hollyday 1992).

SCs play an active role in supporting neuronal outgrowth both during development and after injury by providing NTFs such as NGF (Heumann 1987), BDNF (Meyer, Matsuoka et al. 1992) and platelet derived growth factor (PDGF) (Eccleston, Collarini et al. 1990) and CNTF (Friedman, Scherer et al. 1992), as well as through surface adhesive proteins (Bixby, Lilien et al. 1988).

The interactions between Schwann cells (SCs) and neurotrophins are significant in $\mathrm{SC}$ proliferation, migration, and myelination. BDNF enhances myelination in SCs through $\mathrm{p} 75^{\mathrm{NTR}}$ and subsequently inhibits migration through the RhoA/Rho kinase pathway (Cosgaya, Chan et al. 2002; Yamauchi, Chan et al. 2004). In contrast, NT-3 signaling in SCs enhanced cell migration and inhibited myelin formation via the fulllength TrkC receptor (Cosgaya, Chan et al. 2002; Yamauchi, Chan et al. 2003). In vitro, NT-3 levels were elevated during SC proliferation and migration and decreased during myelination, whereas BDNF levels remained elevated throughout proliferation, migration and myelination (Cosgaya, Chan et al. 2002). 
Recent work demonstrated that SCs are a good candidate for cellular repair strategies in SCI transplantation models (Bunge; Tuszynski and Gage; Xu, Guenard et al. 1995; Xu, Guenard et al. 1995; Xu, Chen et al. 1997; Xu, Zhang et al. 1999; Bamber, Li et al. 2001; Iannotti, Li et al. 2003). Xu et al (Xu, Zhang et al. 1999) further developed adult rat model of thoracic spinal cord hemisection and implantation of a PAN/PVC mini-channel seeded with SCs. In this model SCs form an effective bridge that promotes the in-growth of numerous myelinated and unmyelinated axons of both propriospinal and supraspinal origins, some of these axons re-entered the distal spinal cord.

The combination of SC grafting and intraspinal infusion of BDNF and/or NT-3 following a lateral hemi-section lesion effectively promotes axonal outgrowth from a SC seeded mini channel into the distal host spinal cord (Bamber, Li et al. 2001). Similarly, infusion of NT-3, BDNF and NGF successfully induced regeneration of sensory fibers across a pre-degenerated nerve graft and into the thoracic spinal cord in a dorsal column lesion (Oudega and Hagg, 1999).

\section{Tissue engineering for SCI repair}

Several strategies for spinal cord regeneration have shown that axonal regeneration can be enhanced using neurotrophins and/or blocking the inhibitory molecules at the lesion site, leading to extension of these regenerating axons into the lesion area. However, this is not organized axonal growth that leads to restoration of function or a near normal arrangement of axons into axonal tracts as in the pre-injury spinal cord. 
Axonal growth in vitro is controlled both chemically by cellular interaction (Powell, Fawcett et al. 1997; Biran, Noble et al. 2003; Luo and Shoichet 2004) and protein gradients (Miller, Jeftinija et al. 2002; Cao and Shoichet 2003) and physically by substrate topography (Rajnicek and McCaig 1997; Miller, Jeftinija et al. 2002). The situation in vivo is rather complex, with many factors interfering with the regeneration process including macrophage infiltration and glial scar formation.

Biomaterials can be molded into a three dimensional structure that have the potential to provide support and guide axonal growth. These structures can be seeded with a high concentration of cells and facilitate the formation of blood vessels once implanted into the spinal cord. The principal function of the scaffold is to direct cell migration, proliferation, differentiation (Zhang, Jin et al. 2005; Zhang, Yoo et al. 2005) and axonal growth(Bakshi, Fisher et al. 2004; Stokols and Tuszynski 2004). Therefore the physical characteristics of biomaterial scaffold should include high porosity and large surface area (Bhattarai, Bhattarai et al. 2004; Kidoaki, Kwon et al. 2005). These 3-D structures have been used in the form of a macroporous scaffold (Hurtado, Moon et al. 2006), a polymer foam conduit (Hadlock, Sundback et al. 2000), or a mini-channel seeded with SCs (Xu, Guenard et al. 1995; Xu, Guenard et al. 1995; 1997; 1999) in peripheral nerve regeneration as well as in SCI.

Currently used biomaterials may be classified into two major categories; biodegradable and non-biodegradable. Bio-degradable materials include type I collagen which has been successfully used as a gel (de la Torre 1982; Marchand, Woerly et al. 
1993), combined with NT-3 or BDNF (Houweling, Lankhorst et al. 1998; 1998) or with SCs (Paino and Bunge 1991). Collagen gels were also injected in the subarachnoid space to deliver growth factors to enhance the proliferation of endogenous stem cells in the spinal cord (Jimenez Hamann, Tator et al. 2005). Although successful in peripheral nerve repair (Sterne, Brown et al. 1997), fibronectin did not enhance axonal regeneration even when combined with NT-3, NGF or BDNF (King, Lacey et al. 2004). Other biodegradable material were also used in SCI regeneration studies with variable success, e.g. alginate/agarose (Stokols and Tuszynski 2004), hyaluronic acid (Rochkind, Shahar et al. 2002), chitosan (Khor and Lim 2003), poly-b-hydroxybutirate (Mohanna, Young et al. 2003), poly glycolic/poly lactic (PGA/PLA) (Oudega, Gautier et al. 2001), poly carbonate (Montgomery and Robson 1993), and poly ethylene glycol (PEG) (Borgens, Shi et al. 2002).

Non-biodegradable biomaterials used in SCI offer a major advantage of structural stability over biodegradable materials. These include poly-hydroxymethyle methacrylate (PHEMA/PHEMA-MMA) which were used successfully as porous tubes (Dalton, Flynn et al. 2002) or as coil-reinforced channels to avoid collapse following implantation (Katayama, Montenegro et al. 2006). Poly hydroxypropyl-methacrylamide (PHPMA) is another material used for drug delivery and gene therapy applications (ProkopovaKubinova, Vargova et al. 2001; Parker 2005). It has also successfully induced axonal regeneration and myelination after SCI when used as hydrogels (Woerly, Doan et al. 2004) or when combined with BDNF and CNTF in rat brain injury (Loh, Woerly et al. 2001). 
Poly acrylonitile-co-vinylchloride (PAN/PVC) is a structurally stable and non toxic non-biodegradable biomaterial that has been used both in vivo and in vitro. PAN/PVC has been successfully used by Xu and colleagues (Xu, Guenard et al. 1995; $1995 ; 1997 ; 1999)$ in SCI both with SCs only or combined with neurotrophins. One disadvantage of this material which limits its clinical applicability is the use of organic solvents in the synthesis.

\section{Combination strategy for SCI repair}

Various approaches have been used to promote neuronal survival, axonal regeneration, and recovery after injury. Transplantation of SCs demonstrated that CNS neurons can regenerate for relatively long distances when a permissive environment is provided (David and Aguayo 1981; Schnell and Schwab 1990). Semi-permeable channels (Aebischer, Salessiotis et al. 1989) filled with purified primary SCs (Guenard, Kleitman et al. 1992) implanted into injured rat spinal cord facilitate in-growth of axons from sensory, motor, raphe nucleus, and brain stem neurons (Xu, Guenard et al. 1995; Guest, Klose et al. 1997; Xu, Chen et al. 1997).

SCs are widely accepted as having a great potential to enhance axonal regeneration and myelination (Oudega and $\mathrm{Xu} 2006$ ). The aim of our work is to characterize an effective combination strategy for SCI research, which includes a three dimensional tissue bridge i.e. the PAN/PVC mini-channel seeded with SCs and supplemented with the bi-functional neurotrophin D15A across the lesion gap, with a gradient of an increasing concentration of neurotrophin to guide axons across the gap and 
back to the spinal cord tissue. We hypothesize that this combination will provide an effective repair strategy for the injured axons to grow into and beyond the injury site. In the first chapter, we characterized three viral delivery vectors in the spinal cord environment. In chapter two we compare three types of PAN/PVC channels. Our results showed that, to create a gradient of neurotrophin, one would optimally combine the short expressing retrovirus with the longer expressing lentivirus.

The hemisection model we use gives us the ability to target all axons on one side of the injured cord leaving the other side to serve as an internal control. The channel at both interfaces faces the injured dorsal column, corticospinal tract, rubrospinal tract, vestibulospinal tract, etc. thus all axons in ascending, descending and propriospinal tracts can be studied in such a model. 
Table 1.1 Sensitivity of spinal cord axons to growth factors. (Lu and Tuszynski 2007)

\begin{tabular}{|c|c|c|}
\hline $\begin{array}{l}\text { Growth } \\
\text { factors }\end{array}$ & Injured axons & References \\
\hline NGF & $\begin{array}{l}\text { Nociceptive spinal axons } \\
\text { Cerulospinal axons }\end{array}$ & $\begin{array}{l}\text { (Tuszynski, Peterson et al. 1994; Tuszynski, } \\
\text { Gabriel et al. 1996; Ramer, Priestley et al.) } \\
\text { (Tuszynski, Peterson et al. 1994; Tuszynski, } \\
\text { Gabriel et al. 1996) }\end{array}$ \\
\hline BDNF & $\begin{array}{l}\text { Rubrospinal axons } \\
\text { Raphespinal axons } \\
\text { Coerulospinal axons } \\
\text { Reticulospinal axons }\end{array}$ & $\begin{array}{l}\text { (Kobayashi, Fan et al. 1997; Ye and Houle } \\
\text { 1997; Liu, Kim et al. 1999) } \\
\text { (Bregman, McAtee et al. 1997) } \\
\text { (Menei, Montero-Menei et al. 1998) } \\
\text { (Menei, Montero-Menei et al. 1998) } \\
\text { (Ye and Houle 1997; Jin, Fischer et al. 2002) }\end{array}$ \\
\hline & $\begin{array}{l}\text { Vestibulospinal } \\
\text { Local motor axon } \\
\text { Local sensory axon (CGRP) }\end{array}$ & $\begin{array}{l}\text { (Jin, Fischer et al. 2002) } \\
\text { (Lu, Blesch et al. 2001) }\end{array}$ \\
\hline NT-3 & Corticospinal axons & $\begin{array}{l}\text { (Schnell, Schneider et al. 1994; Grill, Murai } \\
\text { et al. 1997) }\end{array}$ \\
\hline & Dorsal column sensory axons & (Bradbury, Khemani et al. 1999) \\
\hline NT-4/5 & $\begin{array}{l}\text { Local motor axons } \\
\text { Coerulospinal axons } \\
\text { Reticulospinal axons } \\
\text { Propriospinal axons }\end{array}$ & (Blesch, Yang et al. 2004) \\
\hline GDNF & $\begin{array}{l}\text { Local motor axons } \\
\text { Propriospinal axons } \\
\text { Dorsal column sensory axons } \\
\text { Nociceptive spinal axons }\end{array}$ & (Blesch and Tuszynski 2003) \\
\hline
\end{tabular}


Figure 1.1 The Edwin Smith surgical papyrus.

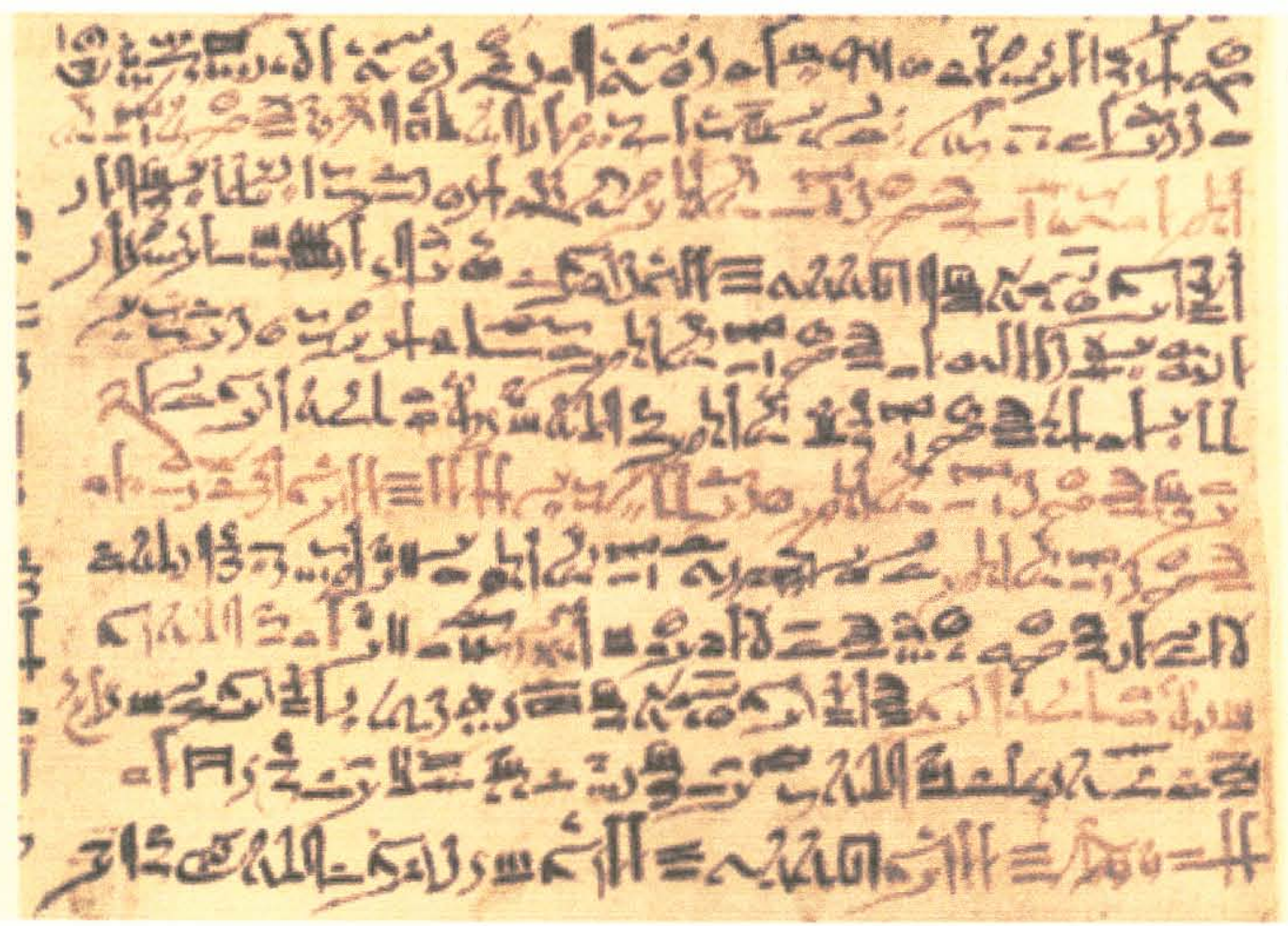




\section{CHAPTER 2}

\section{GENE DELIVERY TO THE SPINAL CORD: COMPARISON BETWEEN LENTIVIRAL, ADENOVIRAL, AND RETROVIRAL VECTOR DELIVERY SYSTEMS}

\section{INTRODUCTION}

Axonal regeneration in the adult central nervous system (CNS) depends on a critical balance between growth-promoting and -inhibiting cues (Chen, Huber et al. 2000). Neurotrophic factors have a potent survival, neuroprotective and growthpromoting activity on neurons both in vitro and in vivo (Davies 1994; Tobias, Shumsky et al. 2003), making them an obvious therapeutic candidate for neurodegenerative and traumatic disorders (Nagatsu 2002; Racine, Adams et al. 2002). The major obstacle for the development of such therapies is the exclusion of the therapeutic molecule from the CNS due to the selectivity of the blood-brain barrier (Pardridge 2002), as well as fast plasma clearance (Dittrich, Ochs et al. 1996). Further, undesirable side effects of systemic delivery of neurotrophins have been shown (Tuszynski and Blesch 2004). To avoid these side effects, direct delivery of neurotrophic factors into the CNS using osmotic-pumps was employed (Olson, Nordberg et al. 1992). However, pump failure, 
variable stability, limited diffusion, and the risk of infection are possible complications limiting the application of this approach (Oudega and Hagg 1996; Tan and Aebischer 1996).

Recent advances in molecular biology offer several possibilities for therapeutic gene delivery including purified plasmids (Piccirillo and Prud'homme 2003), cationic lipid-mediated delivery (Felgner, Tsai et al. 1995), particle bombardment-mediated gene transfer (gene gun) (Jiao, Cheng et al. 1993), receptor-mediated endocytosis (Chen, Gamou et al. 1994), and antisense oligonucleotides (Tomita, Khan et al. 2004). These non-viral methods have several advantages including safety, ease of synthesis/ modification, and unlimited transgene size. They are complicated, however, by cytotoxicity, low efficiency, and limited target cell population (Tomita, Khan et al. 2004).

The use of viral vectors as an approach for gene therapy has been studied in many CNS disorders including Parkinson's disease (Lundberg, Horellou et al. 1996), Huntington's disease (Emerich, Lindner et al. 1996), Alzheimer's disease (Rosenberg, Friedmann et al. 1988), and Tay-Sachs disease (Lacorazza, Flax et al. 1996). In spinal cord injury (SCI), both ex vivo and in vivo approaches employing genetically modified fibroblasts (Nakahara, Gage et al. 1996; Tuszynski, Grill et al. 2003), astrocytes (Smith, Hale et al. 1996), and olfactory ensheathing cells (Ruitenberg, Plant et al. 2003) have been used to deliver neurotrophic factors to enhance neuronal survival, axonal growth, and remyelination (McTigue, Horner et al. 1998; Tuszynski, Weidner et al. 1998). Nonetheless, significant therapeutic efficacy is negated due to downregulation of transgene activity soon after delivery (Andersen, Garber et al. 1992), vector cytotoxicity 
(Hermens and Verhaagen 1998), or host immune response directed against the transgene and viral proteins (Blomer, Naldini et al. 1996). Further, widespread acceptance of viral vector-mediated gene therapy as a therapeutic tool in the treatment of CNS disease is complicated by the unknown long-term safety of their use.

In this study, we examined the temporal expression pattern of D15A, a mutant human NT-3 that binds TrkB and TrkC and has both BDNF and NT-3 activities, after its viral-mediated delivery into the spinal cord (Urfer, Tsoulfas et al. 1994; Strohmaier, Carter et al. 1996; Cao, Xu et al. 2005), as well as the viral induced inflammatory responses after lentiviral, adenoviral, and retroviral gene delivery in the spinal cord.

\section{MATERIALS AND METHODS}

\section{Lentiviral Vector Production}

The preparation and use of all viral vectors was carried out in bio-safety Level 2 laboratories with the approval of the Institutional Biosafety Committee of the University of Louisville. We used a third generation lentiviral vector (Invitrogen, Carlsbad, CA; for vector maps see www.invitrogen.com/content/sfs/vectors/plenti6v5dtopo_map.pdf ), that was produced according to the manufacturer's instructions. Briefly, we utilized the cDNA coding for D15A, a human NT-3 mutant that binds and activates both TrkB and TrkC (Urfer, Tsoulfas et al. 1994). A 780-bp fragment, containing a Kozak consensus sequence was modified using PCR to include the sequence $\mathrm{CACC}$ at the 5 end. These four nucleotides are complimentary to the overhang sequence GTGG in the pLenti6/V5D-Topo vector, a requirement for the Topo cloning reaction, the cloning site is located downstream of a CMV promoter sequence. Viral particles were produced by transient 
transfection of 293FT cells (Naldini, Blomer et al. 1996) with the Virapower packaging mix (Invitrogen) containing the following plasmids: pLP1 (gag/pol), pLP2 (Rev), pLP/VSVG, and pLenti6/V5D-Topo/D15A, or pLenti6/V5-GW/LacZ. Forty-eight hours after transfection, supernatants were collected and filtered. High-titer viral stocks were obtained by ultracentrifugation at $16,000 \mathrm{rpm}$ for $90 \mathrm{~min}$ and the pellet was re-suspended in phosphate buffered saline (PBS) and virus stored at $80^{\circ} \mathrm{C}$ until use.

\section{Adenoviral Vector Production}

The cDNA encoding D15A was cloned into the E1 deleted Ad5C1-I-GFP (D15A expression is under CMV promoter control; vector maps are available at www.stratagene.com/vectors/maps/pdf/pshuttle-IRES-hrGFP-1.pdf) and replicationdeficient Ad5-D15A adenovirus was isolated as described previously (Gao, Qu et al. 1998). The titer obtained was $1.1 \times 10^{11}$ transforming units (TU)/ml. Before surgery, virus was diluted using PBS to either $1 \times 10^{5}, 5 \times 10^{5}$, or $1 \times 10^{6} \mathrm{TU} / \mu \mathrm{l}$.

\section{Retroviral Vector Production}

The D15A cDNA was cloned into MSCV-I-GFP (provided by M.F. Roussel, Dept. of Genetics and Tumor Cell Biology, St. Jude Children's Research Hospital, Memphis, TN) and LZRSpBMN-I-GFP (kindly provided by G. Nolan, Stanford University; for a map of the LZRSpBMN-I-GFP vector see http://www.stanford.edu/group/nolan/) shuttle vectors. D15A expression in both MSCVI-GFP and LZR-SpBMN-I-GFP retroviruses is under the control of the 5 LTR. Viral particles were produced by transient transfection of MSCV-I-GFP and VSV-G plasmids into HEK/293 cells. Stable LZRSpBMN-I-GFP producer lines were obtained by 
transfection into Inx cells (Pear, Nolan et al. 1993; Pear 1997) and also provided by Dr. Nolan. Media were collected, filtered, and viral titer quantified. Virus was concentrated by ultracentrifugation as described previously (Burns, Friedmann et al. 1993).

\section{Tetracycline-Inducible Retroviral System}

Tet-inducible retrovirus was produced according to the manufacturer's instructions (Clontech, Palo Alto, CA; for vector maps see http://orders.clontech.com/clontech/techinfo/vectors/vectorsR-S/prevTRE.shtml). Briefly, after cloning of the D15A cDNA into pRev-TRE vector in which D15A expression is under the control of a minimal CMV promoter, the two-virus system was produced by stably transfecting PT67 cells (NIH/3T3-based cell line expressing 10A1 viral envelope) with pRev-TRE-D15A to produce the first virus. PT67 cells were selected with $0.2 \mathrm{mg} / \mathrm{ml}$ hygromycin for $7-10$ days. The regulator virus was produced by stably transfecting PT67 cells with the pRevTet-On plasmid followed by G418 selection ( 0.4 $\mathrm{mg} / \mathrm{ml}$ ) for 5-7 days. Target cells used in the ex vivo experiment were infected with the pRevTet-On virus and subjected to $\mathrm{G} 418$ selection $(0.4 \mathrm{mg} / \mathrm{ml})$ for $5-7$ days, then infected with pRev-TRE-D15A virus and further subjected to hygromycin selection $(0.2$ $\mathrm{mg} / \mathrm{ml}$ ) for another $7-10$ days in vitro. Before doxycycline induction in vitro, the media was changed to DMEM supplemented with tetracycline-free fetal bovine serum (FBS, Clontech).

\section{Determination of Viral Titer and Vector Bioactivity}

To determine the viral titer, a serial dilution of the viral stock was applied to 23 $10^{5} 293 \mathrm{~T}$ and NIH3T3 cells. The dilution that resulted in $15 \%$ or less $\mathrm{GFP}^{+} / \mathrm{LacZ}^{+}$cells 
after $48 \mathrm{hr}$ was used for calculations. Lentivirus-D15A titer was measured according to the manufacturer's instructions; briefly, serial dilutions (10to 10) of viral stocks were applied to $2 \times 10^{5} \mathrm{NIH} 3 \mathrm{~T} 3$ cells, 4 days later blasticidin $3 \mu \mathrm{g} / \mathrm{ml}$ was added, and cells were maintained for 10 days. Cells were washed in PBS and stained with crystal violet. Bluestained colonies were counted to determine the titer. Viral titers were routinely $1-3 \times 10^{8}$ $\mathrm{TU} / \mathrm{ml}$. Before surgery, virus stock was diluted with sterile saline to $1 \times 10^{5} \mathrm{TU} / \mu 1,5 \mathrm{x}$ $10^{5} \mathrm{TU} / \mu 1$, or $1 \times 10^{6} \mathrm{TU} / \mu \mathrm{l}$ for injection into the spinal cord. All viral vectors used for in vivo delivery were matched for volume and titer before delivery. All viral vectors used in the ex vivo and in vitro experiments were matched for titer before use. Bioactivity in conditioned media of infected NIH3T3 cells was tested by examining neurite outgrowth (Fig. 1D-F) from TrkC-expressing PC12 cells (Tsoulfas, Soppet et al. 1993; Cao, Xu et al. 2005), recombinant human (rh) NT-3 was used to generate the standard curve. Bioassay data were consistent with D15A levels determined by ELISA (R\&D Systems, Minneapolis, MN).

NT-3 ELISA was carried out according to manufacturer's instructions. Briefly, 96-well microplates (Costar, Cambridge, MA) were coated with $100 \mu 1 /$ well of monoclonal mouse anti-NT-3 antibody $(0.5 \mu \mathrm{g} / \mathrm{ml} ;$ R\&D Systems $)$ diluted in PBS buffer overnight at room temperature. The plates were then incubated for $1 \mathrm{hr}$ at room temperature with blocking solution (1\% BSA in PBS). With interceding washes $(0.05 \%$ Tween 20 in PBS, pH 7.4), the plates were subject to sequential $2 \mathrm{hr}$ incubations at room temperature with double aliquots of conditioned media, cell, and protein extracts from spinal cords, or recombinant human NT-3 (rhNT-3; 0-2,000 pg/ml; R\&D Systems), biotinylated polyclonal goat anti-NT3 antibody ( $200 \mathrm{ng} / \mathrm{ml}$; R\&D Systems). The plates 
were then incubated sequentially for $20 \mathrm{~min}$ in Streptavidin-HRP (R\&D Systems), and 1:1 mixture of $\mathrm{H} 2 \mathrm{O} 2$ and tetramethylbenzidine (R\&D Systems). The color reaction was stopped ( $50 \mu \mathrm{l} /$ well of $2 \mathrm{~N} \mathrm{H2SO4}$; R\&D Systems) and absorbance at $450 \mathrm{~nm}$ was measured using a Molecular Devices Spectramax 384+ (Sunnyvale, CA). Using serial dilutions of known amounts of rhNT-3, this color reaction yielded a linear standard curve from $62.5-2,000 \mathrm{pg}$.

\section{Preparation of Purified Populations of Schwann Cells}

Schwann cells (SC) cultures were isolated as described (Morrissey, Kleitman et al. 1991; Xu, Zhang et al. 1999). Briefly, sciatic nerves were dissected from adult rats anaesthetized with pentobarbital sodium $40 \mathrm{mg} / \mathrm{kg}$, I.P. After the epineurium and connective tissue were removed, nerves were cut into $1 \mathrm{~mm}$ explants and placed in 35 mm Corning tissue culture dishes (Baxter, Stone Mountain, GA) containing Dulbecco's modified Eagle's medium (DMEM; Gibco, Grand Island, NY) supplemented with 10\% FBS. The explants were transferred to new culture dishes every 7 days with fresh medium. After 3-5 weeks, explants were incubated overnight in dispase $1.25 \mathrm{U} / \mathrm{ml}$ (Boehringer Mannheim Biochemicals, Indianapolis, $\mathrm{IN}$ ), 0.05\% collagenase (Worthington Biochemicals Corp., Freehold, NJ) and 15\% FBS in DMEM at $378 \mathrm{Cin} 5 \% \mathrm{CO} 2$. The following day, explants were dissociated and cells were plated onto poly-l-lysine-coated $100 \mathrm{~mm}$ dishes in DMEM/10\% FBS, containing $20 \mathrm{mg} / \mathrm{ml}$ pituitary extract (BTI, Stoughton, MA) and 2 mM forskolin (Sigma, St. Louis, MO).

\section{Preparation and Transduction of Cells In Vitro}

Other cell types used in the study (NIH/3T3, HEK 293FT, PT67, and Фnx) were 
maintained in DMEM supplemented with 10\% FBS. RN33B cells (Whittemore and White 1993) were grown at 338C in DMEM/F12 supplemented with 5\% FBS, and 250 $\mu \mathrm{g} / \mathrm{ml} \mathrm{G} 418$.

For transduction of cells for in vitro viral experiments, cells were seeded into 6well plates at a density of $10^{5}$ cells/ well. Cells were pre-treated with $4-6 \mu \mathrm{g} / \mathrm{ml}$ polybrene (Sigman, Poleski et al.) for 30-60 min (Manning, Hackett et al. 1971), then infected for $6-8 \mathrm{hr}$ at a multiplicity of infection (MOI) of 20 , resulting in $80-90 \%$ infection of the cells. Infection media were then replaced with fresh media. Forty-eight hours later, conditioned media was collected for ELISA.

\section{Surgical Procedures}

A total of 150 adult, female, Sprague-Dawley rats (150-175 g) were housed 1 per cage with free access to food and water under 12-hr light:dark cycle. All surgical procedures were approved by and carried out according to the guidelines of the Institutional Animal Care and Use Committee and the Institutional Biosafety Committee at the University of Louisville. Animals were anesthetized with pentobarbital $(40 \mathrm{mg} / \mathrm{kg}$ IP) and placed into a stereotaxic frame (Kopf Instruments, Tujunga, CA). The spinal cord was exposed with a laminectomy at the level of $\mathrm{T} 8$, the dura incised to expose the cord, and a total volume of $1 \mu \mathrm{l}$ of the viral stocks $\left(1 \times 10^{5}\right.$ or $\left.5 \times 10^{5} \mathrm{TU}\right), \mathrm{PBS}$, or cell suspension $\left(1 \times 10^{5} \mathrm{cell} / \mu \mathrm{l}\right)$ was injected into the cord using a glass micro-pipette (outer diameter 10-20 $\mathrm{lm}$ for viral infection and 25-40 $\mathrm{lm}$ for the cell suspension) attached to a pico spritzer (Parker Instrumentation, Fairfield, NJ). Injections were made in the ventrolateral white matter of the cord $(1 \mu \mathrm{l} /$ injection $)$ and the glass pipette remained in 
place for 2-3 min after injection. The incision was closed in layers. For host immune modulation, we used transient immuno-blockade of lymphocytic cells by a combination treatment of purified monoclonal antibodies against the rat CD4 and CD45 (OX-38 and OX-22; Pharmingen, San Diego, CA) lymphocytic receptors. Animals in the adenovirus $+\mathrm{mAb}$ group received $50 \mu \mathrm{g}$ (IP) of the combined anti-sera $24 \mathrm{hr}$ before and $24 \mathrm{hr}$ after the adenovirus administration (Romero and Smith 1998).

\section{Tissue Processing}

At 1,2, and 4 weeks after viral injection, the rats were anesthetized deeply with pentobarbital and transcardially perfused with $200 \mathrm{ml} 0.1 \mathrm{M}$ phosphate buffer $(\mathrm{PB})(\mathrm{pH}=$ 7.4). For ELISA ( $\mathrm{n}=5 /$ group), a $1-\mathrm{cm}$ segment of the spinal cord spanning the injection site was removed, homogenized in lysis buffer $(20 \mathrm{mM}$ Tris- $\mathrm{HCl} \mathrm{pH} 8.0,137 \mathrm{mM} \mathrm{NaCl}$, $1 \% \mathrm{NP} 40$ ), and centrifuged at $10,000 \mathrm{rpm}$ for $5-7 \mathrm{~min}$ at $48 \mathrm{C}$ to remove tissue debris. Protein concentration in each sample was estimated using the Pierce BCA Protein Assay (Pierce Chemical Co., Rockford, IL). Because D15A is a modified NT-3 with antibody binding epitopes preserved, a two-site NT-3 ELISA (R\&D Systems) was used to determine D15A levels in the samples.

For tissue prepared for immunohistochemistry ( $\mathrm{n}=5$ / group), PB perfusion was followed by $250-300 \mathrm{ml}$ of ice-cold $4 \%$ paraformaldehyde in $0.1 \mathrm{M}$ phosphate buffer $(\mathrm{pH}$ 7.4). A $1 \mathrm{~cm}$ segment of the spinal cord spanning the injection site was removed and postfixed for $2 \mathrm{hr}$ at $48^{\circ} \mathrm{C}$, then transferred to $30 \%$ sucrose in $0.1 \mathrm{M} \mathrm{PB}$ for cryoprotection until sectioned on a cryostat (Leica CM3050, Nussloch, Germany) at 20-25 $\mathrm{lm}$ and mounted on microscope slides. The sections were rinsed in phosphate buffered saline 
(PBS), blocked, and permeabilized in PBS containing 10\% normal donkey serum (NDS) and $0.3 \%$ Triton $\mathrm{X}-100$ for $1 \mathrm{hr}$ at room temperature, and incubated in primary antibody overnight at $48 \mathrm{C}$, with 5\% NDS, and $0.25 \%$ Triton X-100 in PBS. Polyclonal rabbit antiglial fibrillary acidic protein antibody (anti-GFAP; 1:100, Chemicon, Temecula, CA), was used to identify astrocytes and monoclonal antibody adenomatous polyposis coli (anti-APC) (1:100; Oncogene, San Diego, CA) to identify oligodendrocytes. Monoclonal antibody anti-NeuN (1:100; Chemicon), and polyclonal antibody anti- $\beta$ III tubulin (1:100; Promega, Madison, WI) were used to identify neurons. Monoclonal antibodies anti-CD4 and anti-CD8 (1:100; Pharmingen, San Diego, CA) were used to identify T lymphocytes. Microglia (both ramified and reactive) and macrophages were stained using monoclonal antibodies anti-OX-42 and anti-ED1 (1:500; Chemicon), respectively, as previously described (Graeber, Banati et al. 1989; Koshinaga and Whittemore 1995). The next day, sections were rinsed in PBS and incubated in either fluorescein-conjugated or rhodamineconjugated Fab fragment secondary antibodies from donkey (1:100; Jackson Laboratories, Baltimore, MD). Slides were washed, mounted, and examined using a Nikon TE300 fluorescent microscope and photographed with an Olympus Fluview confocal microscope. Figures were assembled using Adobe ${ }^{\circledR}$ Photoshop and Illustrator software (San Jose, CA).

\section{Morphologic Analysis}

To quantify the numbers of ED1 macrophages, sections were analyzed using a 203 objective and the appropriate UV-filter on a Nikon E600 microscope. Starting from the center of the injection, five sections from each animal over a distance of $2 \mathrm{~mm}$ were examined and $\mathrm{ED}{ }^{+}$cells were counted using Imagepro Plus software $(\mathbb{R}($ Media 
Cybernetics, San Diego, CA) in an entire field.

Statistical Analysis

One-way ANOVA was used to compare control values with experimental groups followed by Tukey's post-hoc comparison test. A P-value of $<0.05$ is considered statistically significant.

\section{RESULTS}

In Vitro Infection Using Lentivirus, Adenovirus, and Retrovirus

Multiple cell lines were infected in vitro with various D15A viral vectors to detect the differences in gene expression levels between different viral delivery systems. Infection efficiencies were $80-90 \%$ for all viruses as confirmed by immunohistochemistry (Fig. 2.1). Table 2.1 shows that although similar MOI were used, some differences in protein expression levels were noted. D15A protein levels were relatively higher after infection with both lentivirus (62-103-fold) and adenovirus (41175-fold) as compared to the two retroviruses LZRS (35-93-fold) and MSCV (35-53fold). This suggests that differences exist either in the cellular response to viral infection or in internal regulation of gene expression between cells. Consistent with that suggestion, retroviral expression was driven off the 5 LTR and the lentivirus and adenovirus from the CMV promoter. D15A levels were significantly higher $(\mathrm{P}<0.001)$ in the RN33B group than other viral groups tested or uninfected cells. There was no statistically significant difference between the NIH3T3 cells and Schwann cells. 
Retrovirus Shows Rapid Downregulation of Transgene Expression After Ex Vivo Delivery

Schwann cells were infected in vitro with matched MOI (20) using lentivirusD15A, adenovirus-D15A, retrovirus LZRS-D15A, and retrovirus-EGFP. After resuspension in culture media, $1 \mu \mathrm{l}$ containing $1 \times 10^{5}$ cells, with pre-injection viability of $90-95 \%$, was injected into the thoracic spinal cord. Transgene expression was evaluated at 1,2, and 4 weeks (Fig. 2.2). There was no statistically significant difference between the normal cord and EGFP-infected Schwann cell grafted groups at all three time points. The group that received lentiviraly infected Schwann cell grafts showed significantly higher $(\mathrm{P}<0.001)$ expression levels than normal cord, EGFP-, and LZRS-infected cells at 1,2, and 4 weeks, as well as adenovirally-infected cells at 4 weeks. There was no significant difference between groups that received lentivirally-infected and adenovirallyinfected Schwann cells at either 1 or 2 weeks post-grafting. In contrast, grafts of adenovirally-infected Schwann cells showed some down-regulation over time, although D15A levels at 1 week were not significantly different from the 2-week level in groups that received both adenovirally-infected and lentivirally-infected Schwann cells. At 4 weeks, D15A levels were significantly $(\mathrm{P}<0.001)$ lower in the animals that received adenovirally-infected cell grafts than at 1 and 2 weeks, whereas in those that received lentivirally infected cell grafts D15A levels were not significantly different at 2 and 4 weeks. Downregulation in the animals that received retrovirally-infected cell grafts was rapid, with significantly $(\mathrm{P}<0.001)$ lower D15A levels $(20$-fold) at 2 and 4 weeks postgrafting. 


\section{Dose Dependency of Transgene Expression In Vivo}

To compare levels of protein expression in response to different concentrations of adenovirus and lentivirus, we tested a low $1 \times 10^{5} \mathrm{TU} / \mu \mathrm{l}$ (Huber, Ehrengruber et al. 2000; Jakobsson, Ericson et al. 2003) and a moderately high $5 \times 10^{5} \mathrm{TU} / \mu \mathrm{l}$ (Byrnes, Rusby et al. 1995 ) dose. Expression of D15A with both constructs was 3-fold higher in the $5 \times 10^{5}$ $\mathrm{TU} / \mu 1$ group at 1 week. Although not strictly $1: 1$, gene expression was significantly $(\mathrm{P}<$ $0.001)$ dependent on the viral titer. There was no statistically significant difference in D15A levels between the adenovirus and lentivirus infected groups when the same viral titers were used (Fig. 2.3).

Our initial observations with lentiviral-LacZ injections showed an area of necrosis and tissue destruction (data not shown). We were, however, able to eliminate much of that by removing serum from the media during viral preparation in later experiments. These findings are in agreement with previous reports showing a focal necrosis associated with the point of lentiviral injection that was always greater than PBS injection (Zhao, Strappe et al. 2003). We also saw a decrease in NeuN immunoreactivity in the rat spinal cord after lentiviral injection. Baekelandt et al. (2003) have observed a similar decrease in the rat brain and confirmed that this decrease was not associated with neuronal death or apoptosis. These adverse effects are not due to the vector transduction per se but seem to be a result of components of the culture system used in viral preparation, which has been similarly observed in clinical trials for SCID and HIV patients (Selvaggi, Walker et al. 1997; Tuschong, Soenen et al. 2002). Several purification methods were suggested to eliminate this immune response including sucrose 
gradient ultracentrifugation, although this is associated with a decrease in viral titers, and the elimination of serum from culture system (Baekelandt, Eggermont et al. 2003), which in our hands successfully reduced the tissue damage initially observed. Virus prepared under serum-free conditions was used for all data presented in this study.

Lentivirus produces a mild inflammatory response after in vivo delivery. We evaluated the inflammatory response after the in vivo viral delivery for both lentivirus and adenovirus, as well as after injection of PBS. Lentivirus produced very mild ED1 cellular infiltration that was confined to the injection site (Fig. 2.4A). Adenoviral injections induced massive EDI ${ }^{+}$cellular infiltration that was distributed over multiple spinal segments (Fig. 2.4C) both rostral and caudal to the injection site, at 1-week postinjection. Intraperitoneal injection of purified monoclonal antibodies against the rat CD4 and CD45 (OX-38 and OX-22) lymphocytic receptors reduced the inflammatory response (Fig. 2.4B). The number of ED ${ }^{+}$cells at 1 week after lentivirus injection was not significantly different from animals that received PBS or adenovirus injection combined with monoclonal antibodies OX22/OX38 (Fig. 2.4F). When higher dose virus $\left(1 \times 10^{6}\right.$ $\mathrm{TU} / \mu \mathrm{l})$ was used, ED- ${ }^{+} / \mathrm{OX} 42^{+}$cellular infiltration was also similar in the lentivirus and adenovirus combined with $\mathrm{mAb}$ treated groups (Fig. 2.5K, L).

Lentivirus and Adenovirus Infect Mainly Astrocytes After Low Titer Injection

Histologic evaluation of the viral tropism in the spinal cord after in vivo delivery of low titer $\left(1 \times 10^{5} \mathrm{TU} / \mu \mathrm{l}\right)$ lentiviral and adenoviral $+\mathrm{mAb}$ OX22/OX38 injections showed double-labeled cells that were mainly GFAP ${ }^{+}$astrocytes (Fig. 4D,E). No APC ${ }^{+}$ 
oligodendrocytes (Fig. 2.4G, H) or NeuN ${ }^{+}$neurons (Fig. 2.4I, J) were infected. Few ED1 and $\mathrm{OX} 42^{+}$microglia were seen in the area of injection (Fig. $2.4 \mathrm{~L}, \mathrm{M}, \mathrm{O}, \mathrm{P}$ ). No CD4 ${ }^{+} \mathrm{T}^{-}$ cell lymphocytes (Fig. 2.4K, N) were seen at 1 week after lentiviral injection. The rostrocaudal extension of EGFP labeling was $3.060 .5 \mathrm{~mm}$, indicating limited diffusion of virus after low titer injection. Four weeks after low titer adenoviral $+\mathrm{mAb}$ $\mathrm{OX}_{22 / \mathrm{OX} 8}$ injection EGFP ${ }^{+}$cells were still seen in the spinal cord (Fig. 2.4Q).

\section{High Titer Viral Injections}

To evaluate viral tropism after high dose viral administration, we injected $1 \mu \mathrm{l}$ containing $1 \times 10^{6} \mathrm{TU}$ (Blomer, Naldini et al. 1997; Hermens and Verhaagen 1997) of either lentivirus or adenovirus $+\mathrm{mAb} \mathrm{OX} 22 / \mathrm{O} \times 38$ into the thoracic spinal cord. One week after viral injection, EGFP labeling was spread over the entire ventral segment of the spinal cord (Fig. 2.5A, B). Cells resembling ependymal cells surrounding the central canal were also infected (inset in Fig. 2.4A, B). $\beta$ III tubulin ${ }^{+}$neurons (Fig. 2.5C, D) in the ventral horn of the gray matter of the thoracic spinal cord were infected with both viruses. In addition, $\mathrm{EGFP}^{+} / \mathrm{NFH}^{+}$axons were observed both in the ventral white matter and in the ventral roots (Fig. 2.5E, F). The majority of infected cells in both the white and gray matter of the spinal cord were GFAP ${ }^{+}$astrocytes (Fig. $5 \mathrm{G}, \mathrm{H}$ ). No APC ${ }^{+}$oligodendrocytes (Fig. 2.5I, J) were seen infected after lentiviral or adenoviral injection. ED ${ }^{+}$cells infiltrating the injection site were seen (data not shown) and were similar to OX-42 ${ }^{+}$(Fig. 2.5K, L) cellular infiltrates. None of the ED1 ${ }^{+} / \mathrm{OX}-42^{+}$infiltrating macrophages $/$microglia were infected with either virus. The extent of EGFP labeling was $8.0 \pm 3.0 \mathrm{~mm}$ after high 
titer injection indicating substantial diffusion of viral particles.

Temporal Profile of Lentiviral-and Adenoviral-Mediated Transgene Expression After In Vivo Delivery to the Spinal Cord

We chose the lower viral titer $\left(1 \times 10^{5} \mathrm{TU} / \mu \mathrm{l}\right)$ to study the temporal expression of D15A after viral-mediated delivery in vivo. Titer/volume matched vector stocks were injected into the thoracic spinal cord and gene expression was evaluated 1, 2, and 4 weeks later (Fig. 2.6). ELISA for D15A showed that although all groups were significantly higher $(\mathrm{P}<0.001)$ than the basal levels of NT-3, there was no significant difference between groups at 1-week post-injection. Lentiviral transgene delivery showed a stable pattern of gene expression. D15A levels in the lentivirus group were not significantly different at 1,2, and 4 weeks, with D15A levels being significantly higher than both adenovirus groups at 4 weeks. Adenoviral delivery of D15A showed significant downregulation with expression levels gradually decreasing at 2 weeks $(\mathrm{P}<0.001)$ and 4 weeks ( $\mathrm{P}<0.05)$. D15A levels in the adenovirus group were significantly $(\mathrm{P}<0.001)$ lower than the adenovirus $+\mathrm{OX} 22 / \mathrm{OX} 38$ group at 2 weeks and both lentivirus $(\mathrm{P}<$ $0.001)$ and adenovirus $+\mathrm{OX} 22 / \mathrm{OX} 38(\mathrm{P}<0.001)$ at 4 weeks.

Immune Suppression Eliminates Downregulation After Adenoviral Transgene Delivery In Vivo.

In light of our histologic data indicating that the OX22/OX38 monoclonal antibody treatment reduces the inflammatory response noted after adenoviral trans-gene delivery, we hypothesized that treating animals in the adenovirus group with OX22/OX38 mAb $24 \mathrm{hr}$ before and after viral injection would result in stabilization of 
gene expression and minimize the downregulation of D15A (NT3) expression. Our in vivo results confirmed that the use of immuno-blockade successfully reduces downregulation of D15A after adenovirus injection. At 2 weeks post-injection, D15A $(\mathrm{NT}-3)$ levels were significantly higher $(\mathrm{P}<0.05)$ than adenovirus alone, but were not different from lentivirus (Fig. 2.6). At 4 weeks post-infection, D15A levels were significantly lower $(\mathrm{P}<0.001)$ than the lentivirus group, but they were significantly higher $(\mathrm{P}<0.001)$ than the adenovirus alone group.

\section{Inducible D15A Expression After Ex Vivo Delivery With Tet-on Vectors}

Constitutive expression of transgenes may not always be desirable, as the ability to turn a gene on or off at specific times may be therapeutically beneficial. To address the feasibility of this approach, we used the tetracycline-inducible, Tet-on retroviral system. Schwann, RN33B, and NIH3T3 cells were infected in vitro with the two virus Tetinducible system. After antibiotic selection for 1 week, induction of gene expression with the addition of doxycycline to the culture media showed robust gene expression in vitro with increasing concentrations of doxycycline. Although, D15A (NT-3) levels increased about 50-fold over basal expression levels with $6 \mu \mathrm{g} / \mathrm{ml}$ of doxycycline and was significantly $(\mathrm{P}<0.05)$ higher than baseline expression, no significant difference was found between 2,4 , and $6 \mu \mathrm{g} / \mathrm{ml}$ doxycycline. Baseline expression was $40 \mathrm{pg} / 1 \times 10^{5}$ cells $/ \mathrm{ml} / 24 \mathrm{hr}$, showing that the system is somewhat leaky with respect to its transregulation (Fig. 2.7A). In the initial phase of this experiment, we noted a wide range of variation of gene expression levels in vitro, with between 5-25-fold increase observed after the doxycycline induction (data not shown). However, selecting stable clones using G418 for up to 2 weeks resulted in clones that exhibited stable transgene integration and 
expression.

For ex vivo delivery of D15A, we injected $1 \times 10^{5}$ cell/ $\mu 1 \mathrm{RN} 33 \mathrm{~B}$ cells into the spinal cord. Animals were given doxycycline $(1 \mathrm{mg} / \mathrm{ml})$ in their drinking water for up to2weeks. D15A (NT-3) expression in the spinal cord increased significantly, 7-fold at 1 week (Fig. 2.7B). There was no statistically significant difference in DI5A expression between 1 and 2 weeks in animals that received doxycycline for 2 weeks. In one group, doxycycline administration was stopped after 1 week (light gray bars), a significant reduction ( $\mathrm{P}<0.01,2$-fold) in D15A expression at 2 weeks was observed. At 2 weeks post-grafting, D15A levels (black bars) were significantly higher than normal $(\mathrm{P}<0.001$, 5-fold), no-doxycycline (dark gray bars) $(\mathrm{P}<0.001,2$-fold) and animals that received doxycycline for only 1 week $(\mathrm{P}<0.01,1.5$ fold $)$. Note that, at 1 and 2 weeks, levels of $\mathrm{D} 15 \mathrm{~A}$ in the absence of doxycycline are significantly higher at 1 week $(\mathrm{P}<0.05,3$-fold $)$ and 2 weeks after the doxycycline induction $(P<0.01,2.5$-fold $)$ than the control values, again reflecting the inherent leakiness of this expression system.

\section{DISCUSSION}

Transfer of therapeutically beneficial genes to the CNS is an experimental concept that potentially can be tailored and applied to a variety of CNS disorders. This approach may be designed according to specific therapeutic requirements. In diseases characterized by a chronic and progressive course (e.g., Parkinson's disease), a sustained administration of the therapeutic molecule (Costantini, Bakowska et al. 2000; Johansen, Rosenblad et al. 2002) may be appropriate, whereas for other disorders a transient 
delivery may be applied. The purpose of the current study was to evaluate various viral delivery techniques, to better understand the temporal pattern of gene expression, as well as the inflammatory response that follows viral injection, with specific attention to the spinal cord as a unique CNS environment.

We have chosen to compare lentiviral and adenoviral vectors because of their pantropic nature in the nervous system after in vivo delivery. Other viral vectors used currently for gene therapy, HSV and AAV, are mainly neurotropic (Geller, Yu et al. 1997; Buning, Nicklin et al. 2003) in vivo.

We show that high titer injections of adenovirus and lentivirus into the CNS are both pantropic transducing mostly neurons and astrocytes after parenchymal injection, consistent with previous reports (Le Gal La Salle, Robert et al. 1993; Huber, Ehrengruber et al. 2000). Ependymal cells are also infected in our study after parenchymal injections (Fig. 4A,B) and after intra-ventricular injection by others (Bajocchi, Feldman et al. 1993). Oligodendrocytes have been only transduced in vitro (Ohashi, Watabe et al. 1995). In our hands, no oligodendrocytes were infected in vivo after viral administration. After lentiviral injection in the mouse substantia nigra, $45 \%$ of cells were neurons and $17 \%$ were astrocytes (Bensadoun, Deglon et al. 2000), whereas in the rat brain the majority of transduced cells were neurons (Naldini, Blomer et al. 1996; 1996).

The use of a lentiviral vector pseudotype with VSV-G (Burns, Friedmann et al. 1993 ) gives this system an extremely broad host range in the CNS (Blomer, Naldini et al. 1997; Kordower, Bloch et al. 1999) making it most suitable for delivery of therapeutic molecules for different parts of the CNS where different populations of CNS neurons and 
glia exist. Watson et al. (Watson, Kobinger et al. 2002) used pseudotype lentivirus with Mokola, lymphocytic choriomeningitis virus (LCMV), and VSV-G and showed that similar populations were infected by all three types both in vitro and in vivo, with Mokola pseudotype-virus being most efficient when injected in mouse striatum and hippocampus. In contrast, no transduction resulted from injection of Ebola-pseudotype virus. Englund (2000) and Falk (2002) have also shown limited efficiency of lentiviral vectors in mice. Although many studies support the notion that VSV-G-coated lentivirus is neurotropic in the brain (Blomer, Naldini et al. 1997; Kordower, Bloch et al. 1999), Jakobsson et al. (2003) provided evidence that VSV-G allows transduction of both glial and neuronal cells and the promoter dictates in what cell type the transgene will be expressed. The present study detected no difference in the ability of lentivirus and adenovirus to infect Schwann cells and other cell lines in vitro. This contrasts with others who have shown adenovirus to be superior for infection of murine neural stem cells (Falk, Holmstrom et al. 2002). These discrepancies are likely due to murine-specific differences that limit lentivirus nuclear entry and integration leading to decreased transgene production (Johansson, Momma et al. 1999; Englund, Ericson et al. 2000; Falk, Holmstrom et al. 2002).

Lentiviral injection into the spinal cord resulted in stable transgene expression with minimal inflammatory response and tissue damage making this system ideal for situations that require long term delivery of therapeutic molecules to the CNS. $\mathrm{Bgal}^{+}$(data not shown) and EGFP ${ }^{+}$cells were detected as far as $3-4 \mathrm{~mm}$ from the injection site for up to 4 weeks post-injection (the longest time point evaluated). In previous studies, the extent of $\beta$ gal staining ranged from $1 \mathrm{~mm}$ from the injection site after a $1 \mu 1$ injection of 3 


\begin{abstract}
x $10^{8} \mathrm{TU} / \mathrm{ml}$ (Bensadoun, Deglon et al. 2000) to several millimeters away from the injection site. In all cases, long-term expression of the trans-gene was seen for periods ranging from 60 days (Zhao, Strappe et al. 2003) to 6 months post-injection (Blomer, Naldini et al. 1997), with retrograde transport of the virus after injection in the spinal cord, to the substantia nigra and the nigrostriatal (Blomer, Naldini et al. 1997).
\end{abstract}

Not unexpectedly, protein levels after adenovirus-mediated transgene delivery were dose-dependent, although not strictly 1:1. Transgene expression also downregulated after the administration of low titers of adenovirus $\left(1 \times 10^{5} \mathrm{TU} / \mu \mathrm{l}\right)$. Others have used moderate $\left(5 \times 10^{6} \mathrm{TU} / \mu \mathrm{l}\right)$ (Romero and Smith 1998$)$ to high titers $\left(1 \times 10^{9} \mathrm{TU} / \mu \mathrm{l}\right)(\mathrm{Zhou}$ and Shine 2003) in an effort to achieve higher expression of transgene. Although we have only studied the temporal expression after low dose virus delivery, we would anticipate the downregulation after higher doses to be comparable to that observed here, albeit with a more intense inflammatory response. Previous studies have shown that at higher concentrations, the majority of CNS infected cells cease transgene expression within 2 weeks after administration or degenerate due to an immune inflammatory response (Hermens and Verhaagen 1997; Peltekian, Parrish et al. 1997). This downregulation of adenovirus driven expression has also been observed by others employing it in both ex vivo (Blits, Dijkhuizen et al. 1999) and in vivo (Zhou and Shine 2003) approaches. Nonintegrating adenoviral vectors are almost certainly lost during cell replication, but adenovirus expression can be persistent in grafted post-mitotic cells (Boer, van Esseveldt et al. 2001). 
Monoclonal antibodies against CD4 and CD45 T lymphocyte receptors successfully reduced transgene downregulation after adenoviral administration, contributing to significantly higher D15A expression for up to 4 weeks post-infection. This is in agreement with previous work by Romero and Smith (1998). Several other strategies have been developed to avoid this downregulation and inflammation, including the use of immune suppressors (cyclosporine and cyclophosphamide) (Dai, Schwarz et al. 1995), or monoclonal antibodies to CD4, CD40, and TCR (Guerette, Vilquin et al. 1996; Scaria, St George et al. 1997; Zsengeller, Boivin et al. 1997). This strategy likely eliminates only one cause for the downregulation after adenoviral gene delivery as later downregulation may still occur due to a delayed immune response, or cell death.

Although promoter silencing can be a cause for downregulation of transgene production after viral gene delivery, it is not in our opinion the reason for the noted differences in transgene expression patterns between lentivirus and adenovirus noted in the present study, as both lentiviral and adenoviral vectors used CMV promoter to drive D15A expression. Also down-regulation after in vivo adenoviral delivery has been reversed, at least in part, by modifying the animal's immune response using monoclonal antibodies against CD4 and CD45 $\mathrm{T}$ lymphocyte receptors. These data are consistent with an immune-mediated removal of infected cells in the presence of activated $\mathrm{T}$ cells.

One significant finding of this study shows that although EGFP levels were histologically detectable weeks after adenoviral injection, the downregulation of D15A assessed by ELISA was greater than what would have been predicted by the qualitative levels of EGFP. These data indicate that using marker proteins as the sole measure to 
assess the temporal expression after viral injection is problematic. Most studies have relied on histochemical or immunohistologic methods to analyze the duration of transgene expression in neural cells (Bennett, Wilson et al. 1994; Akli, Guidotti et al. 1996) leading to difficulties of interpretations and variable conclusions. For example, although $\beta$ gal has been seen up to 2 months after adenoviral injection (Byrnes, Rusby et al. 1995), others showed rapid downregulation after in vivo and ex vivo studies using both $\beta$ gal histochemistry (Blits, Dijkhuizen et al. 1999) and NT-3 ELISA (Zhou and Shine 2003). Using RT-PCR to detect GDNF mRNA, Baumgartner and Shine (1998) showed adenoviral-driven gene expression in the spinal cord at 3 weeks, but no detectable levels at 6 weeks after adenoviral injection. Collectively, these results indicate that direct assessment of the relevant protein should be employed to measure transgene expression.

The ex vivo gene transfer results using the LZRS retrovirus with a constitutive 5 LTR promoter in Schwann cells showed rapid downregulation of gene expression by 2 weeks post-grafting. These findings are in agreement with previous reports, which have shown variable transgene downregulation independent of either the promoter or cell type used (Liu, Himes et al. 1999; Johansen, Rosenblad et al. 2002). This downregulation and variability is believed to be due to the random integration into the host genome, and the issue has been raised about possible complications related to permanently modifying the host genotype, triggering insertional mutagenesis and the activation of proto-oncogene in host cells (Kohn, Sadelain et al. 2003; Noguchi 2003). This would likely be a very rare event, however, and the rapid downregulation of trans-gene expression could prove useful when only transient spinal cord expression is desired. 
We show robust, doxycycline-dependent induction of gene expression ex vivo with the tetracycline-regulated promoter. Basal expression levels were detectable and were significantly higher than control animals, however, indicating incomplete transcriptional regulation in the absence of doxycycline, highlighting one problem related to the use of this system. Blesch et al. (2001) have shown efficient gene expression for a period of 3 months in vivo using a tet-off system, whereas others reported varying basal expression using tet-on system in vitro (Paulus, Baur et al. 2000) and marked downregulation immediately after transplantation into the rat striatum (Johansen, Rosenblad et al. 2002). Our findings are in line with the latter study, in that we report significant basal expression both in vitro and ex vivo. The basal expression level observed in vitro as well as in vivo in the present study may be explained by multiple factors including, but not limited to, enhancer elements in the promoter, low affinity binding of the activator to the tetracycline responsive element (TRE) in the absence of doxycycline, or basal activity of the promoter (Johansen, Rosenblad et al. 2002).

In summary, the results of the present study indicate that: 1) lentiviral-mediated gene delivery is best suited for situations when long-term delivery of a trans-gene is needed, whereas ex vivo retroviral delivery system is more appropriate for transient delivery of therapeutic molecules, with adenoviral-driven expression intermediate; 2) the use of transgene-specific assays to determine the protein level after delivery are more reliable and biologically relevant than the use of marker proteins as indicators of transgene levels; and 3) protein levels are dependent on viral titer, as greater concentrations of the therapeutic molecules can be obtained by increasing viral dose. The 
caveat to this later point is that as viral loads increase, so does the extent of the inflammatory response.

Taken together, these results provide further support for the use of viral vectors for gene transfer of therapeutic molecules aimed at enhancing regeneration after SCI. Moreover, results indicate that multiple viral delivery approaches may be used singly or in combination to achieve a targeted temporal, as well as spatial, delivery of transgene to the injured CNS. 
Table 2.1: D15A (NT-3) expression (pg/ 24 hours $/ \mathrm{ml}$ ) in conditioned media of Schwann cells, NIH3T3 and RN33B cells following viral infection in vitro.

\begin{tabular}{|l|l|l|l|l|l|}
\hline & No virus & Lentivirus & Adenovirus & $\begin{array}{l}\text { LZRS } \\
\text { retrovirus }\end{array}$ & $\begin{array}{l}\text { MSCV } \\
\text { retrovirus }\end{array}$ \\
\hline $\begin{array}{l}\text { Schwann } \\
\text { Cells }\end{array}$ & $41 \pm 10$ & $\begin{array}{l}3108 \pm 641 \\
* * *\end{array}$ & $\begin{array}{l}2742 \pm 568 \\
* * *\end{array}$ & $1578 \pm 288$ & $2278 \pm 541$ \\
\hline $\begin{array}{l}\text { Fold } \\
\text { induction }\end{array}$ & & 75 & 66 & 38 & 55 \\
\hline NIH 3T3 & $49 \pm 12$ & $5061 \pm 704$ & $\begin{array}{l}8587 \pm 630 \\
*\end{array}$ & $4570 \pm 784$ & $2612 \pm 484$ \\
\hline $\begin{array}{l}\text { Fold } \\
\text { Induction }\end{array}$ & & 103 & 175 & 93 & 53 \\
\hline $\begin{array}{l}\text { RN33B } \\
244 \pm 110\end{array}$ & $15273 \pm 1529$ \\
$\#, * * *$ & $\begin{array}{l}10040 \pm 2378 \\
\#\end{array}$ & $\begin{array}{l}7346 \pm 852 \\
\#\end{array}$ & $\begin{array}{l}8590 \pm 731 \\
\#\end{array}$ \\
\hline $\begin{array}{l}\text { Fold } \\
\text { induction }\end{array}$ & 62 & 41 & 30 & 35 \\
\hline
\end{tabular}

In Schwann cells, D15A (NT-3) levels in the lentiviral and adenoviral-infected cells were not different from those in the MSCV retroviral-infected group but were significantly higher than no virus and LZRS retrovirus $(\mathrm{p}<.001)$. In NIH 3 T3 cells, D15A levels in adenoviral-infected cells was significantly higher $(\mathrm{p}<.001)$ than all other groups. MSCV infected cells, D15A levels were significantly $(\mathrm{p}<.001)$ lower than all other viral infected groups. In RN33B cells, D15A levels were significantly higher (\# $\mathrm{p}<.001$ ) than other cell types in all groups tested. D15A levels in the Lentiviral infected RN33B cells were significantly higher $(p<.001)$ than all other viruses. All cells were seeded at $1 \times 10^{5}$ cell/well. Data are expressed as mean $\mathrm{pg}$ D15A/24hours $/ \mathrm{ml} \pm \mathrm{SD}(\mathrm{n}=6)$. 


\section{Figure Legends}

Figure 2.1. Schwann cells were infected in vitro with either lentivirus (A), adenovirus $(B)$, or retrovirus $(\mathrm{C})(\mathrm{MOI}=20)$. Cells were stained for EGFP and counterstained with Hoechst 33342. TrkC expressing PC12 cells (arrow heads in D) were used to determine the bioactivity of D15A. Recombinant human (rh) NT-3 was added (100 pg/ml-1 ng/ml) to the media of $\mathrm{PC} 12$ cells for $3-4$ days, neurite outgrowth from PC12 cells (arrow heads in E) was compared to that of conditioned media of infected NIH3T3 cells added at a concentration range of $10-100 \%$, bioactive $\mathrm{D} 15 \mathrm{~A}$ in media was identified by examining neurite outgrowth (arrowheads in F) from PC12 cells. Conditioned media at a concentration of $75-100 \%$ were similar to an NT-3 concentration of $500 \mathrm{pg} / \mathrm{ml}-1 \mathrm{ng} / \mathrm{ml}$. Control PC12 cells (D) maintained on DMEM did not show any neurite outgrowth. There was no difference between conditioned media collected from NIH3T3 cells infected with lentivirus, adenovirus, or retrovirus. Scale bar $=40 \mu \mathrm{m}$.

Figure 2.2. Temporal expression of D15A in the spinal cord after ex vivo gene delivery using lentivirus, adenovirus, EGFP, and retrovirus. Schwann cells were infected with similar MOI (20) and $48 \mathrm{hr}$ later $1 \times 10^{5}$ cells were transplanted into the spinal cord. There was no significant difference between normal spinal cord and EGFP-infected groups at any of the three time points. D15A expression was significantly higher ( $\mathrm{P}<$ 0.001 ) in the lentiviral-infected group than normal, EGFP, and retrovirus infected groups at 1 and 2 weeks. No significant difference was found between lentiviral and adenoviral infected groups at 1- and 2-weeks post-transplantation. At 4 weeks, D15A expression was 
significantly higher $(\mathrm{P}<0.001)$ in the lentiviral-infected group than all other groups. In the adenoviral-infected group, D15A levels were significantly lower $(\mathrm{P}<0.001)$ at 4 weeks. Downregulation of D15A in the retroviral-infected group was rapid with significantly lower $(\mathrm{P}<0.001)$ D15A levels at 2 and 4 weeks compared to that of 1 week. Although the lentiviral-infected group showed some downregulation with D15A levels significantly lower $(\mathrm{P}<0.01)$ at 2 weeks, D15A levels plateau and were not significantly different at 2 and 4 weeks. Data shown are the mean $\pm \operatorname{SD}(n=4)$.

Figure 2.3. D15A protein expression is dependent on viral titer. One microliter of $1 \mathrm{x}$ $10^{5} \mathrm{TU} / \mu 1$ or $5 \times 105 \mathrm{TU} / \mu 1$ of virus was injected into the spinal cord. One week after injection, expression of D15A was significantly $(\mathrm{P}<0.001)$ higher than normal in all groups tested. D15A levels were significantly higher after high titer adenoviral (5 x $10^{5}$ $\mathrm{TU} / \mu 1, \mathrm{n}=3 ; \mathrm{P}=0.001)$ and lentiviral injections $\left(5 \times 10^{5} \mathrm{TU} / \mu \mathrm{l}, \mathrm{n}=3 /\right.$ group $\left.; \mathrm{P}<0.001\right)$ than after the low titer injections ( $1 \times 10^{5} \mathrm{TU} / \mu \mathrm{l}, \mathrm{n}=6 /$ group $)$. D15A expression was not significantly different between titer matched adenoviral and lentiviral injected groups. Data shown are mean $\pm \mathrm{SD}$.

Figure 2.4. Inflammatory response and cell-specific infection by low titer lentiviral and adenoviral vectors in the spinal cord. Photomicrographs taken within $2 \mathrm{~mm}$ from the injection site show representative sections after; lentivirus (A,D,G,I,L,N,O), adenovirus + mAb OX22/OX38 (B,E,H,J,K,M,P,Q) and adenovirus (C) injections. In both lentivirus (A) and antibody-treated adenovirus groups (B) EDl+ cells were limited to the area surrounding the injection site (arrows), whereas in the non-antibody treated adenovirus 
group (C) ED1+ cells were widespread over the entire gray and white matter of the spinal cord. ED1+ cells were counted (F) in five sections $2 \mathrm{~mm}$ from the injection site from each animal. Cells were counted using ImageproPlus ${ }^{\circledR}$ software in an entire $20 x$ field. The numbers of $\mathrm{EDI}^{+}$cells in the adenovirus group were significantly higher $(\mathrm{P}<0.001)$ than all other groups. There was no significant difference among PBS, lentivirus, and adenovirus $+m A b$ groups. Data shown are the mean $\pm S D,(n=7 /$ group $)$. To identify cellular phenotypes infected with low titer $\left(1 \times 10^{5} \mathrm{TU} / \mu \mathrm{l}\right)$ lentivirus and adenovirus, sections were double-labeled for EGFP (green) and the cell-specific markers; neurons $(\mathrm{NeuN})$, oligodendrocytes (APC), astrocytes (GFAP), microglia/macrophages ED1/OX42, and T lymphocytes (CD4). Confocal microscopy showed that astrocytes (arrows) were infected with both viruses (D,E). In contrast, APC + oligodendrocytes $(\mathrm{G}, \mathrm{H})$ and NeuN + neurons (I,J) (arrows) were not infected after both viral injections. A decrease in NeuN immunoreactivity was also seen after lentiviral injection but not after adenoviral injection with immune suppression. CD4+ T cells were not seen 1 week after low titer adenoviral injection with the OX22/OX38 immunosuppression (K) or lentiviral injection $(\mathrm{N})$.

ED1+ macrophages $(\mathrm{L}, \mathrm{M})$ and $\mathrm{OX} 42+$ reactive microglia (O,P; arrows) were not infected after either viral injection. EGFP labeling was detected at 4 weeks after adenoviral injection with OX22/OX38 immunosuppression (arrows in Q). Data are representative of five animals per group. Scale bar $=200 \mu \mathrm{m}$ (in A,B); $20 \mu \mathrm{m}$ (in D-P), and $80 \mu \mathrm{m}(\mathrm{C}, \mathrm{Q})$. 
Figure 2.5. Identification of cell types infected with high titer lentivirus and adenovirus. EGFP labeling was found in both the gray and white matter of the spinal cord after lentiviral (A,C,E,G,I,K) and adenoviral (B,D,F,H,J,L) injections. Ependymal cells surrounding the central canal were infected by both types of viruses that could be clearly seen at high magnifications (arrows in A,B; insets in A and B are from adjacent sections). EGFP labeling was localized in $\beta I I I$ tubulin + neurons (C,D; arrows), NFH+ axons in the ventral white matter (E,F; arrows) and the ventral rootlets (E,F; triangular arrow heads) associated with motor neurons as well as GFAP+ astrocytes ( $\mathrm{G}, \mathrm{H}$; arrows). In contrast, neither oligodendrocytes (I, J; arrows) nor reactive microglia/macrophages (K,L; arrows) were labeled with EGFP. Scale bar $=200 \mu \mathrm{m}(\mathrm{A}, \mathrm{B}) ; 40 \mu \mathrm{m}(\mathrm{C}, \mathrm{F}$ and insets in A,B); 20 $\mu \mathrm{m}$ (in $\mathrm{G}, \mathrm{H}, \mathrm{K}, \mathrm{L}$ ); $13 \mu \mathrm{m}$ (I,J). cc, central canal; VH, ventral horn; VR, ventral root. Data are representative of $\mathrm{n}=5$ animals/group.

Figure 2.6. Temporal expression of D15A in the spinal cord after in vivo gene delivery. Lentiviral delivery resulted in robust and stable gene expression for up to 4 weeks postinjection. At 4 weeks post-injection, the D15A levels were significantly higher than both adenoviral infected groups $(\mathrm{P}<0.001)$. In contrast, adenoviral infection showed significant downregulation of D15A at $2(\mathrm{P}<0.001)$ and 4 weeks $(\mathrm{P}<0.05)$ postinfection. Treatment of animals with mAb OX-22/OX-38 successfully reduced the downregulation of adenoviral-delivered D15A expression compared to the nonOX22/OX38 treated groups that was significantly lower $(\mathrm{P}<0.001)$ than lentivirus and adenovirus $+m A b$ groups at 4 weeks. Data represent the mean $\pm S D(n=5 /$ experimental group). 
Figure 2.7. Induction of D15A expression using doxycycline (Dox) in vitro (A) and in vivo (B). A: NIH/3T3 cells were transduced in vitro using the two virus (pRev-Tre D15A and pRev-Tre Tet-on) tetracycline inducible Tet-on system. After antibiotic selection for 1 week in vitro, increasing Dox concentrations were added to the culture media. No significant difference was found between 2,4 , and $6 \mu \mathrm{g} / \mathrm{ml}$ Dox concentrations. D15A levels at $6 \mu \mathrm{g} / \mathrm{ml}$ Dox were significantly higher than baseline expression $(\mathrm{P}<0.05)$. Data shown are the mean $6 \mathrm{SD}(\mathrm{n}=5$ /experimental group). B: $13105 \mathrm{D} 15 \mathrm{~A}$ infected RN33B cells were injected into the spinal cord. After the addition of $1 \mathrm{mg} / \mathrm{ml}$ Dox to the animal's drinking water, D15A levels at 1 week were significantly higher than both normal (open bars, $\mathrm{P}<0.001$ ) and no-Dox (dark gray bars, $\mathrm{P}<0.001$ ) groups. In one group of animals, Dox administration was stopped after 1 week, which resulted in a significant drop in D15A levels at 2 weeks (light gray bars, $\mathrm{P}<0.001$ ). At 2 weeks, D15A levels in the group that received Dox for 2 weeks were significantly higher than normal (black bars, $\mathrm{P}$ $<0.001)$, no-Dox $(\mathrm{P}<0.001)$ and animals that received Dox for only 1 week $(\mathrm{P}<0.01)$. Basal expression levels were detectable and were significantly higher $(\mathrm{P}<0.05$ at 1 week and $\mathrm{P}<0.01$ at 2 weeks) than in control animals indicating incomplete transcriptional regulation in the absence of Dox. Data shown are the mean $\pm \operatorname{SD}(n=4)$. 
Figure 2.1
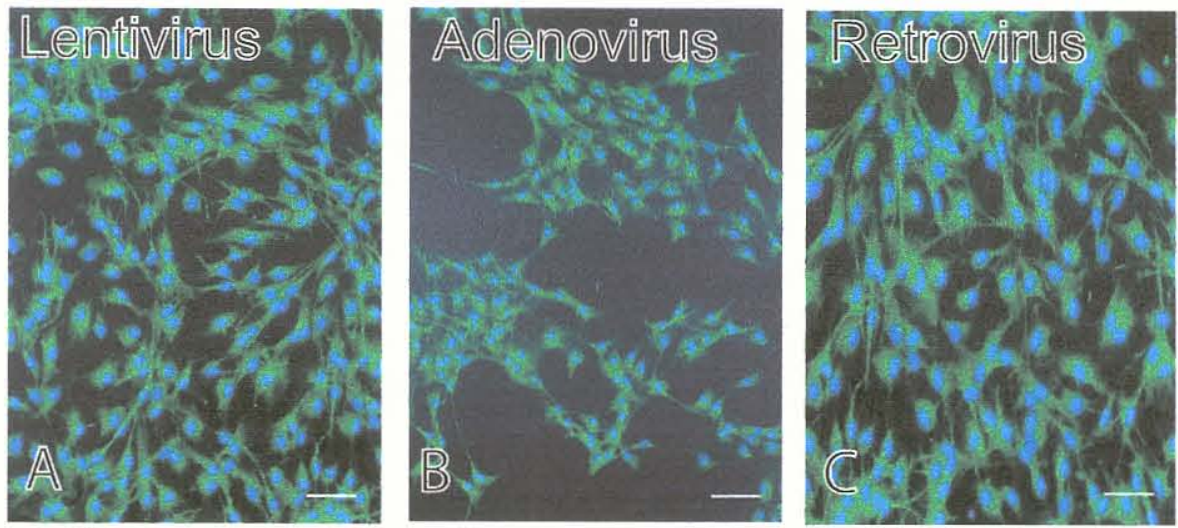

Control

D
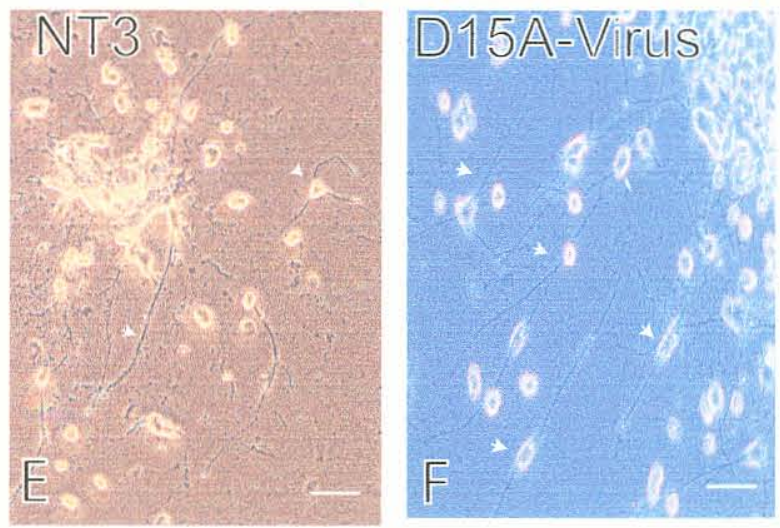
Figure 2.2

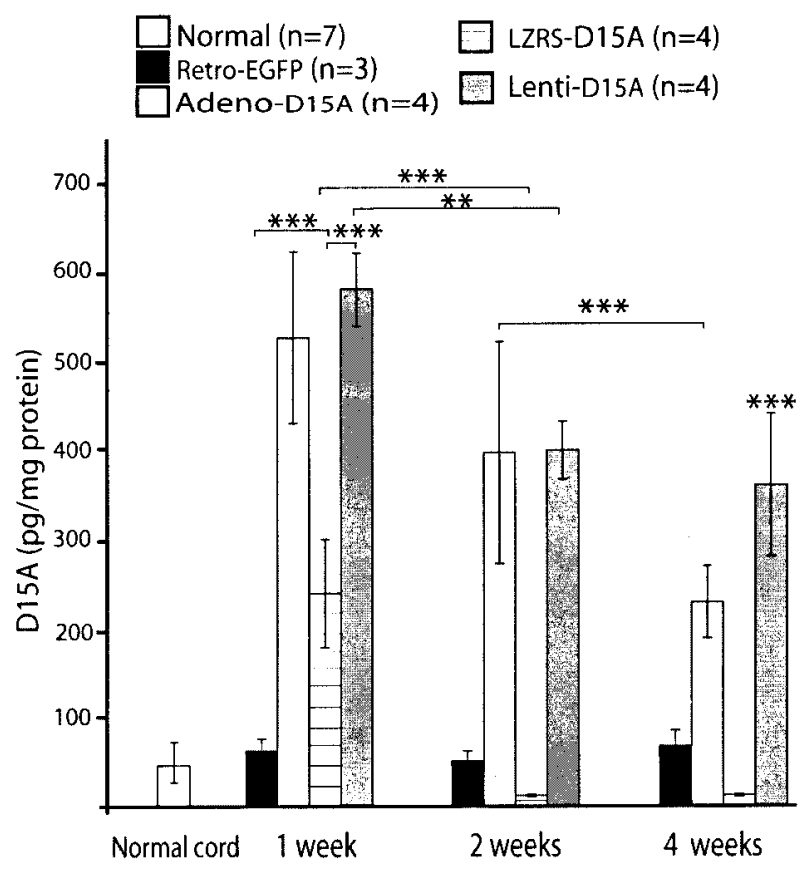

Figure 2.3

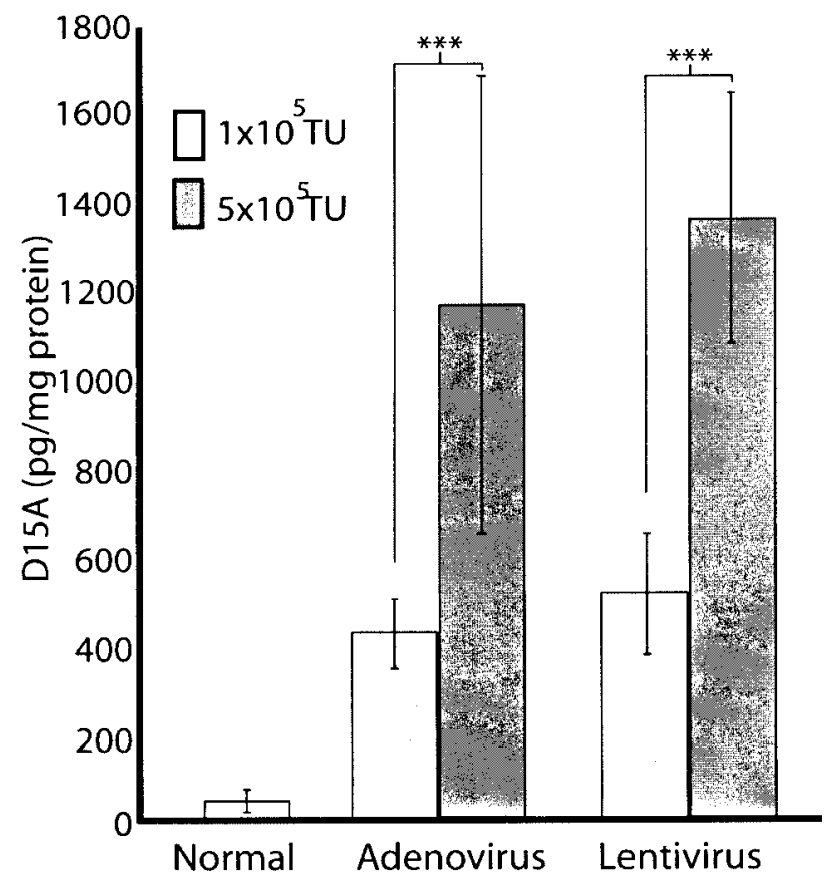


Figure 2.4

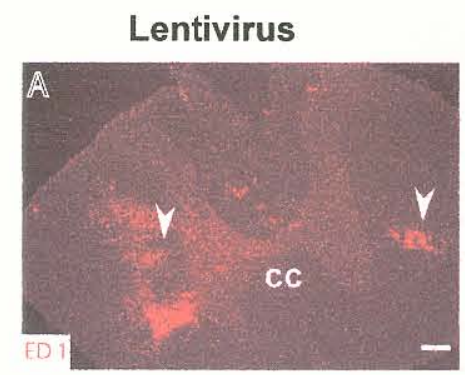

Adenovirus+ $0 \times 22 / 0 \times 38$
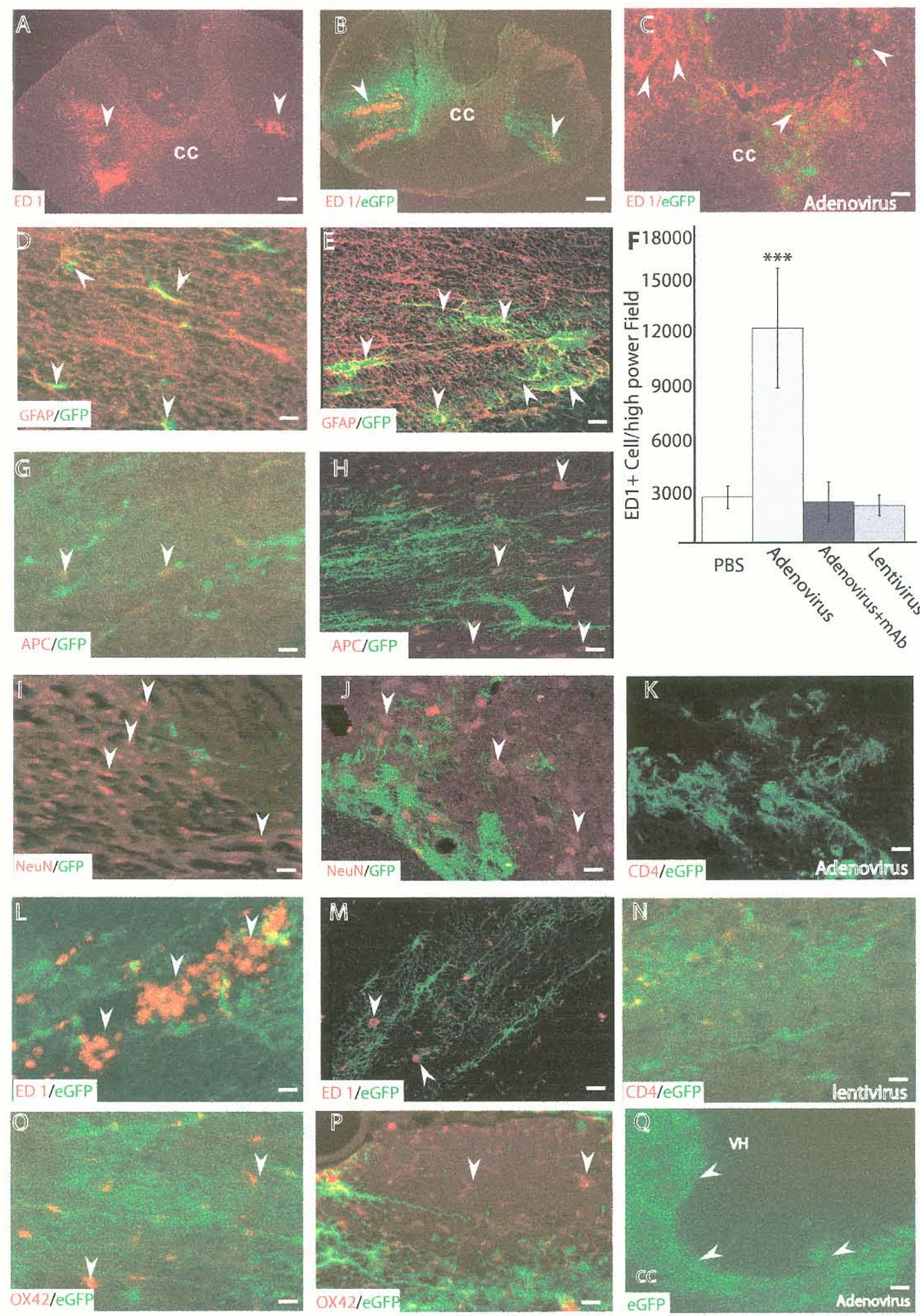
Figure 2.5
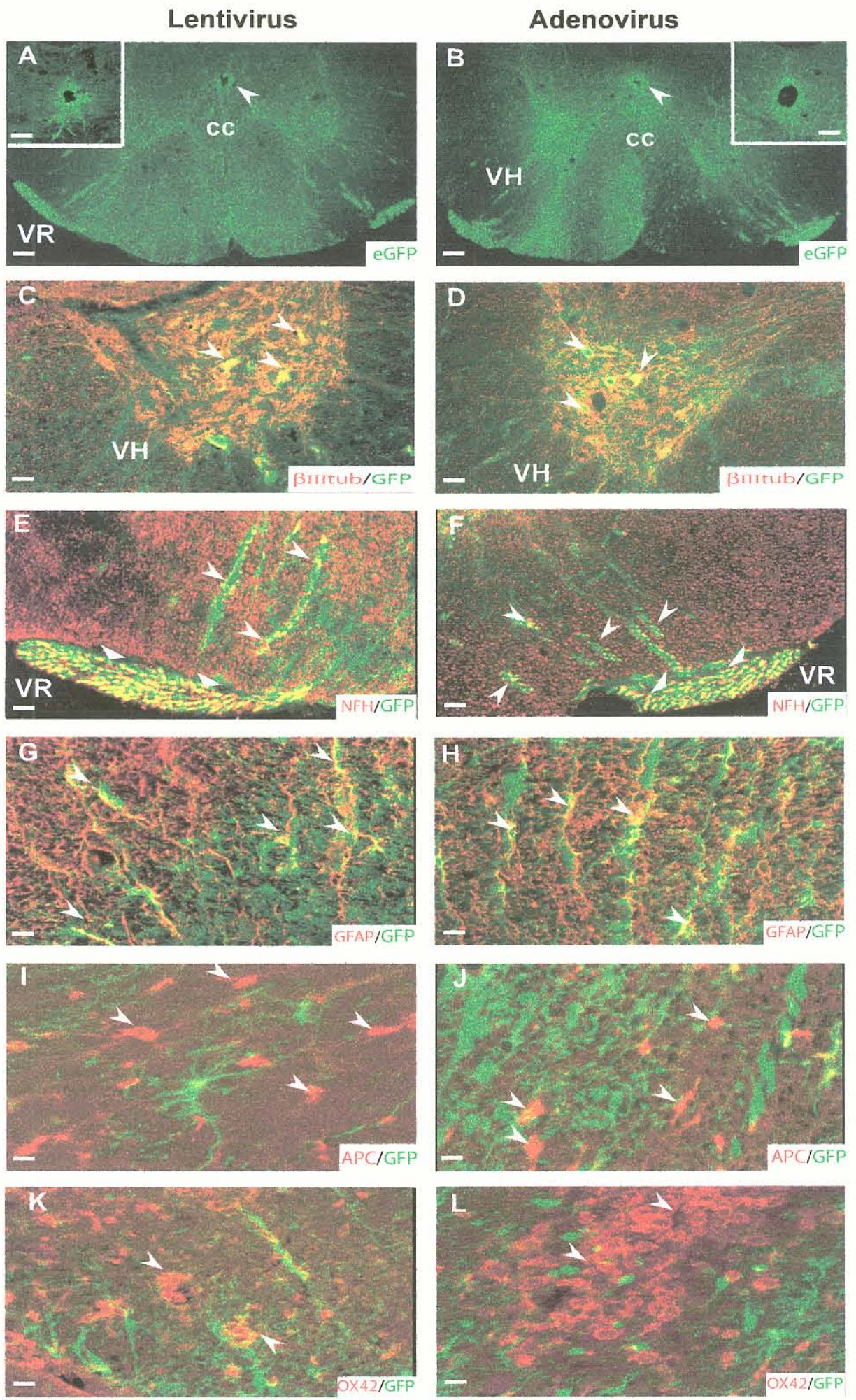
Figure 2.6

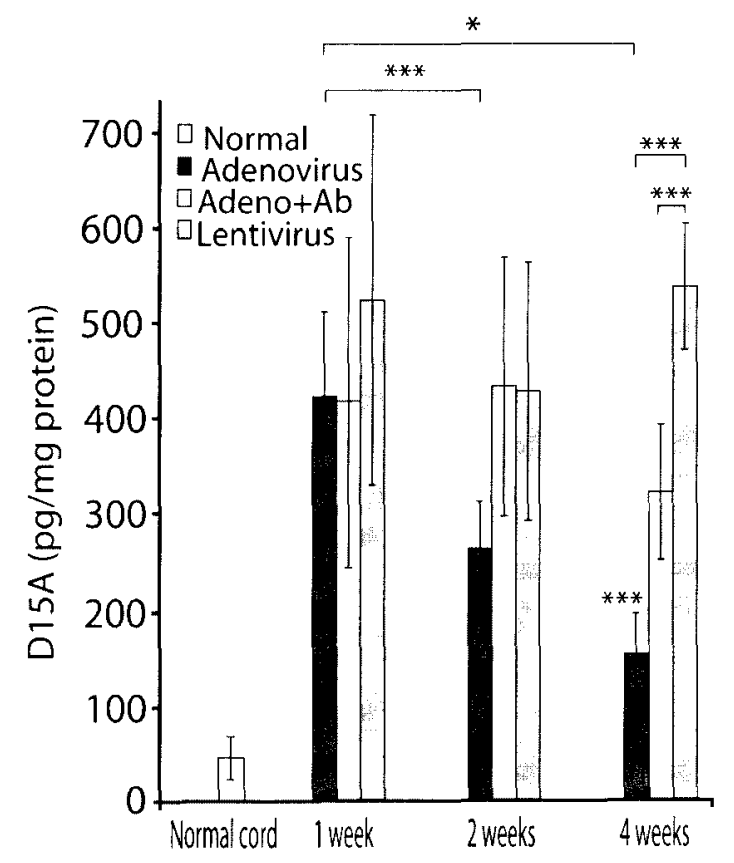


Figure 2.7

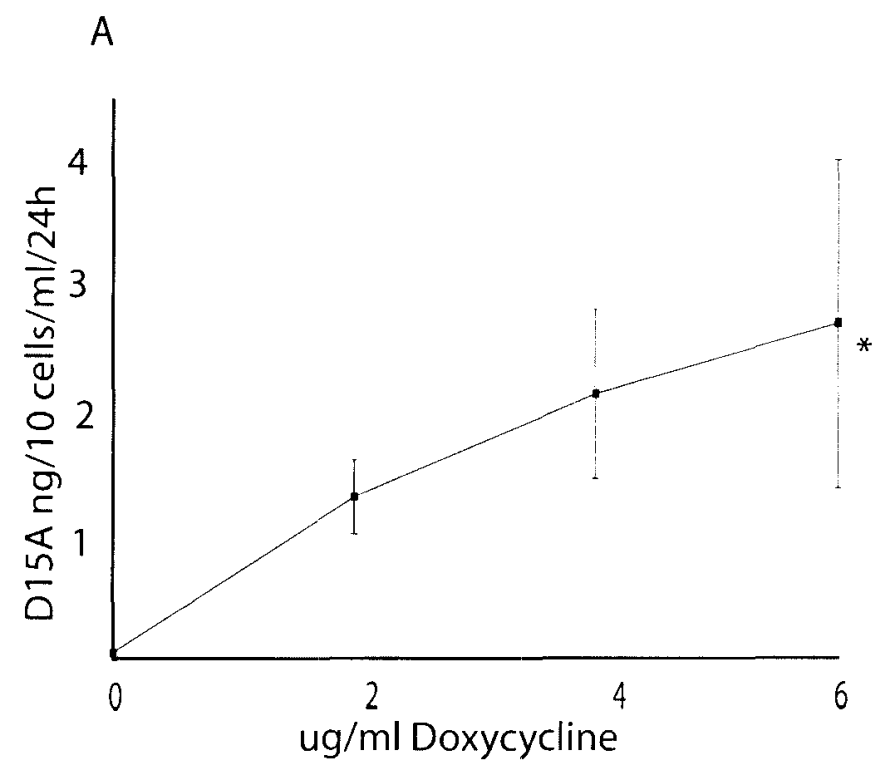

B

- Dox2wk $\square$ Dox 1 wk $\square$ NoDox

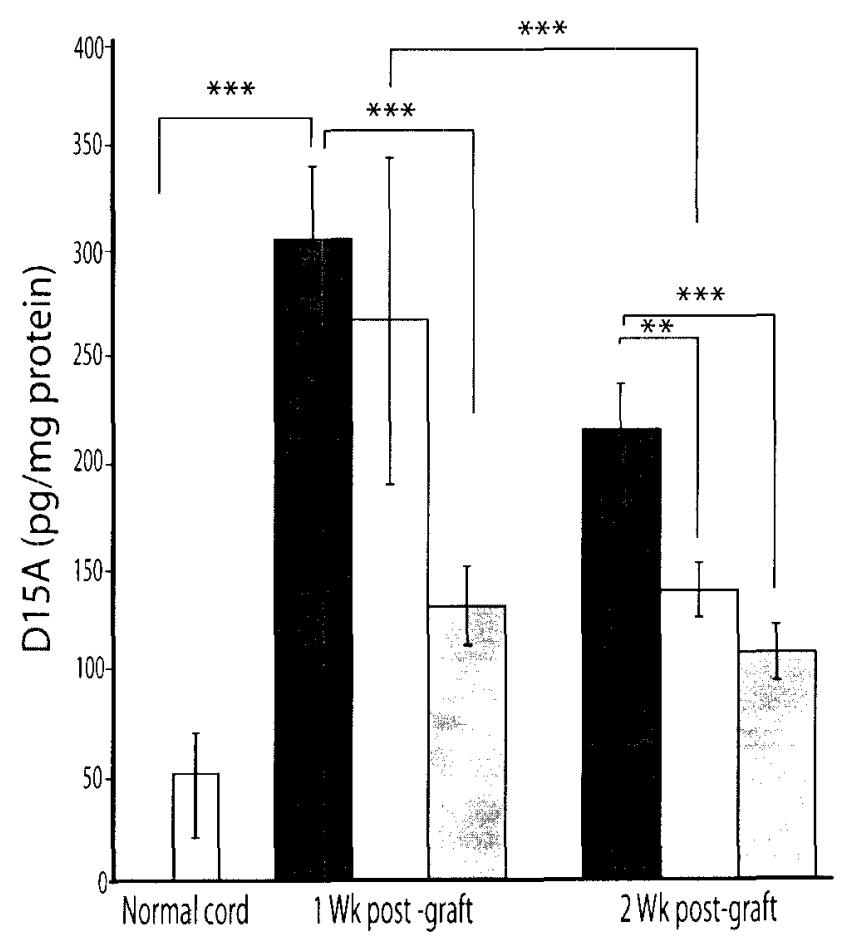




\section{CHAPTER 3}

\section{AXONAL REGENERATION INTO SCHWANN CELL-SEEDED PAN/PVC \\ GUIDANCE CHANNELS FOLLOWING A MID-THORACIC SPINAL CORD}

HEMISECTION: A COMPARISON BETWEEN 3 TYPES OF CHANNEL

\section{GEOMETRY}

\section{INTRODUCTION}

Spinal cord injury ( $\mathrm{SCl}$ ) produces damage of ascending and descending axons in the spinal cord, leading to long lasting functional loss with glial scarring and cavity formation that form barriers to regenerating axons. To overcome these barriers, different bridging modalities and tissue engineering strategies (reviewed in (Geller and Fawcett 2002; Zhang, Yan et al. 2005)) offer promising results for regeneration through and beyond the injury site. Schwann cells (SCs) were successfully used to promote axonal regeneration and myelination in spinal cord injury models using either biodegradable tubular scaffolds made of poly lactic acid (Oudega, Gautier et al. 2001), polylactide-coglycolide (PLGA) (1999; Hadlock, Sundback et al. 2000) or non-biodegradable polyacrylonitrile and polyvinylchloride copolymer (PAN/PVC) channels (Xu, Guenard et al. $1995 ; 1995 ; 1999)$. Studies of the effect of filaments with a diameter ranging from 5$100 \mu \mathrm{m}$, used alone or inside a sleeve, have demonstrated axonal and glial alignment parallel to the long axis of filaments both in vitro and in vivo (Khan, Dauzvardis et al. 
1991; Terada, Bjursten et al. 1997; Steuer, Fadale et al. 1999; Rangappa, Romero et al. 2000).

Previously, we demonstrated successful axonal regeneration into a large (outer diameter, $\mathrm{OD}, 3 \mathrm{~mm}$ ) or small (OD, $1.25 \mathrm{~mm})$ diameter, smooth inner surfaced PAN/PVC guidance channels seeded with SCs after either a total transection or hemisection, respectively, of the spinal cord (Xu, Guenard et al. 1995; 1995; 1999; Bamber, Li et al. 2001; Iannotti, Li et al. 2003). In this study we compared three types of channels that either having two different inner wall surface topography (smooth or grooved inner surface) or channels filled with filaments measuring $20 \mu \mathrm{m}$ in diameter.

\section{MATERIAL AND METHODS}

Forty four adult female Sprague-Dawley (SD) rats (150-175 g) were divided into three groups. Group $1(n=15)$ received transplantation of a channel with smooth inner wall, group $2(n=20)$ received a channel with grooved inner wall, and group $3(n=9)$ received a channel that filled with densely packed filaments of $20 \mu \mathrm{m}$ in diameter. In all groups, SCs were seeded into guidance channels at a density of $120 \times 106 / \mathrm{ml}$ prior to transplantation, as described previously (Xu, Guenard et al. 1995).

\section{Schwann cell preparation}

The procedures for harvesting and preparation of purified populations of rat SCs were described in previous publications (Xu, Guenard et al. 1995; 1997). Briefly, SCs were harvested from the sciatic nerve of adult SD rats (Harlan, Indianapolis, IN) under 
aseptic conditions, purified and expanded in culture. The purity of the SCs was ascertained by previously described methods (Xu, Guenard et al. 1995; 1997). When the purified SCs reached confluence, they were collected for either in vitro spinal cord explant culture or seeding into mini-guidance channels.

\section{Surgery \& Transplantation}

Under appropriate anesthesia with pentobarbital (40 mg/kg IP), the thoracic spinal cord was exposed with a laminectomy at T8 vertebra and the dura incised longitudinally. A right side hemi-section was performed using iridectomy scissors and a $3 \mathrm{~mm}$ segment of the spinal cord removed. A $3 \times 1.25 \mathrm{~mm}$ SC-seeded mini-channel was placed in the hemisection gap. The dura was closed with 10-0 nylon suture and the wound was closed in layers. The animals were allowed to recover from anesthesia before being returned to their cages. Post-operative care followed previously reported protocols $(\mathrm{Xu}, \mathrm{Zhang}$ et al. 1999), and all animal handling, surgical procedures, and post-operative care were provided in strict accordance with the Guide for the Care and Use of Laboratory Animals (National Research Council, 1996) and the Guidelines and Policies for Rodent Survival Surgery provided by the Animal Care Committees of University of Louisville.

\section{Perfusion, histology, and immunohistochemistry}

Six weeks after surgery, rats were anesthetized deeply with pentobarbital and transcardially perfused with $200 \mathrm{ml} 0.1 \mathrm{M}$ phosphate buffer (PB) (pH 7.4), followed by 250-300 $\mathrm{ml}$ of ice-cold $4 \%$ para-formaldehyde in $0.1 \mathrm{M}$ phosphate buffer $(\mathrm{pH} 7.4)$. A $2.5 \mathrm{~cm}$ segment of the spinal cord spanning the transplantation site was removed and 
post-fixed for 2 hours at $4^{\circ} \mathrm{C}$, then transferred to $30 \%$ sucrose in $0.1 \mathrm{M} \mathrm{PB}$ for cryoprotection until sectioned. The middle $1 \mathrm{~mm}$ segment of the channel and adjacent cord was cut, fixed in $1 \%$ Osmium oxide in $0.1 \mathrm{M}$ cacodylate buffer, dehydrated, and epoxy resin embedded. One micron $(1 \mu \mathrm{m})$ semi-thin sections were cut and stained with $1 \%$ toluidine blue. The proximal and distal channel-cord segments were sectioned longitudinally on a Leica cryostat at 20-25 $\mu \mathrm{m}$ and mounted on microscope slides. Sections were rinsed in phosphate buffered saline (PBS), blocked and permeabilized in PBS containing $10 \%$ normal donkey serum (NDS) and $0.3 \%$ Triton X-100 for $1 \mathrm{hr}$ at room temperature, and incubated in primary antibody overnight at $4 \mathrm{oC}$, with $5 \%$ NDS, and $0.25 \%$ Triton X-100 in PBS. Polyclonal rabbit anti-glial fibrillary acidic protein antibody (anti-GFAP; 1:100, Chemicon, Temecula, CA), was used to identify astrocytes. Twenty four hours later, sections were rinsed in PBS and incubated in either fluoresceinconjugated or rhodamine-conjugated Fab' fragment secondary antibodies from donkey (1:100; Jackson Laboratories, Baltimore, MD). Slides were washed in PBS, mounted, and examined using fluorescent microscope and photographed. Figures were assembled using Adobe Illustrator ${ }^{\circledR}$ software.

\section{Data analysis}

Myelinated axons, blood vessels and tissue cable mid-section area were determined on $1 \mu \mathrm{m}$ semi-thin, toludine blue-stained sections using a stereology workstation (StereoInvestigator; MicroBrightField, Williston, VT, USA). The examiners were blinded for the groups of animals. Four to six sections per animal were counted and the mean was calculated for each animal. The area of tissue cable was delineated using a 
$4 \mathrm{x}$ objective lens, and then divided in counting frames of 40 by $40 \mu \mathrm{m}$ using the Optical Fractionator probe. Counting was performed using an oil-immersion objective with a high numerical aperture $(100 \mathrm{x}$, oil, NA=1.00). Section thickness was measured for every section counted per animal $(\sim 1 \mu \mathrm{m})$. Total numbers of myelinated axons and blood vessels in the tissue cable were generated using the stereo-investigator ${ }^{\circledR}$ software, by multiplying the numbers of counted axons or blood vessels with the sampling probability (for technical details see (Schmitz and Hof 2000). One way ANOVA was used to compare control values with experimental groups followed by Tukey's post-hoc comparison test. A p value of $<0.05$ was considered as statistically significant.

\section{RESULTS}

To study the effect of the internal surface of the channel on axonal regeneration we used a smooth inner wall channel (Fig. 3.1 A, D, G, J) and a grooved inner wall channel (Fig. 3.1B, E, H, K); the channels filled with filaments (Fig. 3.1C, F, I, L) were used in a second comparison based on our hypothesis that fillaments would form an extra scaffold to enhance axonal regeneration.

Using unbiased stereological counting of myelinated axons in the mid-section of the tissue cable (Fig. 3.1M), the group with grooved inner wall had $730.66 \pm 252.76$ myelinated axons. This was significantly higher $(\mathrm{p}<0.01)$ than that of the smooth inner wall group (539.4 \pm 287.63$)$, indicating an enhancement of axonal regeneration when grooved inner wall topography was provided. In contrast, channels filled with filaments had a significantly lower $(\mathrm{p}<0.001)$ number of myelinated axons $(163.54 \pm 76.04)$ than both grooved and smooth inner wall channel groups (Fig 3.1M). 
The cross-sectional area of the regenerative tissue cable at the graft mid-point inside the channel was significantly higher in the filaments channel group (590865.3 \pm $143344.2 \mu \mathrm{m}^{2}$ ) when compared with the other two groups. This is due to the presence of filaments in the tissue cable. The area of the tissue cable in the grooved channel $\left(216942.2 \pm 83503.6 \mu \mathrm{m}^{2}\right)$ group was significantly higher $(\mathrm{p}<0.001)$ than that of the smooth channel group $\left(136435 \pm 90009.2 \mu \mathrm{m}^{2}\right)($ Fig $3.1 \mathrm{~N})$.

Stereological study of the number of blood vessels in the mid-section of the tissue cable showed significantly lower number $(16.96 \pm 11.77 ; \mathrm{p}<0.001)$ of blood vessels in the smooth inner wall channel group when compared with either the grooved channels group (42.15 \pm 22.56$)$ or filament-filled channel group $(34.91 \pm 23.83)$ (Fig. 3.1O). There was no statistically significant difference in the number of blood vessels between the grooved channels and filament-filled channels.

Immuno-histochemical study of the rostral and caudal graft host interface showed successful apposition of the channel and the spinal tissue at both ends of the graft with very limited cavity formation.

\section{DISCUSSION}

Tissue engineering has a great potential to replace or restore the anatomical structure and function of the injured spinal cord tissue. Biomaterials are combined with cells in a three dimensional structure to support axonal growth and myelination across the lesion gap. Previous work in our laboratory have shown successful regeneration and myelination of axons in a PAN/PVC channel seeded with SCs with myelinated axon 
numbers ranging from $734 \pm 139$ to $1004 \pm 126$ when SCs were used alone or $935 \pm 323$ to $1523 \pm 292$ when Schwann cells were combined with neurotrophins (Xu, Guenard et al. 1995; 1999; Bamber, Li et al. 2001). In this study we show similar success in axonal regeneration and myelination in the two non-filament groups, i.e. grooved (730.66 \pm 252.76$)$ and smooth $(539.4 \pm 287.63)$ inner wall groups.

A significant finding of this study is that deep grooving of the inner surface of a PAN/PVC channel enhances myelinated axonal numbers within grafts of SC-seeded tissue cable. Although the exact mechanism by which longitudinal grooving affect axonal regeneration remains unclear, one possibility is that grooves on the inner surface of the channel provide greater contact interface between the spinal cord tissue and the channel at the graft-host interface. During tissue healing after injury, the growth of regenerative tissue is influenced by the topographical features created by cells, matrix molecules, surfaces of biomaterials, a phenomenon which has been historically called contact guidance (Weiss 1945). It has also been noted recently that mouse sympathetic axons align to nano-imprinted patterns in vitro (Johansson, Carlberg et al. 2006) and hippocampal neurons extend their axons on a micro-scale chemical pattern made of polyL-lysine-laminin in vivo (Kam, Shain et al. 2001). These results indicate that the surface topography has a significant role in axonal guidance and regeneration.

Aebischer et al (1990) examined the effect of surface microgeometry of the inner wall of a guidance channel on myelination and morphology of regenerating peripheral nerves. Smooth inner wall channels induced discrete nerve cables, while grooved channels induced the formation of scattered nerve fascicles in an unorganized fibrin matrix. Other factors may also contribute to axonal regeneration inside guidance channels 
including the molecular weight cutoff of the channel wall, and piezoelectric properties of the guidance channels as previous studies show that electrically charged channels induce more myelinated axons compared to uncharged ones (Fujiki, Kobayashi et al. 2003; Mangold, Keller et al. 2005).

In this study we tested whether a filament-filled channel, seeded with SCs, promote the growth and myelination of regenerated axons following a thoracic spinal cord hemisection. The number of myelinated axons in this kind of channel was significantly lower than the other non-filament channels, indicating that at least at the present density filaments do not enhance axonal regeneration. In fact they may have physically impeded axonal growth into the graft because they occupied a significant area of the potential space for the axons to regenerate. These filaments may need to be modified either with coating with a regeneration enhancing extra-cellular matrix substrate and/or using them at a lower density. In previous studies, Rangappa et al (2000) observed higher neurite outgrowth rate on laminin pre-coated filament bundles compared to the poly-L-lysine coated and uncoated controls. Wen et al (2006) compared different diameters of filaments in vitro and showed enhanced Schwann cell migration on filaments coated with laminin and successful alignment and robust outgrowth of neurites on filament bundles in vitro with filament diameter in the range of 5 and $30 \mu \mathrm{m}$ that was enhanced with laminin and fibronectin coating of filaments. These observations indicate the promise of using engineered filaments, combined with appropriate coating materials, to enhance the growth and directionality of regenerated axons for better repair of the injured spinal cord. 


\section{Figure legend}

Figure 3.1. Comparison between three types of channels. Photomicrograph showing cross section of the non-grooved (a), grooved (b) and filament filled channel (c). Cross section of a single filament is shown in higher magnification (inset in c). D-F show higher magnification photomicrographs of the channel wall. Effective regeneration and myelination of axons was observed with variable results in all channels used, G-L show photomicrographs (G-I low power, J-L high power) from semi-thin toluidine blue stained sections from the mid-segment of the tissue cable showing blood vessels (BV) and filaments $(F)$.

The number of myelinated axons was significantly lower in the filament group compared to the other two groups, while myelinated axons were significantly higher in the grooved channel group compared to the smooth channel group $(\mathrm{m})$. The mid-section cable area was significantly higher in the filament group compared to the other groups. (Scale bars $200 \mu \mathrm{m}$ in A-C, $40 \mu \mathrm{m}$ D-F, $200 \mu \mathrm{m}$ in G-I, $20 \mu \mathrm{m}$ in J-L). ${ }^{*} \mathrm{p}<0.05,{ }^{* *}$ $\mathrm{p}<0.01,{ }^{* * *} \mathrm{p}<0.001$ 
Figure 3.1 Comparison between three types of channels
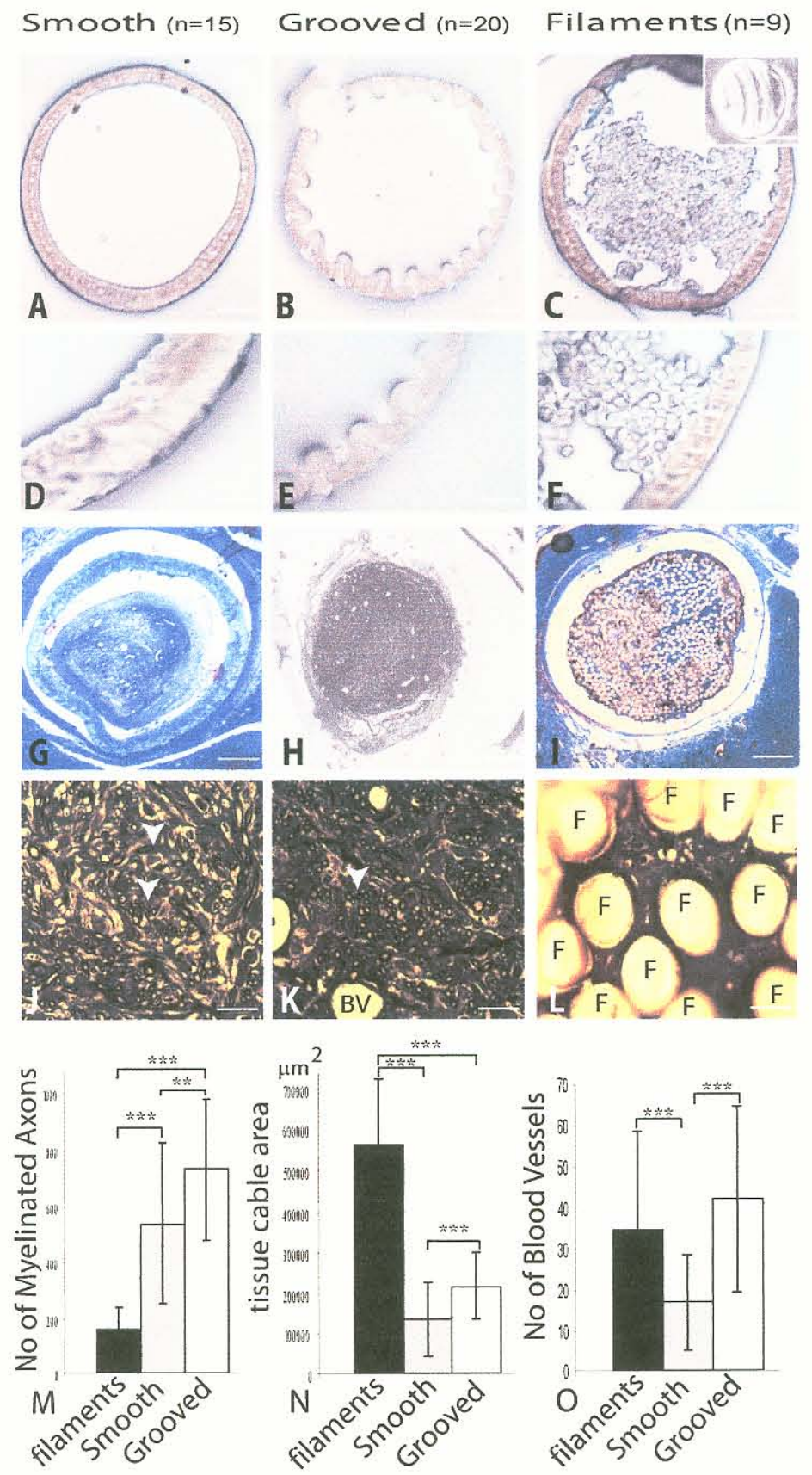


\section{CHPATER 4}

\section{AXONAL REGENERATION INTO GUIDANCE CHANNELS SEEDED WITH NEUROTROPHIN-SECRETING SCHWANN CELLS FOLLOWING A MID- THORACIC SPINAL CORD HEMISECTION: EFFECTS OF ALTERED TEMPORAL EXPRESSION.}

\section{INTRODUCTION}

SCs are an essential component to the injured CNS axons regeneration success encountered in the early transplantation experiments using peripheral nerves (Blakemore 1977; Kao, Chang et al. 1977; Richardson, McGuinness et al. 1980; David and Aguayo 1985 ) as possible solution to the inhibitory nature of the injured spinal cord environment following spinal cord injury (SCI). SCs naturally exhibit robust interaction with axons as they proliferate and migrate along axons and eventually myelinate individual axons (Oudega and Xu 2006). SCs also express the neurotrophin receptors tyrosine kinase receptor TrkC and the low affinity neurotrophin receptor $\mathrm{p} 75^{\mathrm{NTR}}$ (Chan, Cosgaya et al. 2001; Cosgaya, Chan et al. 2002). Brain derived neurotrophic factor (BDNF) enhances $\mathrm{SC}$ myelination by interacting with $\mathrm{p} 75^{\mathrm{NTR}}$. Neurotrophin-3 (NT-3) stimulates SC migration (Maniwa, Iwata et al. 2003; Yamauchi, Chan et al. 2003), SCs populate areas in the spinal cord following injury and remyelinate axons with peripheral type myelin both in rats (Bresnahan 1978; Bunge 1983; Blakemore and Crang 1985; Titsworth, 
Onifer et al. 2007) and humans (Bunge 1994). Previously, Bamber et al. (2001) showed that BDNF and/or NT3 infusion into the spinal cord parenchyma enhanced axonal regeneration and myelination only in $\mathrm{SC}$ groups compared to Matrigel only groups. BDNF and NT3 infusion into guidance channels seeded with SCs enhanced axonal regeneration from the stump of the transected adult rat spinal cord and myelination, with predominantly serotonergic fibers invading the graft (Xu, Guenard et al. 1995).

The combination of tissue engineering and $\mathrm{SC}$ transplantation offer a promising approach to enhance axonal regeneration and functional recovery following SCI. In Chapter 3, we compared three types of guidance channels made of polyacrylonitrile and polyvinylchloride (PAN/PVC) co-polymers with smooth or grooved inner walls or filled with filaments combined with SC grafts. We showed greater axonal growth and myelination into the channels with grooved inner walls than channels with smooth inner walls. The addition of filaments inside the channels did not enhance axonal regeneration.

Menei and colleagues (Menei, Montero-Menei et al. 1998) compared normal SCs with SCs genetically modified to secrete human BDNF, grafted in the transection site as well as a trail $5 \mathrm{~mm}$ long in the cord distal to a transection site. Schwann cells-BDNF improved the regenerative response across a transection site in the thoracic cord.

Our previous work showed that the expression of a transgene can be controlled by utilizing the intrinsic characteristics of the viral delivery system (Abdellatif, Pelt et al. 2006). For example, transgene expression following retroviral-mediated delivery downregulates reaching near baseline levels in approximately 2 weeks, whereas adenoviralmediated delivery peaked at 2 weeks dropping to $50 \%$ expression levels at 4 weeks. On 
the other hand, lentiviral-mediated delivery leads to longer lasting transgene expression. To test whether different temporal expression levels of neurotrophins from SC infected with retroviral, adenoviral, or lentiviral vectors affect axonal regeneration and myelination, we transplanted infected SC-seeded mini-channels into a thoracic SCI. We also reported successful in vitro infection of SCs with adenovirus, retrovirus and lentivirus carrying the cDNA for D15A (Abdellatif, Pelt et al. 2006), a bi-functional neurotrophin molecule with BDNF and NT3 functions (Urfer, Tsoulfas et al. 1994). We hypothesize that the combination of SC transplantation and a defined time period of viralmediated transgene delivery will optimally enhance axonal regeneration and myelination.

\section{MATERIAL AND METHODS}

Cell culture.

SCs were isolated as described previously (Morrissey, Kleitman et al. 1991; Xu, Zhang et al. 1999). Briefly, sciatic nerves were dissected from pentobarbital anaesthetized adult SD rats. Following removal of the epineurium and connective tissue, nerves were cut into $1 \mathrm{~mm}$ explants and placed in $35 \mathrm{~mm}$ Corning tissue culture dishes (Baxter, Stone Mountain, GA) containing Dulbecco's Modified Eagle's Medium (DMEM; Gibco Lab., Grand Island, NY) supplemented with 10\% FBS. Explants were transferred to new culture dishes every 7 days with fresh medium. Five weeks later, explants were incubated overnight in $1.25 \mathrm{U} / \mathrm{ml}$ dispase (Boehringer Mannheim Biochemicals, Indianapolis, IN), $0.05 \%$ collagenase (Worthington Biochemicals Corp., Freehold, NJ), and $15 \% \mathrm{FBS}$ in DMEM at $37^{\circ} \mathrm{C}$ in $5 \% \mathrm{CO}_{2}$. The next day, explants were dissociated and cells were plated onto poly-L-lysine-coated $100 \mathrm{~mm}$ dishes in 
DMEM $/ 10 \%$ FBS, containing $20 \mathrm{mg} / \mathrm{ml}$ pituitary extract (BTI, Stoughton, MA) and 2 mM forskolin (Sigma, St Louis, MO).

Viral vectors.

Adenoviral (Ad5-D15A), lentiviral (pLenti6-D15A), and retroviral (LZRS-D15A) vectors, respectively, encoding D15A, as well as control (LZRS expressing EGFP) vectors were constructed, titered, concentrated, and used exactly as previously described (Abdellatif, Pelt et al. 2006).

Animal groups.

Forty three adult female Sprague-Dawley (SD, Harlan, Indianapolis, IN) rats were divided into experimental groups as shown in Table 4.1. Rats were housed 2-3 per cage with free access to food and water under 12-hr light:dark cycle according to the guidelines of the Institutional Animal Care and Use Committee (IACUC) at the University of Louisville. Animals were anesthetized with pentobarbital ( $40 \mathrm{mg} / \mathrm{kg}$ IP). All animals injected with live virus were isolated in a biohazard animal suite for 7 days post injection and after 7 days were housed in common housing suites according to the University of Louisville IACUC housing regulations. Animals received a right thoracic hemisection and transplantation of a grooved inner wall channel seeded with LZRSD15A, pLenti6-D15A, or LZRS-EGFP SCs.

Hargreaves testing.

Two weeks prior to sacrifice, each rat was gently grasped by an observer blinded to experimental groups and placed on the warmed $\left(32^{\circ} \mathrm{C}\right)$ glass platform $(36 \mathrm{~cm} \times 95 \mathrm{~cm})$ 
(Model 400 heated base, IITC Life Sciences, Woodland Hills, CA) of a planter test analgesia meter (Series 8, Model 390G, IITC Life Sciences, Woodland Hills, CA). The testing head of the apparatus was placed $6 \mathrm{~cm}$ below the glass platform and a heated light $\left(42^{\circ} \mathrm{C}\right)$ focused on the glass surface was applied to the plantar surface of both hind paws. The time to withdrawal of each hind paw was recorded by another blinded observer. The analgesia meter was set to a maximum exposure time of 20 seconds after which time the light was automatically turned off. Each rat was tested 4-5 times with a minimum of 5 minutes between each test. The time to withdraw the injured side was compared with that of the un-injured side. Uninjured sham and naive animals were included in the analysis and statistical analyses performed as described below.

\section{Grid walk test.}

Once daily for a minimum of three trials per animal on three different days, each rat was gently removed from its cage by its tail and placed in the middle of $1 \mathrm{~m} \times 1 \mathrm{~m}$ wire grid, with grid holes $3.5 \mathrm{~cm} \times 3.5 \mathrm{~cm}$ (Onifer, Zhang et al. 2005). Two observers blinded to the experimental groups, were positioned on opposite sides of the grid and counted the left and right hind limb footfalls during 3 minutes of spontaneous locomotion. A footfall was counted when the entire hind paw extended through a grid hole. The average numbers of footfalls of the right side (injured for experimental groups) were compared to the left side.

Histology.

Rats were anesthetized with pentobarbital and transcardially perfused with $200 \mathrm{ml}$ of $0.1 \mathrm{M}$ phosphate buffer ( $\mathrm{pH} 7.4 ; \mathrm{PB})$ followed by $250-300 \mathrm{ml}$ of ice-cold $4 \%$ 
paraformaldehyde in PB. A 2.5-3.0 cm segment of the spinal cord that included the transplantation site was removed and post-fixed for 2 hours at $4^{\circ} \mathrm{C}$, then transferred to $30 \%$ sucrose in $0.1 \mathrm{M} \mathrm{PB}$ for cryoprotection until sectioned. The middle $1 \mathrm{~mm}$ segment of the channel and adjacent spinal cord was cut, fixed in $1 \%$ osmium oxide in $0.1 \mathrm{M}$ cacodylate buffer, dehydrated, and embedded in epoxy resin. One micron semi-thin transverse sections were stained with $1 \%$ toluidine blue.

The proximal and distal channel-cord segments were sectioned longitudinally on a Leica cryostat at $20-25 \mu \mathrm{m}$ and mounted on microscope slides. Sections were rinsed in phosphate buffered saline (PBS) and blocked and permeabilized in PBS containing 10\% normal donkey serum (NDS) and $0.3 \%$ Triton $\mathrm{X}-100$ for $1 \mathrm{hr}$ at room temperature. They were subsequently incubated overnight at $4^{\circ} \mathrm{C}$ in primary antibody containing $5 \%$ NDS and $0.25 \%$ Triton X-100 in PBS. Polyclonal rabbit anti-glial fibrillary acidic protein antibody (anti-GFAP; 1:100, Chemicon, Temecula, CA) were used to identify astrocytes. Macrophages were stained using monoclonal antibodies anti-ED1 (1:500; Chemicon). Twenty four hours later, sections were rinsed in PBS and incubated in either fluoresceinconjugated or rhodamine-conjugated Fab' fragment secondary antibodies from donkey (1:100; Jackson Laboratories, Baltimore, MD). Slides were washed in PBS, mounted, and examined using fluorescent microscopy and photographed. Figures were assembled using Adobe Illustrator ${ }^{\circledR}$ software. Estimation of the relative density of $\mathrm{GFAP}^{+}$and $\mathrm{ED} 1^{+}$ staining was performed using Scion image software ${ }^{\circledR}$ (Scion Corporation, Frederick, Maryland).

Stereology. 
Stereological counting was performed as previously described (Abdellatif et al. 2007). Briefly, $1 \mu \mathrm{m}$ semi-thin toludine blue-stained sections were examined using a stereology workstation (StereoInvestigator ${ }^{\circledR}$, MicroBrightField, Williston, VT). The investigator was blinded to the experimental groups of animals. Four-six sections per animal were counted and the mean calculated for myelinated axons and blood vessels. The area of tissue cable was determined using $4 \mathrm{x}$ objective lens and then divided in counting frames of 40 by $40 \mu \mathrm{m}$ using the Optical Fractionator probe. Counting was performed using an oil-immersion objective with a high numerical aperture $(100 \mathrm{x}$, $\mathrm{NA}=1.00)$. Section thickness was measured for every section counted per animal $(\sim 1$ $\mu \mathrm{m})$. Total numbers of myelinated axons and blood vessels in the tissue cable were generated using the StereoInvestigator $($ software by multiplying the numbers of counted axons or blood vessels with the sampling probability (see, (Schmitz and Hof 2000) Statistical analysis.

One way ANOVA was used to compare control values with experimental groups followed by Tukey's post-hoc comparison test. $\mathrm{p}<0.05$ was considered as statistically significant.

\section{RESULTS}

\section{Ad5-D15A SCs optimally enhance axonal regeneration and myelination}

We compared the number of myelinated axons, tissue cable area, and the number of blood vessels in the tissue cable midsection of transplanted PAN/PVC mini-guidance channels seeded with SCs that were infected ex vivo with pLenti6-D15A, Ad5-D15A, or LZRS-D15A, or LZRS-EGFP. The number of myelinated axons was significantly $(\mathrm{p}<0.001)$ higher in the Ad5-D15A- SC grafted group $(3,334.43 \pm 469.01)$ compared to 
that of pLenti6-D15A-SCs $(1,155.11 \pm 62.92)$ or LZRS-D15A-SCs $(665.44 \pm 125.58)$

(Fig. 4.1a). All groups had significantly $(\mathrm{p}<0.001)$ higher number of myelinated axons compared to the LZRS-EGFP SC-grafted animals $(357.29 \pm 27.96)$

The group grafted with channels seeded with pLenti6-D15A SCs had significantly higher $(\mathrm{p}<0.01)$ tissue cable area $\left(378,556.63 \pm 106,168.30 \mu \mathrm{m}^{2}\right)$ at the midsection of the channel (Fig. 4.1b) compared to all other experimental groups. There was no significant difference between the Ad5-D15A SCs $\left(191,858.75 \pm 12,206.47 \mu \mathrm{m}^{2}\right)$ and either the LZRS-D15A SCs $\left(170,881.69 \pm 67,727.43 \mu \mathrm{m}^{2}\right)$ or the LZRS-EGFP-SCs $(207,293.36 \pm$ $40,646.96 \mu \mathrm{m}^{2}$ ) grafted groups.

The number of blood vessels in the tissue cable at the channel midsection was not significantly different between Ad5-D15A (77.5 \pm 17.35$)$ and pLenti6-D15A (62.13 \pm 10.38) SC grafted groups and both had significantly higher $(\mathrm{p}<0.01 ;(\mathrm{p}<0.001)$ numbers of blood vessels than the LZRS-D15A SC (38.97 \pm 4.37$)$ or LZRS-EGFP SC (13.75 \pm 9.20) grafted groups, respectively. The pLenti6-D15A SC grafted animals were significantly higher $(\mathrm{p}<0.01)$ than the LZRS-EGFP SC grafted group (Fig 4.1c).

Transplantation of mini-channels with LZRS-D15A SCs leads to functional recovery following a thoracic SCI hemisection injury.

For the second part of this study we tested the behavioral effects of transient versus long term D15A expression by comparing LZRS-D15A SC and pLenti6-D15A SC grafted rats with those that received LZRS-EGFP SC grafts and sham controls. Animals were tested on grid walk task and Hargreaves's planter analgesia testing. Animals that received mini-channels seeded with SC infected with LZRS-D15A had significantly 
lower ( $\mathrm{p}<0.001)$ numbers of foot falls of the right hind paw (injury side) when compared to other experimental groups. There was a significant $(\mathrm{p}<0.01)$ difference between LZRS-D15A SC and LZRS-EGFP-SC groups. The pLenti6-D15A SC group had significantly $(\mathrm{p}=0.01)$ worse performance on the grid task as compared with LZRS-EGFP SCs group. There was a consistent significant difference $(p<0.01)$ in all experimental groups between the right and left hind paw foot falls, indicating residual deficits on the injury side (Fig 4.2a). Hargreaves's planter analgesia testing showed no significant difference between right and left hind paws within groups or between experimental groups (Fig 4.2b).

Histological analysis of GFAP ${ }^{+}$staining at the graft host interfaces showed no significant difference in glial scarring between groups (Fig 4.3). There was also no significant difference in $\mathrm{ED}^{+}$staining, a marker of activated microglial and macrophages, at the interfaces between groups.

\section{DISCUSSION}

Axons normally extend down diffusible gradients of chemo-attractant and chemorepellent molecules during development (Tessier-Lavigne 1994; Tessier-Lavigne and Goodman 1996). The use of the closed semi-permeable channel allowed the possibility of re-creating a gradient following SCI to test the hypothesis that regenerating axons would similarly follow neurotrophic factor gradients. Previous data showed that D15A expression from SCs infected with Ad5-D15A-, pLenti6-D15A-, and LZRS-D15A- SCs and then grafted into the spinal cord had differential expression patterns with retroviral 
expression at levels half of lentiviral or adenoviral expression at 1 week and downregulating to baseline at 2 weeks. Lentiviral and adenoviral expression levels were identical at 1 and 2 weeks, but adenoviral-driven expression dropped significantly lower than lentiviral driven levels at 4 weeks (Abdellatif, Pelt et al. 2006). The fact that Ad5D15A- pLenti6-D15A-, and LZRS-D15A- SC grafts had 9.3X, 3.3X, and 1.9X more myelinated axons in the tissue cable than LZRS-EGFP-SC grafts suggests that high levels of neurotrophic factor expression in the $\mathrm{SC} /$ channel are necessary early during axonal ingrowth but that sustained high levels of neurotrophins are detrimental for those axons to be myelinated. That the pLenti-6D15A-SC grafts had twice the tissue cable area than the other groups would further support the contention that continued axonal ingrowth and/or sprouting is maximal in the high neurotrophin environment. However, electron microscopic analyses would be needed to conclusively determine if the greater tissue cable size reflected increased numbers of unmyelinated axons or enhanced survival of grafted SCs.

Previously, Xu et al. (1995) showed that the infusion of a combination of BDNF and NT3 into the SC-grafted channel leads to significantly higher number of myelinated axons when compared to SC-vehicle groups. Although the infusion of BDNF and NT3 into to the distal spinal cord parenchyma had no significant effect on axonal numbers within the channel, it led to enhanced axonal re-entry into the cord tissue for up to $6 \mathrm{~mm}$ (Bamber, Li et al. 2001).

Present data show that viral-mediated delivery of D15A leads to better outcome compared with protein infusion of BDNF and NT3. This may be due to better biological availability of the expressed protein to targets within the channel environment. SCs 
grafts alone lead to regeneration of mainly propriospinal axons into the graft and only when BDNF and NT3 were infused into the channel were supraspinal axons seen in the graft (Xu, Guenard et al. 1995). Some of these regenerating axons were from raphe nucleus and two thirds of axons originated from spinal and lateral vestibular nuclei.

Previous data show that in SC only grafts there are about 8 time more unmyelinated axons within the tissue cable than myelinated ones (Xu, Guenard et al. 1995; Xu, Chen et al. 1997; Golden, Pearse et al. 2007). When SCc infected with LentiD15A or Adeno-D15A were transplanted 1 week post injury, the ratio of myelinated axons to unmyelinated ones changed to $1: 1$ (Golden, Pearse et al. 2007). This may be due to the increase in myelination of regenerating axons or the absence of unmyelinated axons within the graft area because of the inhibitory effect of high concentration of D15A within the graft environment.

Neurotrophin expression also increased blood vessel number, with no differences between the Ad5-D15A and pLenti6-D15A SC grafted groups, but twice what was observed in LZRS-D15A-SC and 5-fold higher than EGFP-SC grafted animals. Recent data has implicated BDNF as a regulator of angiogenesis (Kermani and Hempstead 2007) and neurotrophins may interact with other angiogenic factors such as VEGF (Ando, Kaneko et al. 2004). Present data would suggest that neurotrophin treatment after SCI may be a novel therapeutic approach to maintain vascular homeostasis which is disrupted after SCI (Casella, Marcillo et al. 2002; Loy, Magnuson et al. 2002). Importantly, there may be different optimal concentrations of exogenous genes that facilitate axonal growth and/or maintenance and those that are optimal for revascularization/vascular stabilization. 
As both are likely necessary for long term maintenance of regenerating CNS tissues, this may be problematic when designing therapeutic strategies.

Histological evaluation indicated no effect on the astrocyte reaction at either graft-host interface. There was no difference in EDl immunoreactivity between all experimental groups indicating that the release of neurotrophins from SCs inside the mini-channel did not alter the host tissue response, at least at this early level of analysis, in a manner that could affect axonal regeneration at least as indicated by the two parameters chosen in this study.

Functionally, the pLenti6-D15A-SC group made significantly more stepping errors on the grid than did the LZRS-D15A SC grafted group, the latter of which were significantly different from EGFP-D15A-SC animals. High D15A levels in the channel may affect distal sensory neurons that influenced hind limb locomotor reflex circuits. If the former postulation is accurate, it raises a cautionary concern that altering neuronal function in the context of SCI may ultimately prove to be functionally detrimental.

One confounding variable in the present experimental design is the fact that no physiological impetus was given to the regenerating/sprouting axons, either ascending or descending, to exit the channel graft. High D15A levels may actually retard axons from entering spinal cord parenchyma. The creation of a rapidly down regulating transgene expression zone inside the channel that is followed by an increasing concentration of neurotrophins in the spinal cord parenchyma may further enhance the exit of axons from the channel environment and into the cord tissue. Previously, pump infusion of BDNF and/or NT3 at the distal end of the channel in the spinal cord parenchyma had no effect on the number of myelinated axons in the tissue cable formed inside the mini channel 
following transplantation (Bamber, Li et al. 2001). However, this study showed that the infusion of these neurotrophins enhanced axonal re-entry into the distal host spinal cord.

More recently, Ramer et al (2000) showed that in adult rats with injured dorsal roots, treatment with, NT3 but not BDNF, resulted in selective regrowth of damaged axons across the dorsal root entry zone and into the spinal cord. Only animals treated with NGF and GDNF recovered sensitivity to noxious heat and pressure. This clearly indicates the selective nature of neurotrophins on distinct subpopulations of sensory neurons.

Temporally and spatially regulating transgene expression specific for defined populations of ascending sensory and descending motor axons, as well as controlling effects on neovascularization and inflammatory responses, poses a daunting challenge to effectively use exogenous transgenes to facilitate SCI repair. It is only through thorough investigation of combinatorial therapeutic effects on individual effectors systems that rational therapeutic strategies can be devised. 
Table 4.1: Animal groups used for the comparison of different viral delivery vectors.

\begin{tabular}{|l|l|l|l|l|}
\hline group & $\mathbf{n}$ & $\begin{array}{l}\text { Thoracic Hemisection \& transplantation of } \\
\text { a SC-channel seeded with SC infected } \\
\text { with virus }\end{array}$ & $\begin{array}{l}\text { Behavioral } \\
\text { testing }\end{array}$ & Sacrifice \\
\hline 1 & 6 & Ad5-D15A-SC & NA & 6 weeks \\
\hline 2 & 10 & LZRS-D15A-SC & $4-6$ weeks & 6 weeks \\
\hline 3 & 13 & pLenti6-D15A-SC & $4-6$ weeks & 6 weeks \\
\hline 4 & 8 & LZRSEGFP-SC & $4-6$ weeks & 6 weeks \\
\hline 5 & 6 & Naive rats for behavior & $4-6$ & NA \\
\hline
\end{tabular}




\section{Figure Legends}

Figure 4.1. a. Stereological assessment of the number of myelinated axons, showed significantly $(\mathrm{p}<0.001)$ higher number of myelinated axons in Ad5-D15A- SC group $(3,334.43 \pm 469.01)$ compared to pLenti6-D15A-SC group $(1,155.11 \pm 62.92)$ and LZRSD15A-SCs group $(665.44 \pm 125.58)$. All groups had significantly $(\mathrm{p}<0.001)$ higher number of myelinated axons compared to the LZRS-EGFP SC-grafted animals (357.29 $\pm 27.96)$. b. Measurement of the cross section area of the tissue cable at the channel midpoint showed that pLenti6-D15A SCs group had significantly $(\mathrm{p}<0.01)$ bigger tissue cable compared to all other experimental groups. There was no difference between the Ad5-D15A SCs and either LZRS-D15A SCs or the LZRS-EGFP-SCs groups. c. Counting the number of blood vessels in the midsection of tissue cable no significant difference between Ad5-D15A and pLenti6-D15A SC groups. Both groups were significantly higher than the LZRS-D15A SC $(\mathrm{p}<0.01)$ and LZRS-EGFP SC $(\mathrm{p}<0.001)$ groups. The pLenti6-D15A SC group was significantly higher $(\mathrm{p}<0.01)$ than the LZRSEGFP SC grafted group. Data shown as mean $\pm \mathrm{SD}\left({ }^{* *}=\mathrm{p}<0.01, * * *=\mathrm{p}<0.001\right)$

Figure 4.2 a. Comparison of foot falls on grid walking test showed significantly lower numbers of foot falls of the right hind paw (injury side) $(\mathrm{p}<0.001)$ in animals receiving mini-channels seeded with SC infected with LZRS-D15A when compared to all other groups. The pLenti6-D15A SC group was significantly ( $\mathrm{p}=0.01$ ) worse as compared with LZRS-EGFP SCs group. There was significant difference $(p<0.01)$ in all experimental groups between the right and left hind paw foot falls. b. Testing the latency of hind limb withdrawal in response to heated light stimulus on Hargreaves's planter analgesia testing 
apparatus showed no significant difference between right and left hind paws within groups or between experimental groups. Data shown as mean $\pm \mathrm{SD},\left({ }^{* *}=\mathrm{p}<0.01\right.$, $* * *=\mathrm{p}<0.001)$.

Figure 4.3. Relative density of $\mathrm{ED}^{+}{ }^{+}$staining and $\mathrm{GFAP}^{+}$staining was estimated using Scion image software ${ }^{\circledR}$ (Scion Corporation, Frederick, Maryland) at both rostral and caudal graft host interfaces. Three sections per animal were used for estimation. ED1 ${ }^{+}$at the rostral and caudal graft host interfaces was not different between all tested groups. There was no difference of GFAP+ staining at either distal or proximal graft host interfaces between all experimental groups. Data shown as mean $\pm \mathrm{SD}$. 
Figure 4.1
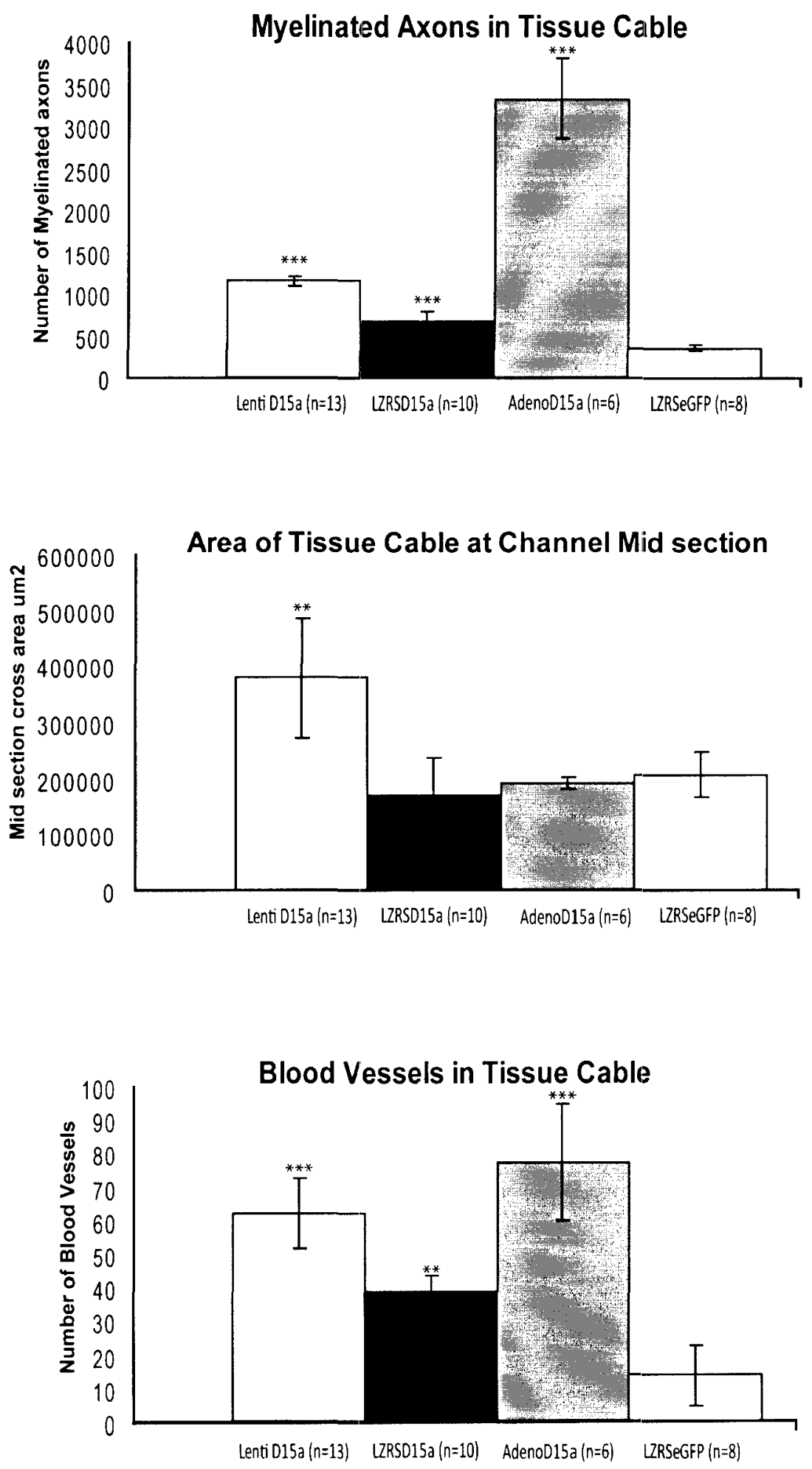
Figure 4.2
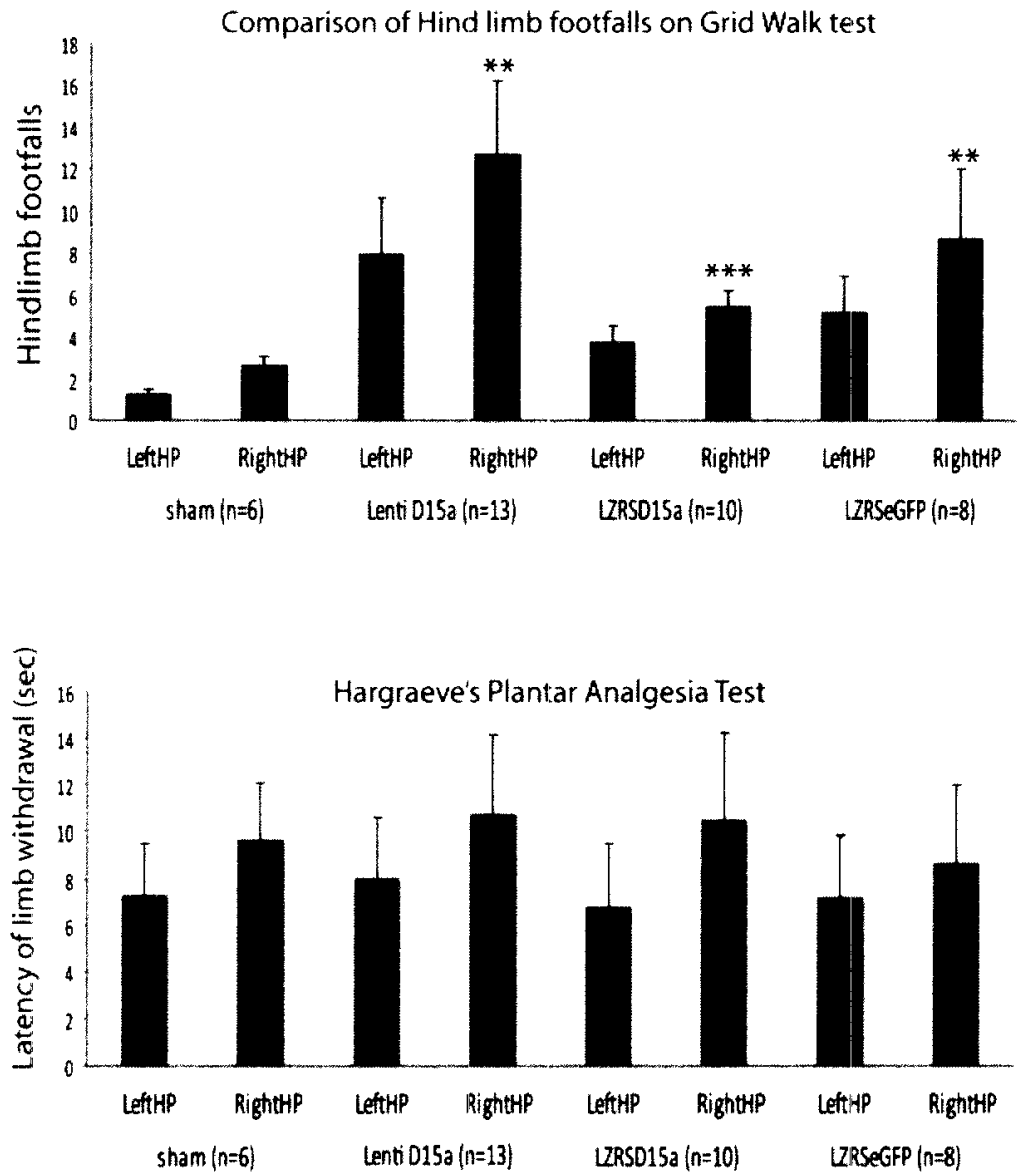

Figure 4.3

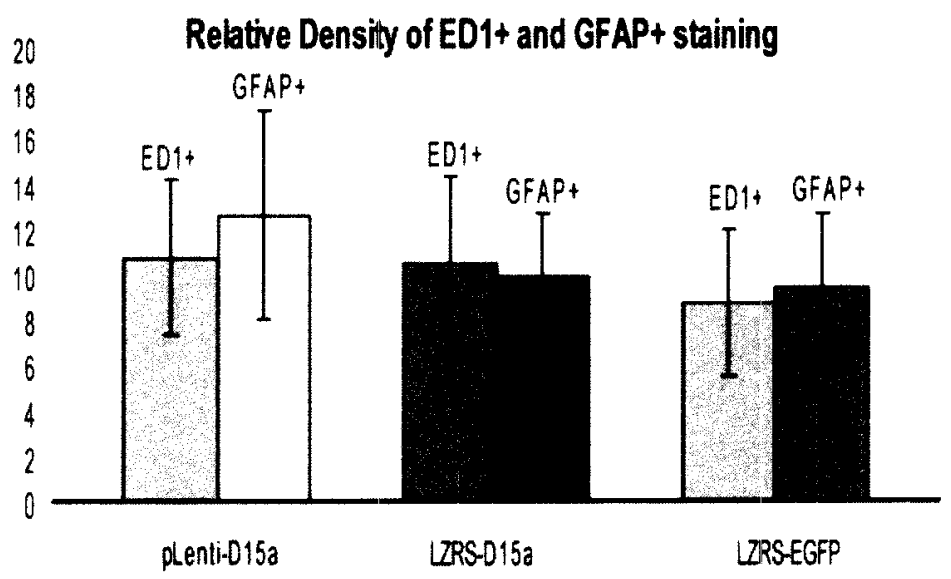




\section{CHAPTER 5}

\section{DISCUSSION}

Immediately following spinal cord injury ( $\mathrm{SCI}$ ), acute hemorrhage of the injury site occurs. This is followed by a transient macrophage infiltration which clears necrotic tissue. Subsequent scarring occurs at the primary injury site. What makes the healing process of the CNS unique is the secondary damage that occurs to local, as well as distant, neurons as a result of the primary injury to their axons at the initial damage site. The current consensus is that CNS repair strategies should aim at one or more of the following:

- Controlling the initial injury and inflammation.

- Preventing both local and distant secondary cell death.

- Altering the glial reaction/scarring to create a more favorable environment for axonal regeneration.

- Promoting axonal regeneration and enhancing myelination of both spared and regenerating injured axons.

Repair of the damaged spinal cord is a complicated task that will require the right combination of factors to address one or more of the above mentioned points to achieve neuronal protection, axonal regeneration, myelination, and eventually functional 
recovery. Neurotrophins, cellular transplants, and tissue bridges or bio-scaffolds to help axons cross the scarred area, are a few examples of possible therapeutic approaches. In recent years, a variety of those proposed therapies, either singly or in combination, have led to variable functional improvement in rats and mice.

The "tissue engineering" approach proposed here utilizes a bio-material bridge (here, 60:40 PAN/PVC mini-channel) which provides a milieu in which the cellular scaffold can be directed. The channel provides an in vivo environment in which to examine cell proliferation, migration, survival and maintenance of phenotype as well as cell-axon interaction following injury and regeneration. Biomaterials used in regeneration studies should have certain favorable characteristics including large surface area, large pore size, and the ability to modulate the organization of the cells and the extracellular matrix derived from them (Atala 2005; Zhang, Yan et al. 2005). Early attempts at providing a favorable tissue bridge utilized peripheral nerve segments to bridge complete SCI transaction lesions (Richardson, McGuinness et al. 1980), a concept that dates back to the early work of Ramon y Cajal (1928) which led him to speculate that if the environment is favorable CNS axons are able to re-grow.

The work presented here is an effort to test and provide a suitable combination of neurotrophins delivered using viral vectors, combined with cellular transplantation and a biomaterial bridge to cross the injury gap following an experimental thoracic SCI in adult rats. Our work builds on the previous success in transplanting SC-seeded mini channels in a spinal cord hemisection model (Xu, Guenard et al. 1995). These previous experiments illustrated that the transplanted SCs enhance regeneration of axons and myelinate regenerating axons when transplanted inside a polyacrylonitrile/poly- 
vinylchloride (PAN/PVC) mini-channel into the hemisected thoracic cord. Although the hemisection model is not clinically relevant, it offers the chance for testing different therapeutic approaches in the mini-channel environment as well as test the interaction of the cellular graft with the host spinal cord at both distal and proximal graft-host interfaces.

Transplantation strategies for $\mathrm{SCl}$ aim at enhancing regeneration of severed axons, effective myelination of regenerating axons as well as demyelinated intact axons, and changing the post-SCI local environment in a favorable way to allow regenerating axons reach their potential targets. The approaches that have been used include the delivery of neurotrophins or other neuronal survival enhancing molecules (e.g. cAMP, (Pearse, Pereira et al. 2004), extracellular matrix modulators (e.g. chondroitinase ABC; (Bradbury, Moon et al. 2002; Barritt, Davies et al. 2006), or the provision of physical bridge to help regenerating axons cross the injury gap (Xu, Chen et al. 1997; Teng, Lavik et al. 2002). Several cell types have been investigated as possible candidates for use in transplant-mediated SCI repair with variable success. Examples of these cell types include fibroblasts, whether naive or genetically modified to secrete neurotrophic factors or matrix metalloproteases (Dekker, Winkler et al. 1994; Emerich, Hammang et al. 1994; Tuszynski, Peterson et al. 1994; 1996; Franzen, Martin et al. 1999; Frechilla, Insausti et al. 2000; Tobias, Shumsky et al. 2003; Pizzi and Crowe 2006), neural stem cells (Cao, Zhang et al. 2001; Nakamura and Toyama 2003; Okano, Ogawa et al. 2003), bone marrow stromal cells (Sykova, Jendelova et al. 2006), oligodendrocyte precursor cells (OPCs) (Keirstead and Blakemore 1999; Cao, Xu et al. 2005), olfactory ensheathing glial cells usually referred to as OECs, OEGs or OEGCs (Heredia, Gascuel et al. 1998; Li, 
Field et al. 1998; 1998; Ramon-Cueto 2000; 2000), astrocytes (Davies, Huang et al. 2006; Love 2006), and SCs (Xu, Guenard et al. 1995; Xu, Chen et al. 1997; Xu, Zhang et al. 1999). These cells were also tested in various combinations of OECs and stem cells (Ao, Wang et al. 2007), OECs and SCs (Fouad, Schnell et al. 2005; Pearse, Sanchez et al. 2007), stem cells and SCs (Zeng, Ding et al. 2005). When SC were compared to OECs after a more clinically relevant contusion $\mathrm{SCI}$ ( $10 \mathrm{gm}, 12.5 \mathrm{~mm} \mathrm{NYU}$ impactor), SC grafted animals showed more myelinated axons than those that received OEC, with significant improvement in hind limb function in SC group (Takami, Oudega et al. 2002). Following transplantation, SCs remyelinate demyelinated axons (Li and Raisman 1994) and enhance regeneration (Tuszynski, Weidner et al. 1998). However, the interaction of SCs with astrocytes may limits their usefulness in CNS repair (Franklin and Barnett 1997), as SCs do not to co-exist with astrocytes (Lal, Ghirnikar et al. 1996; Lakatos, Franklin et al. 2000; Shields, Blakemore et al. 2000). This potential problem can be solved by altering the cell adhesion properties of SCs, e.g. with a retroviral vector encoding sialyl-transferase $\mathrm{X}$ to express polysialic acid (PSA) on the naturally present neural cell adhesion molecule (NCAM), leading to better integration with astrocytes in vitro and better functional recovery in vivo (Papastefanaki, Chen et al. 2007).

While the therapeutic potential of any cell type used for grafting in $\mathrm{SCI}$ is essential, it would be optimal to be able to obtain the relevant tissue from the patient to enable autologous transplantation. This would avoid tissue rejection and the need for immune suppressive therapy. Therefore, the use of human astrocytes, OPCs, or OECs in SCI would require heterologous grafting as it would be difficult to obtain the tissue from SCI patients. We contend that at present, SCs are one of the most clinically relevant cell 
types for use in SCI repair as they can be autologously obtained. Therefore, we chose SCs as a cellular graft in our combination strategy. Although currently we are still far from achieving clinically acceptable success, SCs offer an excellent source of autologous cells that can be easily harvested from the SCI patient, purified and grown in culture and transplanted back into the same donor thus eliminating the need for immune suppression following transplantation. SCs can be harvested from peripheral nerves that will not lead to significant functional deficit in humans (e.g. sural nerve) that are commonly used for other clinical applications such as facial nerve repair, SCs can also be harvested from skin (Biernaskie, Sparling et al. 2007).

Axonal failure to exit SC grafts can be attributed to many factors including the lack of interaction between SCs and astrocytes, higher expression of neurocan, phosphacan, and NG2 are expressed near the rostral and caudal graft host interfaces with higher concentrations of phosphacans at the caudal graft-host interface (Plant, Bates et al. 2001). This phenomenon has been also observed in grafts of neural stem cells expressing NT-3 (Lu, Jones et al. 2003). Even when OECs grafts were combined with a SC bridge and chondroitinase ABC infusion (Fouad, Schnell et al. 2005), there was significant functional improvement, although no corticospinal or rubrospinal fibers crossed the graft and only some regenerating serotonergic fibers did. Axons normally extend down diffusible gradient during development (Tessier-Lavigne 1994). The lack of motivation for axons to exit the new graft permissive environment and re-enter the host spinal cord may be due to the cellular graft itself as it may offer regenerating axons a more favorable environment with little or no motivation for the axons to exit and re-enter the spinal cord 
parenchyma. We hypothesize that the creation of a gradient of neurotrophins may lead to enhanced axonal regeneration and re-entry into the spinal cord tissue.

We here report the initial success of creating such a gradient and provide evidence of functional recovery following transplantation of SC infected with retrovirus expressing D15A. Ex vivo retroviral LZRS-D15A delivery leads to transient expression of the transgene within the channel environment. Although we found a significantly lower number of myelinated axons in the retrovirus group when compared with lentivirus, functional recovery was significantly better in the retrovirus group. A possible explanation for this phenomenon would be that different patterns of transgene expression within the channel environment lead to recruitment of different populations of axons. Alternatively, the high sustained neurotrophin levels may detrimentally affect hind limb circuitry by affecting ingrowing (regenerating and/or sprouting) sensory axons.

Recently, Hill and colleagues (2007) found an $80 \%$ reduction in SCs numbers within I week post transplantation after contusive SCI. Death of transplanted cells by necrosis and apoptosis is not unexpected, as SCs survive poorly within the contused spinal cord environment and delayed transplantation only improved survival minimally (Hill, Moon et al. 2006). This may explain the modest improvement in functional recovery encountered in our hand as well as with others (Takami, Oudega et al. 2002). Hill and colleagues (2006) used labeled SCs from human placental alkaline phosphatase (hPAP) transgenic rats to assess SC survival in a spinal cord contusion lesion. Few hPAP SCs survived and delaying transplantation for 7 days was followed by a second wave of cell death after surviving SCs had integrated into the spinal cord. Immunosuppression with cyclosporine combined with delayed transplantation resulted in the best survival. A 
very interesting finding was that in all cases extensive infiltration of endogenous $\mathrm{p} 75^{+}$ SCs into the injury site suggested that endogenous SCs may play an important role in the repair observed after SC transplantation. Interventions to enhance the survival of SCs may be necessary to achieve better functional recovery. The exposure of SCs to the spinal cord environment in contusion model may explain the massive reduction in cell numbers which may not be the case when SCs are transplanted in an enclosed semiisolated environment within the mini-channel. However, diffusible signals from the injured cord may still cross the channel wall and affect SCs survival. We cannot confirm whether or not endogenous SCs may be a contributing factor in the behavioral recovery observed following transplantation of LZRS-D15A infected SCs.

The interactions between SCs and neurotrophins are significant to our findings that myelinated axons numbers do not correlate with functional recovery. In this study, we used D15A, a bi-functional molecule with both BDNF and NT-3 activities. There seems to be significant competition between the two neurotrophins with regards to SC function. BDNF enhances myelination through $\mathrm{p} 75^{\mathrm{NTR}}$ and inhibits migration (Cosgaya, Chan et al. 2002; Yamauchi, Chan et al. 2004). In contrast, NT-3 enhances migration and inhibits myelin formation through TrkC receptor (Cosgaya, Chan et al. 2002; Yamauchi, Chan et al. 2003). It remains to be seen whether the combination of BDNF and NT-3 leads to conflicts in signaling pathways that leads to SC dysfunction or a differential response where myelination or proliferation takes the upper hand.

SCs play an active role in supporting neuronal outgrowth after injury by producing significant amounts of NTFs such as NGF (Heumann 1987), BDNF (Meyer, Matsuoka et al. 1992), PDGF (Eccleston, Collarini et al. 1990) and CNTF (Friedman, 
Scherer et al. 1992). The levels of NTFs produced from both transplanted and endogenous SCs may be another significant contributing factor in re-organizing local circuitry within the spinal cord leading to the functional improvement noted in our study.

The second step of creating a gradient is the provision of an increasing concentration of neurotrophins in the spinal cord parenchyma at the graft host interface. We show in Chapter 2 that increasing the titer of the injected virus significantly increases the concentration of the transgene at the injection site. Ongoing work is examining the effect of creating an increasing gradient of neurotrophins at the proximal graft host interface. Previous data (Taylor, Jones et al. 2006) show that although such gradients are successful in axonal bridging beyond the lesion, growth for longer distances is not sustainable with a trophic stimulus. Other factors may be needed to enhance axonal growth over longer distances to enable these injured axons to reach their targets.

The angiogenic response following $\mathrm{SCI}$ is an important element of injury and the restoration of a functional vascular bed is important to recovery of function. A change in the microvasculature of the spinal cord after contusion injury is essential for the spinal cord to undergo self-repair (Loy, Crawford et al. 2002; Hagg and Oudega 2006). We here show significant increase in the number of blood vessels in the tissue cable following LentiD15A and Adeno D15A use within the channel. Although the functional integrity of these blood vessels cannot be verified we believe that these vessels are an essential component of the tissue cable success in bridging the injury gap and supporting axonal growth and myelination. The use of D15A seems to enhance angiogenesis significantly. Moreover, prolonged expression of D15A seems to enhance 
vascularization significantly more than transient expression following LZRS-D15A retrovirus.

The use of viral gene delivery in a clinical setting is still in the early stages. Many viral options are available for use in $\mathrm{SCI}$ research. Some have the advantage of being used both in vitro and in vivo the use of adenovirus is complicated by the intense immune response it elicits in the CNS tissue (Abdellatif, Pelt et al. 2006). Viral vectors do not initiate an intense inflammatory reaction include lentivirus, adeno-associated virus (AAV) and Herpes simplex virus (HSV) (Tyler and Federoff 2006; Tyler, Wuertzer et al. 2006; Kitamura, Iwanami et al. 2007). Other viral vectors including lentiviral variants including feline immunodeficiency virus have been also employed in CNS research. Until safely issue and immune response reach an acceptable level for human trials, the use of many of these viral vectors may be limited to experimental models for the time being.

The use of viral gene therapy have been complicated by many factors that affect the outcome. In cystic fibrosis (Alton, Geddes et al. 2000; Alton 2007), the use of adenoviral delivery has led to a transient gene expression where perhaps a long term expression would have more appropriate. In another unfortunate complication of intrahepatic injection of E1/E4 deleted adenoviral vector to treat ornithine transcarbamylase OTC deficiency, has led to the death of an 18 year old patient as a complication of the inflammatory response of the liver to the injected virus. However, this was likely a death related to a much too high viral dose. These trials with variable outcomes make it difficult for SCI research to take the risk and proceed to human studies using viral vectors. We believe that as the safety and efficiency of viral delivery become more 
clinically acceptable, it will be more appropriate to use viral delivery methods in clinical $\mathrm{SCI}$ research.

For the spinal cord injured patient, complete sensory and motor recovery is a dream that may take more than one's life time to achieve. In the mean time, quality of life improvement may be a reachable goal. Recovery of bladder and bowel control, regain of sexual function, and treatment of autonomic dysreflexia are a few examples of what may be a more realistic approach to target rather than locomotion. Eventually, return to the pre-injury level of function would be the ultimate goal for these patients. However, for now researchers can and will approach SCI as a complicated pathology that can only be tackled as small pieces of an extremely complex multifaceted puzzle.

It is my vision that a combination strategy will be the answer for human spinal cord injured patients. I suggest that one feasible approach would be a combination of SCs (or maybe an alternative cell type) with a cocktail of neurotrophins delivered using viral mediated delivery in vivo and/or ex vivo and extracellular matrix modifying agents that will be then surgically applied at the center of the injury. Such an approach would take weeks to expand cells collected from the patient and have them modified to secrete the specific neurotrophins or other molecules. It is thus extremely critical to develop successful approaches to decrease the secondary injury and prevent further damage to local as well as distant axons and neurons, to prepare the local injury site for the definitive therapeutic "mix". I am confident that there will be a cure for SCI, I may not live long enough to see that happen, but I am glad that I had a chance to take a step forward in this thousand mile road and I wish that this work will benefit future research and help achieve that dream. 


\section{REFERENCES}

Abdellatif, A. A., J. L. Pelt, et al. (2006). "Gene delivery to the spinal cord: comparison between lentiviral, adenoviral, and retroviral vector delivery systems." J Neurosci Res 84(3): 553-67.

Aebischer, P., V. Guenard, et al. (1990). "The morphology of regenerating peripheral nerves is modulated by the surface microgeometry of polymeric guidance channels." Brain Res 531(1-2): 211-8.

Aebischer, P., A. N. Salessiotis, et al. (1989). "Basic fibroblast growth factor released from synthetic guidance channels facilitates peripheral nerve regeneration across long nerve gaps." J Neurosci Res 23(3): 282-9.

Agrawal, H. C. and D. Agrawal (1991). "Proteolipid protein and DM-20 are synthesized by Schwann cells, present in myelin membrane, but they are not fatty acylated." Neurochem Res 16(8): 855-8.

Akli, S., J. E. Guidotti, et al. (1996). "Restoration of hexosaminidase A activity in human Tay-Sachs fibroblasts via adenoviral vector-mediated gene transfer." Gene Ther 3(9): 769-74.

Allen, W. E., 3rd, C. M. D'Angelo, et al. (1974). "Correlation of microangiographic and electrophysiologic changes in experimental spinal cord trauma." Radiology 111(1): 107-15.

Altar, C. A., N. Cai, et al. (1997). "Anterograde transport of brain-derived neurotrophic factor and its role in the brain." Nature 389(6653): 856-60. 
Andersen, J. K., D. A. Garber, et al. (1992). "Gene transfer into mammalian central nervous system using herpes virus vectors: extended expression of bacterial lacZ in neurons using the neuron-specific enolase promoter." Hum Gene Ther 3(5): 487-99.

Ando, A., S. Kaneko, et al. (2004). "[The effect of growth factors on the proliferation of cultured porcine trabecular meshwork cells]." Nippon Ganka Gakkai Zasshi 108(9): 549-53.

Ao, Q., A. J. Wang, et al. (2007). "Combined transplantation of neural stem cells and olfactory ensheathing cells for the repair of spinal cord injuries." Med Hypotheses.

Atala, A. (2005). "Tissue engineering, stem cells and cloning: current concepts and changing trends." Expert Opin Biol Ther 5(7): 879-92.

Baekelandt, V., K. Eggermont, et al. (2003). "Optimized lentiviral vector production and purification procedure prevents immune response after transduction of mouse brain." Gene Ther 10(23): 1933-40.

Bajocchi, G., S. H. Feldman, et al. (1993). "Direct in vivo gene transfer to ependymal cells in the central nervous system using recombinant adenovirus vectors." Nat Genet 3(3): 229-34.

Bakshi, A., O. Fisher, et al. (2004). "Mechanically engineered hydrogel scaffolds for axonal growth and angiogenesis after transplantation in spinal cord injury." $\underline{\mathbf{J}}$ Neurosurg Spine 1(3): 322-9.

Bamber, N. I., H. Li, et al. (2001). "Neurotrophins BDNF and NT-3 promote axonal reentry into the distal host spinal cord through Schwann cell-seeded mini-channels." Eur J Neurosci 13(2): 257-68.

Baron-Van Evercooren, A., A. Gansmuller, et al. (1992). "Repair of a myelin lesion by Schwann cells transplanted in the adult mouse spinal cord." J Neuroimmunol 40(2-3): 235-42. 
Barritt, A. W., M. Davies, et al. (2006). "Chondroitinase ABC promotes sprouting of intact and injured spinal systems after spinal cord injury." J Neurosci 26(42): 10856-67.

Basso, D. M., M. S. Beattie, et al. (1996). "Graded histological and locomotor outcomes after spinal cord contusion using the NYU weight-drop device versus transection." Exp Neurol 139(2): 244-56.

Baumgartner, B. J. and H. D. Shine (1998). "Neuroprotection of spinal motoneurons following targeted transduction with an adenoviral vector carrying the gene for glial cell line-derived neurotrophic factor." Exp Neurol 153(1): 102-12.

Beattie, M. S. (2004). "Inflammation and apoptosis: linked therapeutic targets in spinal cord injury." Trends Mol Med 10(12): 580-3.

Beattie, M. S., G. E. Hermann, et al. (2002). "Cell death in models of spinal cord injury." Prog Brain Res 137: 37-47.

Beattie, M. S., Q. Li, et al. (2000). "Cell death and plasticity after experimental spinal cord injury." Prog Brain Res 128: 9-21.

Bennett, J., J. Wilson, et al. (1994). "Adenovirus vector-mediated in vivo gene transfer into adult murine retina." Invest Ophthalmol Vis Sci 35(5): 2535-42.

Bensadoun, J. C., N. Deglon, et al. (2000). "Lentiviral vectors as a gene delivery system in the mouse midbrain: cellular and behavioral improvements in a 6-OHDA model of Parkinson's disease using GDNF." Exp Neurol 164(1): 15-24.

Bhattarai, S. R., N. Bhattarai, et al. (2004). "Novel biodegradable electrospun membrane: scaffold for tissue engineering." Biomaterials 25(13): 2595-602.

Biernaskie, J., J. S. Sparling, et al. (2007). "Skin-derived precursors generate myelinating Schwann cells that promote remyelination and functional recovery after contusion spinal cord injury." J Neurosci 27(36): 9545-59. 
Biran, R., M. D. Noble, et al. (2003). "Directed nerve outgrowth is enhanced by engineered glial substrates." Exp Neurol 184(1): 141-52.

Bixby, J. L., J. Lilien, et al. (1988). "Identification of the major proteins that promote neuronal process outgrowth on Schwann cells in vitro." J Cell Biol 107(1): 35361.

Black, P. and E. Rossitch. (1995). Neurosurgery: An Introductory Text. New york, Oxford University Press.

Blakemore, W. F. (1977). "Remyelination of CNS axons by Schwann cells transplanted from the sciatic nerve." Nature 266(5597): 68-9.

Blakemore, W. F. and A. J. Crang (1985). "The use of cultured autologous Schwann cells to remyelinate areas of persistent demyelination in the central nervous system." $\underline{\mathrm{J}}$ Neurol Sci 70(2): 207-23.

Blesch, A., J. M. Conner, et al. (2001). "Modulation of neuronal survival and axonal growth in vivo by tetracycline-regulated neurotrophin expression." Gene Ther 8(12): 954-60.

Blesch, A. and M. H. Tuszynski (2003). "Cellular GDNF delivery promotes growth of motor and dorsal column sensory axons after partial and complete spinal cord transections and induces remyelination." J Comp Neurol 467(3): 403-17.

Blesch, A., H. Yang, et al. (2004). "Axonal responses to cellularly delivered NT-4/5 after spinal cord injury." Mol Cell Neurosci 27(2): 190-201.

Blits, B., P. A. Dijkhuizen, et al. (1999). "Adenoviral vector-mediated expression of a foreign gene in peripheral nerve tissue bridges implanted in the injured peripheral and central nervous system." Exp Neurol 160(1): 256-67.

Blomer, U., L. Naldini, et al. (1997). "Highly efficient and sustained gene transfer in adult neurons with a lentivirus vector." J Virol 71(9): 6641-9. 
Blomer, U., L. Naldini, et al. (1996). "Applications of gene therapy to the CNS." Hum Mol Genet 5 Spec No: $1397-404$.

Boer, G. J., K. E. van Esseveldt, et al. (2001). "Adenoviral vector-mediated expression of neurotrophin-3 increases neuronal survival in suprachiasmatic nucleus grafts." Exp Neurol 169(2): 364-75.

Borgens, R. B., R. Shi, et al. (2002). "Behavioral recovery from spinal cord injury following delayed application of polyethylene glycol." J Exp Biol 205(Pt 1): 1-12.

Bothwell, M. (1995). "Functional interactions of neurotrophins and neurotrophin receptors." Annu Rev Neurosci 18: 2.23-53.

Bradbury, E. J., S. Khemani, et al. (1999). "NT-3 promotes growth of lesioned adult rat sensory axons ascending in the dorsal columns of the spinal cord." Eur J Neurosci 11(11): 3873-83.

Bradbury, E. J., L. D. Moon, et al. (2002). "Chondroitinase ABC promotes functional recovery after spinal cord injury." Nature 416(6881): 636-40.

Breasted, J. H. (1980). The Edwin Smith surgical papyrus. Chicago, University of Chicago Press.

Bregman, B. S., M. McAtee, et al. (1997). "Neurotrophic factors increase axonal growth after spinal cord injury and transplantation in the adult rat." Exp Neurol 148(2): 475-94.

Bresnahan, J. C. (1978). "An electron-microscopic analysis of axonal alterations following blunt contusion of the spinal cord of the rhesus monkey (Macaca mulatta)." J Neurol Sci 37(1-2): 59-8.2.

Brunden, K. R., A. J. Windebank, et al. (1990). "Role of axons in the regulation of P0 biosynthesis by Schwann cells." J Neurosci Res 26(2): 135-43.

Bunge, M. B. (1994). "Transplantation of purified populations of Schwann cells into lesioned adult rat spinal cord." J Neurol 242(1 Suppl 1): S36-9. 
Bunge, R. P. (1983). "Recent observations on the control of Schwann cell functions." Anat Rec Suppl 1: 3-25.

Bunge, R. P. (1994). "The role of the Schwann cell in trophic support and regeneration." J Neurol 242(1 Suppl 1): S19-21.

Bunge, R. P., W. R. Puckett, et al. (1993). "Observations on the pathology of human spinal cord injury. A review and classification of 22 new cases with details from a case of chronic cord compression with extensive focal demyelination." Adv Neurol 59: 75-89.

Buning, H., S. A. Nicklin, et al. (2003). "AAV-based gene transfer." Curr Opin Mol Ther 5(4): 367-75.

Burns, J. C., T. Friedmann, et al. (1993). "Vesicular stomatitis virus G glycoprotein pseudotyped retroviral vectors: concentration to very high titer and efficient gene transfer into mammalian and nonmammalian cells." Proc Natl Acad Sci U S A 90(17): 8033-7.

Byrnes, A. P., J. E. Rusby, et al. (1995). "Adenovirus gene transfer causes inflammation in the brain." Neuroscience 66(4): 1015-24.

Cajal, R. S. (1952). "Structure and Connections of Neurons." Bull Los Angel Neuro Soc 17(1-2): 5-46.

Cajal, R. Y. (1928). Degeneration and regeneration of the nervous system. New York, Oxford University press.

Cao, Q., X. M. Xu, et al. (2005). "Functional recovery in traumatic spinal cord injury after transplantation of multineurotrophin-expressing glial-restricted precursor cells." J Neurosci 25(30): 6947-57.

Cao, Q. L., Y. P. Zhang, et al. (2001). "Pluripotent stem cells engrafted into the normal or lesioned adult rat spinal cord are restricted to a glial lineage." Exp Neurol 167(1): 48-58. 
Cao, X. and M. S. Shoichet (2003). "Investigating the synergistic effect of combined neurotrophic factor concentration gradients to guide axonal growth." Neuroscience 122(2): 381-9.

Carpenter, E. M. and M. Hollyday (1992). "The location and distribution of neural crestderived Schwann cells in developing peripheral nerves in the chick forelimb." Dev Biol 150(1): 144-59.

Case, L. C. and M. Tessier-Lavigne (2005). "Regeneration of the adult central nervous system." Curr Biol 15(18): R749-53.

Casella, G. T., A. Marcillo, et al. (2002). "New vascular tissue rapidly replaces neural parenchyma and vessels destroyed by a contusion injury to the rat spinal cord." Exp Neurol 173(1): 63-76.

Chan, J. R., J. M. Cosgaya, et al. (2001). "Neurotrophins are key mediators of the myelination program in the peripheral nervous system." Proc Natl Acad Sci U S A 98(25): 14661-8.

Chen, J., S. Gamou, et al. (1994). "A novel gene delivery system using EGF receptormediated endocytosis." FEBS Lett 338(2): 167-9.

Chen, M. S., A. B. Huber, et al. (2000). "Nogo-A is a myelin-associated neurite outgrowth inhibitor and an antigen for monoclonal antibody IN-1." Nature 403(6768): 434-9.

Coppola, V., J. Kucera, et al. (2001). "Dissection of NT3 functions in vivo by gene replacement strategy." Development 128(21): 4315-27.

Cosgaya, J. M., J. R. Chan, et al. (2002). "The neurotrophin receptor p75NTR as a positive modulator of myelination." Science 298(5596): 1245-8.

Costantini, L. C., J. C. Bakowska, et al. (20010). "Gene therapy in the CNS." Gene Ther 7(2): 93-109. 
Crowe, M. J., J. C. Bresnahan, et al. (1997). "Apoptosis and delayed degeneration after spinal cord injury in rats and monkeys." Nat Med 3(1): 73-6.

Dahm, L. M. and L. T. Landmesser (1988). "The regulation of intramuscular nerve branching during normal development and following activity blockade." Dev Biol 130(2): 621-44.

Dai, Y., E. M. Schwarz, et al. (1995). "Cellular and humoral immune responses to adenoviral vectors containing factor IX gene: tolerization of factor IX and vector antigens allows for long-term expression." Proc Natl Acad Sci U S A 92(5): 14015 .

Dalton, P. D., L. Flynn, et al. (2002). "Manufacture of poly(2-hydroxyethyl methacrylateco-methyl methacrylate) hydrogel tubes for use as nerve guidance channels." Biomaterials 23(18): 3843-51.

David, S. and A. J. Aguayo (1981). "Axonal elongation into peripheral nervous system "bridges" after central nervous system injury in adult rats." Science 214(4523): 931-3.

David, S. and A. J. Aguayo (1985). "Axonal regeneration after crush injury of rat central nervous system fibres innervating peripheral nerve grafts." J Neurocytol 14(1): 112.

Davies, A. M. (1994). "The role of neurotrophins during successive stages of sensory neuron development." Prog Growth Factor Res 5(3): 263-89.

Davies, J. E., C. Huang, et al. (2006). "Astrocytes derived from glial-restricted precursors promote spinal cord repair." J Biol 5(3): 7.

de la Torre, J. C. (1982). "Catecholamine fiber regeneration across a collagen bioimplant after spinal cord transection." Brain Res Bull 9(1-6): 545-52.

Dekker, A. J., J. Winkler, et al. (1994). "Grafting of nerve growth factor-producing fibroblasts reduces behavioral deficits in rats with lesions of the nucleus basalis magnocellularis." Neuroscience 60(2): 299-309. 
Dittrich, F., G. Ochs, et al. (1996). "Pharmacokinetics of intrathecally applied BDNF and effects on spinal motoneurons." Exp Neurol 141(2): 225-39.

Ducker, T. B. and H. F. Hamit (1969). "Experimental treatments of acute spinal cord injury." J Neurosurg 30(6): 693-7.

Eccleston, P. A., E. J. Collarini, et al. (1990). "Schwann Cells Secrete a PDGF-like Factor: Evidence for an Autocrine Growth Mechanism involving PDGF." Eur J Neurosci 2(11): 985-992.

Emerich, D. F., J. P. Hammang, et al. (1994). "Implantation of polymer-encapsulated human nerve growth factor-secreting fibroblasts attenuates the behavioral and neuropathological consequences of quinolinic acid injections into rodent striatum." Exp Neurol 130(1): 141-50.

Emerich, D. F., M. D. Lindner, et al. (1996). "Implants of encapsulated human CNTFproducing fibroblasts prevent behavioral deficits and striatal degeneration in a rodent model of Huntington's disease." J Neurosci 16(16): 5168-81.

Englund, U., C. Ericson, et al. (2000). "The use of a recombinant lentiviral vector for ex vivo gene transfer into the rat CNS." Neuroreport 11(18): 3973-7.

Falk, A., N. Holmstrom, et al. (2002). "Gene delivery to adult neural stem cells." Exp Cell Res 279(1): 34-9.

Fawcett, J. (2002). "Repair of spinal cord injuries: where are we, where are we going?" Spinal Cord 40(12): 615-23.

Felgner, P. L., Y. J. Tsai, et al. (1995). "Improved cationic lipid formulations for in vivo gene therapy." Ann N Y Acad Sci 772: 126-39.

Fouad, K., L. Schnell, et al. (2005). "Combining Schwann cell bridges and olfactoryensheathing glia grafts with chondroitinase promotes locomotor recovery after complete transection of the spinal cord." J Neurosci 25(5): 1169-78. 
Franklin, R. J. and S. C. Barnett (1997). "Do olfactory glia have advantages over Schwann cells for CNS repair?" J Neurosci Res 50(5): 665-72.

Franzen, R., D. Martin, et al. (1999). "Grafts of meningeal fibroblasts in adult rat spinal cord lesion promote axonal regrowth." Neuroreport 10(7): 1551-6.

Frechilla, D., R. Insausti, et al. (2000). "Implanted BDNF-producing fibroblasts prevent neurotoxin-induced serotonergic denervation in the rat striatum." Brain Res Mol Brain Res 76(2): 306-14.

Friedman, B., S. S. Scherer, et al. (1992). "Regulation of ciliary neurotrophic factor expression in myelin-related Schwann cells in vivo." Neuron 9(2): 295-305.

Fujiki, M., H. Kobayashi, et al. (2003). "High frequency electrical stimulation attenuates progressive necrosis and cavitation following spinal cord injury." Acta Neurochir Suppl 86: 395-7.

Gao, G. P., G. Qu, et al. (1998). "High-titer adeno-associated viral vectors from a Rep/Cap cell line and hybrid shuttle virus." Hum Gene Ther 9(16): 2353-62.

Geller, A. I., L. Yu, et al. (1997). "Helper virus-free herpes simplex virus-1 plasmid vectors for gene therapy of Parkinson's disease and other neurological disorders." Exp Neurol 144(1): 98-102.

Geller, H. M. and J. W. Fawcett (2002). "Building a bridge: engineering spinal cord repair." Exp Neurol 174(2): 125-36.

Giese, K. P., R. Martini, et al. (1992). "Mouse P0 gene disruption leads to hypomyelination, abnormal expression of recognition molecules, and degeneration of myelin and axons." Cell 71(4): 565-76.

Golden, K. L., D. D. Pearse, et al. (2007). "Transduced Schwann cells promote axon growth and myelination after spinal cord injury." Exp Neurol 207(2): 203-17. 
Graeber, M. B., R. B. Banati, et al. (1989). "Immunophenotypic characterization of rat brain macrophages in culture." Neurosci Lett 103(3): 241-6.

Grill, R., K. Murai, et al. (1997). "Cellular delivery of neurotrophin-3 promotes corticospinal axonal growth and partial functional recovery after spinal cord injury." J Neurosci 17(14): 5560-72.

Guenard, V., N. Kleitman, et al. (1992). "Syngeneic Schwann cells derived from adult nerves seeded in semipermeable guidance channels enhance peripheral nerve regeneration." J Neurosci 12(9): 3310-20.

Guerette, B., J. T. Vilquin, et al. (1996). "Prevention of immune reactions triggered by first-generation adenoviral vectors by monoclonal antibodies and CTLA4Ig." Hum Gene Ther 7(12): 1455-63.

Guest, R. S., K. J. Klose, et al. (1997). "Evaluation of a training program for persons with SCI paraplegia using the Parastep 1 ambulation system: part 4. Effect on physical self-concept and depression." Arch Phys Med Rehabil 78(8): 804-7.

Guth, L., Z. Zhang, et al. (1994). "Spinal cord injury in the rat: treatment with bacterial lipopolysaccharide and indomethacir enhances cellular repair and locomotor function." Exp Neurol 126(1): 76-87.

Hadlock, T., C. Sundback, et al. (2000). "A polymer foam conduit seeded with Schwann cells promotes guided peripheral nerve regeneration." Tissue Eng 6(2): 119-27.

Hadlock, T., C. Sundback, et al. (1999). "A novel, biodegradable polymer conduit delivers neurotrophins and promotes nerve regeneration." Laryngoscope 109(9): 1412-6.

Heredia, M., J. Gascuel, et al. (1998). "Two novel monoclonal antibodies (1.9.E and 4.11.C) against olfactory bulb ensheathing glia." Glia 24(3): 352-64.

Hermens, W. T. and J. Verhaagen (1997). "Adenoviral vector-mediated gene expression in the nervous system of immunocompetent Wistar and T cell-deficient nude rats: preferential survival of transduced astroglial cells in nude rats." $\underline{\text { Hum Gene Ther }}$ 8(9): 1049-63. 
Hermens, W. T. and J. Verhaagen (1998). "Suppression of inflammation by dexamethasone prolongs adenoviral vector-mediated transgene expression in the facial nucleus of the rat." Brain Res Bull 47(2): 133-40.

Heumann, R. (1987). "Regulation of the synthesis of nerve growth factor." J Exp Biol 132: $133-50$.

Houweling, D. A., A. J. Lankhorst, et al. (1998). "Collagen containing neurotrophin-3 (NT-3) attracts regrowing injured corticospinal axons in the adult rat spinal cord and promotes partial functional recovery." Exp Neurol 153(1): 49-59.

Houweling, D. A., J. T. van Asseldonk, et al. (1998). "Local application of collagen containing brain-derived neurotrophic factor decreases the loss of function after spinal cord injury in the adult rat." Neurosci Lett 251(3): 193-6.

Huber, A. B., M. U. Ehrengruber, et al. (2000)). "Adenoviral gene transfer to the injured spinal cord of the adult rat." Eur J Neurosci 12(9): 3437-42.

Hurtado, A., L. D. Moon, et al. (2006). "Poly (D,L-lactic acid) macroporous guidance scaffolds seeded with Schwann cells genetically modified to secrete a bifunctional neurotrophin implanted in the completely transected adult rat thoracic spinal cord." Biomaterials 27(3): 430-42.

Iannotti, C., H. Li, et al. (2003). "Glial cell line-derived neurotrophic factor-enriched bridging transplants promote propriospinal axonal regeneration and enhance myelination after spinal cord injury." Exp Neurol 183(2): 379-93.

Jakobsson, J., C. Ericson, et al. (2003). "Targeted transgene expression in rat brain using lentiviral vectors." J Neurosci Res 73(6): 876-85.

Jiao, S., L. Cheng, et al. (1993). "Particle bombardment-mediated gene transfer and expression in rat brain tissues." Biotechnology (N Y) 11(4): 497-502. 
Jimenez Hamann, M. C., C. H. Tator, et al. (2005). "Injectable intrathecal delivery system for localized administration of EGF and FGF-2 to the injured rat spinal cord." Exp Neurol 194(1): 106-19.

Jin, Y., I. Fischer, et al. (2002). "Transplants of fibroblasts genetically modified to express BDNF promote axonal regeneration from supraspinal neurons following chronic spinal cord injury." Exp Neurol 177(1): 265-75.

Johansen, J., C. Rosenblad, et al. (2002). "Evaluation of Tet-on system to avoid transgene down-regulation in ex vivo gene transfer to the CNS." Gene Ther 9(19): 1291301.

Johansson, C. B., S. Momma, et al. (1999). "Identification of a neural stem cell in the adult mammalian central nervous system." Cell 96(1): 25-34.

Johansson, F., P. Carlberg, et al. (2006). "Axonal outgrowth on nano-imprinted patterns." Biomaterials 27(8): 1251-8.

Johnson, R. D., J. S. Taylor, et al. (1995). "Rescue of motoneuron and muscle afferent function in cats by regeneration into skin. I. Properties of afferents." $\underline{\mathbf{J}}$ Neurophysiol 73(2): 651-61.

Kakulas, A. (1988). "The applied neurobiology of human spinal cord injury: a review." Paraplegia 26(6): 371-9.

Kam, L., W. Shain, et al. (2001). "Axonal outgrowth of hippocampal neurons on microscale networks of polylysine-conjugated laminin." Biomaterials 22(10): 1049-54.

Kanellopoulos, G. K., H. Kato, et al. (1997). "Spinal cord ischemic injury. Development of a new model in the rat." Stroke 28(12): 2532-8.

Kao, C. C., L. W. Chang, et al. (1977). "The mechanism of spinal cord cavitation following spinal cord transection. Part 3: Delayed grafting with and without spinal cord retransection." J Neurosurg 46(6): 757-66. 
Kao, C. C., L. W. Chang, et al. (1977). "Axonal regeneration across transected mammalian spinal cords: an electron microscopic study of delayed microsurgical nerve grafting." Exp Neurol 54(3): 591-615.

Kaplan, D. R. and F. D. Miller (1997). "Signal transduction by the neurotrophin receptors." Curr Opin Cell Biol 9(2): 213-21.

Katayama, Y., R. Montenegro, et al. (2006). "Coil-reinforced hydrogel tubes promote nerve regeneration equivalent to that of nerve autografts." Biomaterials 27(3): 505-18.

Keirstead, H. S. and W. F. Blakemore (1999). "The role of oligodendrocytes and oligodendrocyte progenitors in CNS remyelination." Adv Exp Med Biol 468: 18397.

Kermani, P. and B. Hempstead (2007). "Brain-derived neurotrophic factor: a newly described mediator of angiogenesis." Trends Cardiovase Med 17(4): 140-3.

Khan, T., M. Dauzvardis, et al. (1991). "Carbon filament implants promote axonal growth across the transected rat spinal cord." Brain Res 541(1): 139-45.

Khor, E. and L. Y. Lim (2003). "Implantable applications of chitin and chitosan." Biomaterials 24(13): 2339-49.

Kidoaki, S., I. K. Kwon, et al. (2005). "Mesoscopic spatial designs of nano- and microfiber meshes for tissue-engineering matrix and scaffold based on newly devised multilayering and mixing electrospinning techniques." Biomaterials 26(1): 37-46.

King, C., R. Lacey, et al. (2004). "Characterisation of tectal ephrin-A2 expression during optic nerve regeneration in goldfish: implications for restoration of topography." Exp Neurol 187(2): 380-7.

Kobayashi, N. R., D. P. Fan, et al. (1997). "BDNF and NT-4/5 prevent atrophy of rat rubrospinal neurons after cervical axotomy, stimulate GiAP-43 and Talpha1tubulin mRNA expression, and promote axonal regeneration." J Neurosci 17(24): 9583-95. 
Kohn, D. B., M. Sadelain, et al. (2003). "Occurrence of leukaemia following gene therapy of X-linked SCID." Nat Rev Cancer 3(7): 477-88.

Kordower, J. H., J. Bloch, et al. (1999). "Lentiviral gene transfer to the nonhuman primate brain." Exp Neurol 160(1): 1-16.

Koshinaga, M. and S. R. Whittemore (1995). "The temporal and spatial activation of microglia in fiber tracts undergoing anterograde and retrograde degeneration following spinal cord lesion." J Neurotrauma 12(2): 209-22.

Lacorazza, H. D., J. D. Flax, et al. (1996). "Expression of human beta-hexosaminidase alpha-subunit gene (the gene defect of Tay-Sachs disease) in mouse brains upon engraftment of transduced progenitor cells." Nat Med 2(4): 424-9.

Lakatos, A., R. J. Franklin, et al. (2000). "Olfactory ensheathing cells and Schwann cells differ in their in vitro interactions with astrocytes." Glia 32(3): 214-25.

Lal, P. G., R. S. Ghirnikar, et al. (1996). "Astrocytoma and Schwann cells in coculture." Mol Chem Neuropathol 29(1): 93-104.

Le Gal La Salle, G., J. J. Robert, et al. (1993). "An adenovirus vector for gene transfer into neurons and glia in the brain." Science 259(5097): 988-90.

Lemons, M. L., D. R. Howland, et al. (1999). "Chondroitin sulfate proteoglycan immunoreactivity increases following spinal cord injury and transplantation." Exp Neurol 160(1): 51-65.

Levi-Montalcini, R. (1987). "The nerve growth factor 35 years later." Science 237(4819): 1154-62.

Lewin, G. R. and Y. A. Barde (1996). "Physiology of the neurotrophins." Annu Rev Neurosci 19: 289-317. 
Li, Y., P. M. Field, et al. (1998). "Regeneration of adult rat corticospinal axons induced by transplanted olfactory ensheathing cells." J Neurosci 18(24): 10514-24.

Li, Y. and G. Raisman (1994). "Schwann cells induce sprouting in motor and sensory axons in the adult rat spinal cord." J Neurosci 14(7): 4050-63.

Lindholm, D. (1994). "Role of neurotrophins in preventing glutamate induced neuronal cell death." J Neurol 242(1 Suppl 1): S16-8.

Lindholm, D., M. Castren, et al. (1994). "Glucocorticoids and neurotrophin gene regulation in the nervous system." Arın N Y Acad Sci 746: 195-202; discussion 202-3.

Lindholm, D., M. da Penha Berzaghi, et al. (1994). "Brain-derived neurotrophic factor and neurotrophin-4 increase neurotrophin-3 expression in the rat hippocampus." Int J Dev Neurosci 12(8): 745-51.

Lindholm, D., J. Harikka, et al. (1994). "Fibroblast growth factor-5 promotes differentiation of cultured rat septal cholinergic and raphe serotonergic neurons: comparison with the effects of neurotrophins." Eur J Neurosci 6(2): 244-52.

Liu, X. Z., X. M. Xu, et al. (1997). "Neuronal and glial apoptosis after traumatic spinal cord injury." J Neurosci 17(14): 5395-406.

Liu, Y., B. T. Himes, et al. (1999). "Intraspinal delivery of neurotrophin-3 using neural stem cells genetically modified by recombinant retrovirus." Exp Neurol 158(1): 926.

Liu, Y., D. Kim, et al. (1999). "Transplants of fibroblasts genetically modified to express BDNF promote regeneration of adult rat rubrospinal axons and recovery of forelimb function." J Neurosci 19(11): 4370-87.

Loh, N. K., S. Woerly, et al. (2001). "The regrowth of axons within tissue defects in the CNS is promoted by implanted hydrogel matrices that contain BDNF and CNTF producing fibroblasts." Exp Neurol 170(1): 72-84. 
Love, R. (2006). "Stem-cell derived astrocytes promote repair of spinal cord." Lancet Neurol 5(6): 474-5.

Loy, D. N., D. S. Magnuson, et al. (2002). "Functional redundancy of ventral spinal locomotor pathways." J Neurosci 22(1): 315-23.

Lu, P., A. Blesch, et al. (2001). "Neurotrophism without neurotropism: BDNF promotes survival but not growth of lesioned corticospinal neurons." J Comp Neurol 436(4): 456-70.

Lu, P., L. L. Jones, et al. (2003). "Neural stem cells constitutively secrete neurotrophic factors and promote extensive host axonal growth after spinal cord injury." Exp Neurol 181(2): 115-29.

Lu, P. and M. H. Tuszynski (2007). "Growth factors and combinatorial therapies for CNS regeneration." Exp Neurol.

Lu, P., H. Yang, et al. (2006). "Olfactory ensheathing cells do not exhibit unique migratory or axonal growth-promoting properties after spinal cord injury." $\mathbf{J}$ Neurosci 26(43): 11120-30.

Lundberg, C., P. Horellou, et al. (1996). "Generation of DOPA-producing astrocytes by retroviral transduction of the human tyrosine hydroxylase gene: in vitro characterization and in vivo effects in the rat Parkinson model." Exp Neurol 139(1): 39-53.

Luo, Y. and M. S. Shoichet (2004). "A photolabile hydrogel for guided three-dimensional cell growth and migration." Nat Mater 3(4): 249-53.

Mangold, S., T. Keller, et al. (2005). "Transcutaneous functional electrical stimulation for grasping in subjects with cervical spinal cord injury." Spinal Cord 43(1): 1-13.

Maniwa, S., A. Iwata, et al. (2003). "Effects of neurotrophic factors on chemokinesis of Schwann cells in culture." Scand J Plast Reconstr Surg Hand Surg 37(1): 14-7. 
Manning, J. S., A. J. Hackett, et al. (1971). "Effect of polycations on sensitivity of BALD-3T3 cells to murine leukemia and sarcoma virus infectivity." Appl Microbiol 22(6): 1162-3.

Marchand, R., S. Woerly, et al. (1993). "Evaluation of two cross-linked collagen gels implanted in the transected spinal cord." Brain Res Bull 30(3-4): 415-22.

Mautes, A. E., M. R. Weinzierl, et al. (2000). "Vascular events after spinal cord injury: contribution to secondary pathogenesis." Phys Ther 80(7): 673-87.

McDonald, N. Q. and T. L. Blundell (1991). "Crystallization and characterization of the high molecular weight form of nerve growth factor (7 S NGF)." J Mol Biol 219(4): 595-601.

McTigue, D. M., P. J. Horner, et al. (1998). "Neurotrophin-3 and brain-derived neurotrophic factor induce oligodendrocyte proliferation and myelination of regenerating axons in the contused adult rat spinal cord." J Neurosci 18(14): $5354-65$.

Menei, P., C. Montero-Menei, et al. (1998). "Schwann cells genetically modified to secrete human BDNF promote enhanced axonal regrowth across transected adult rat spinal cord." Eur J Neurosci 10(2): 607-21.

Metz, G. A., A. Curt, et al. (2000). "Validation of the weight-drop contusion model in rats: a comparative study of human spinal cord injury." J Neurotrauma 17(1): 117.

Meyer, M., I. Matsuoka, et al. (1992). "Enhanced synthesis of brain-derived neurotrophic factor in the lesioned peripheral nerve: different mechanisms are responsible for the regulation of BDNF and NGF mRNA." J Cell Biol 119(1): 45-54.

Miller, C., S. Jeftinija, et al. (2002). "Synergistic effects of physical and chemical guidance cues on neurite alignment and outgrowth on biodegradable polymer substrates." Tissue Eng 8(3): 367-78.

Mohanna, P. N., R. C. Young, et al. (2003). "A composite poly-hydroxybutyrate-glial growth factor conduit for long nerve gap repairs." J Anat 203(6): 553-65. 
Montgomery, C. T. and J. A. Robson (1993). "Implants of cultured Schwann cells support axonal growth in the central nervous system of adult rats." Exp Neurol 122(1): 107-24.

Morrissey, T. K., N. Kleitman, et al. (1991). "Isolation and functional characterization of Schwann cells derived from adult peripheral nerve." J Neurosci 11(8): 2433-42.

Nagatsu, T. (2002). "Parkinson's disease: changes in apoptosis-related factors suggesting possible gene therapy." J Neural Transm 109(5-6): 731-45.

Nakahara, Y., F. H. Gage, et al. (1996). "Grafts of fibroblasts genetically modified to secrete NGF, BDNF, NT-3, or basic FGF elicit differential responses in the adult spinal cord." Cell Transplant 5(2): 191-204.

Nakamura, M. and B. S. Bregman (2001). "Differences in neurotrophic factor gene expression profiles between neonate and adult rat spinal cord after injury." Exp Neurol 169(2): 407-15.

Nakamura, M. and Y. Toyama (2003). "[Transplantation of neural stem cells into spinal cord after injury]." Nippon Rinsho 61(3): 463-8.

Naldini, L., U. Blomer, et al. (1996). "Efficient transfer, integration, and sustained longterm expression of the transgene in adult rat brains injected with a lentiviral vector." Proc Natl Acad Sci U S A 93(21): 11382-8.

Naldini, L., U. Blomer, et al. (1996). "In vivo gene delivery and stable transduction of nondividing cells by a lentiviral vector." Science 272(5259): 263-7.

Noakes, P. G. and M. R. Bennett (1987). "Growth of axons into developing muscles of the chick forelimb is preceded by cellls that stain with Schwann cell antibodies." $\underline{J}$ Comp Neurol 259(3): 330-47.

Noble, L. J. and J. R. Wrathall (1989). "Distribution and time course of protein extravasation in the rat spinal cord after contusive injury." Brain Res 482(1): 5766. 
Noguchi, P. (2003). "Risks and benefits of gene therapy." N Engl J Med 348(3): 193-4.

Ohashi, T., K. Watabe, et al. (1995). "Successful transduction of oligodendrocytes and restoration of arylsulfatase A deficiency in metachromatic leukodystrophy fibroblasts using an adenovirus vector." Gene Ther 2(7): 443-9.

Okano, H., Y. Ogawa, et al. (2003). "Transplantation of neural stem cells into the spinal cord after injury." Semin Cell Dev Biol 14(3): 191-8.

Olson, L., A. Nordberg, et al. (1992). "Nerve growth factor affects 11C-nicotine binding, blood flow, EEG, and verbal episodic memory in an Alzheimer patient (case report)." J Neural Transm Park Dis Dement Sect 4(1): 79-95.

Onifer, S. M., Y. P. Zhang, et al. (2005). "Adult rat forelimb dysfunction after dorsal cervical spinal cord injury." Exp Neurol 192(1): 25-38.

Oppenheim, R. W. and L. J. Haverkamp (1988). "Neurotrophic interactions in the development of spinal cord motoneurons." Ciba Found Symp 138: 152-71.

Oppenheim, R. W., L. J. Houenou, et al. (2000). "Glial cell line-derived neurotrophic factor and developing mammalian motoneurons: regulation of programmed cell death among motoneuron subtypes." J Neurosci 20(13): 5001-11.

Oppenheim, R. W., D. Prevette, et al. (1993). "Biological studies of a putative avian muscle-derived neurotrophic factor that prevents naturally occurring motoneuron death in vivo." J Neurobiol 24(8): 1065-79.

Oppenheim, R. W., D. Prevette, et al. (1991). "Control of embryonic motoneuron survival in vivo by ciliary neurotrophic factor." Science 251(5001): 1616-8.

Oppenheim, R. W., Q. W. Yin, et al. (1992). "Brain-derived neurotrophic factor rescues developing avian motoneurons from cell death." Nature 360(6406): 755-7. 
Oudega, M., S. E. Gautier, et al. (2001). "Axonal regeneration into Schwann cell grafts within resorbable poly(alpha-hydroxyacid) guidance channels in the adult rat spinal cord." Biomaterials 22(10): 1125-36.

Oudega, M. and T. Hagg (1996). "Nerve growth factor promotes regeneration of sensory axons into adult rat spinal cord." Exp Neurol 140(2): 218-29.

Oudega, M. and T. Hagg (1999). "Neurotrophins promote regeneration of sensory axons in the adult rat spinal cord." Brain Res 818(2): 431-8.

Oudega, M. and X. M. Xu (2006). "Schwann cell transplantation for repair of the adult spinal cord." J Neurotrauma 23(3-4): 453-67.

Paino, C. L. and M. B. Bunge (1991). "Induction of axon growth into Schwann cell implants grafted into lesioned adult rat spinal cord." Exp Neurol 114(2): 254-7.

Papastefanaki, F., J. Chen, et al. (2007). "Grafts of Schwann cells engineered to express PSA-NCAM promote functional recovery after spinal cord injury." Brain 130(Pt 8): 2159-74.

Pardridge, W. M. (2002). "Blood-brain barrier drug targeting enables neuroprotection in brain ischemia following delayed intravenous administration of neurotrophins." Adv Exp Med Biol 513: 397-430.

Parker, D. (2005). "Pharmacological approaches to functional recovery after spinal injury." Curr Drug Targets CNS Neurol Disord 4(2): 195-210.

Paulus, W., I. Baur, et al. (2000). "Variability of transcriptional regulation after gene transfer with the retroviral tetracycline system." J Biotechnol 81(2-3): 159-65.

Pear, W., Scott, M., and Nolan, G.P. (1997). Generation of high titre, helper-free retroviruses by transient transfection. In Methods in Molecular Medicine: Gene Therapy Protocols. Totowa, NJ, Humana Press.

Pear, W. S., G. P. Nolan, et al. (1993). "Production of high-titer helper-free retroviruses by transient transfection." Proc Natl Acad Sci U S A 90(18): 8392-6. 
Pearse, D. D., F. C. Pereira, et al. (2004). "cAMP and Schwann cells promote axonal growth and functional recovery after spinal cord injury." Nat Med 10(6): 610-6.

Pearse, D. D., A. R. Sanchez, et al. (2007). "Transplantation of Schwann cells and/or olfactory ensheathing glia into the contused spinal cord: Survival, migration, axon association, and functional recovery." Glia 55(9): 976-1000.

Peltekian, E., E. Parrish, et al. (1997). "Adenovirus-mediated gene transfer to the brain: methodological assessment." J Neurosci Methods 71(1): 77-84.

Piccirillo, C. A. and G. J. Prud'homme (2003). "Gene therapy with plasmids encoding cytokine- or cytokine receptor--IgG chimeric proteins." Methods Mol Biol 215: 153-70.

Pizzi, M. A. and M. J. Crowe (2006). "Transplantation of fibroblasts that overexpress matrix metalloproteinase- 3 into the site of spinal cord injury in rats." $\mathrm{J}$ Neurotrauma 23(12): 1750-65.

Plant, G. W., M. L. Bates, et al. (2001). "Inhibitory proteoglycan immunoreactivity is higher at the caudal than the rostral Schwann cell graft-transected spinal cord interface." Mol Cell Neurosci 17(3): 471-87.

Powell, E. M., J. W. Fawcett, et al. (1997). "Proteoglycans Provide Neurite Guidance at an Astrocyte Boundary." Mol Cell Neurosci 10(1/2): 27-42.

Prokopova-Kubinova, S., L. Vargova, et al. (2001). "Poly[N-(2hydroxypropyl)methacrylamide] polymers diffuse in brain extracellular space with same tortuosity as small molecules." Biophys J 80(1): 542-8.

Racine, R. J., B. Adams, et al. (2002). "Neural growth, neural damage and neurotrophins in the kindling model of epilepsy." Adv Exp Med Biol 497: 149-70.

Rajnicek, A. and C. McCaig (1997). "Guidance of CNS growth cones by substratum grooves and ridges: effects of inhibitors of the cytoskeleton, calcium channels and signal transduction pathways." J Cell Sci 110 ( Pt 23): 2915-24. 
Ramer, M. S., E. J. Bradbury, et al. (2003). "Glial cell line-derived neurotrophic factor increases calcitonin gene-related peptide immunoreactivity in sensory and motoneurons in vivo." Eur J Neurosci 18(10): 2713-21.

Ramer, M. S., J. V. Priestley, et al. (2000). "Functional regeneration of sensory axons into the adult spinal cord." Nature 403(6767): 312-6.

Ramon-Cueto, A. (2000). "Olfactory ensheathing glia transplantation into the injured spinal cord." Prog Brain Res 128: 265-72.

Ramon-Cueto, A., M. I. Cordero, et al. (2000). "Functional recovery of paraplegic rats and motor axon regeneration in their spinal cords by olfactory ensheathing glia." Neuron 25(2): 425-35.

Ramon-Cueto, A., G. W. Plant, et al. (1998). "Long-distance axonal regeneration in the transected adult rat spinal cord is promoted by olfactory ensheathing glia transplants." J Neurosci 18(10): 3803-15.

Rangappa, N., A. Romero, et al. (2000). "Laminin-coated poly(L-lactide) filaments induce robust neurite growth while providing directional orientation." J Mater Res 51(4): 625-34.

Richardson, P. M., U. M. McGuinness, et al. (1980). "Axons from CNS neurons regenerate into PNS grafts." Nature 284(5753): 264-5.

Rochkind, S., A. Shahar, et al. (2002). "Transplantation of embryonal spinal cord nerve cells cultured on biodegradable microcarriers followed by low power laser irradiation for the treatment of traumatic paraplegia in rats." Neurol Res 24(4): $355-60$.

Romero, M. I. and G. M. Smith (1998). "Adenoviral gene transfer into the normal and injured spinal cord: enhanced transgene stability by combined administration of temperature-sensitive virus and transient immune blockade." Gene Ther 5(12): $1612-21$. 
Rosenberg, M. B., T. Friedmann, et al. (1988). "Grafting genetically modified cells to the damaged brain: restorative effects of NGF expression." Science 242(4885): 15758.

Ruitenberg, M. J., G. W. Plant, et al. (2002). "Viral vector-mediated gene expression in olfactory ensheathing glia implants in the lesioned rat spinal cord." Gene Ther 9(2): 135-46.

Ruitenberg, M. J., G. W. Plant, et al. (2003). "Ex vivo adenoviral vector-mediated neurotrophin gene transfer to olfactory ensheathing glia: effects on rubrospinal tract regeneration, lesion size, and functional recovery after implantation in the injured rat spinal cord." J Neurosci 23(18): 7045-58.

Scaria, A., J. A. St George, et al. (1997). "Antibody to CD40 ligand inhibits both humoral and cellular immune responses to adenoviral vectors and facilitates repeated administration to mouse airway." Gene Ther 4(6): 611-7.

Schmitz, C. and P. R. Hof (2000). "Recommendations for straightforward and rigorous methods of counting neurons based on a computer simulation approach." J Chem Neuroanat 20(1): 93-114.

Schnell, L., R. Schneider, et al. (1994). "Neurotrophin-3 enhances sprouting of corticospinal tract during development and after adult spinal cord lesion." Nature 367(6459): 170-3.

Schnell, L. and M. E. Schwab (1990). "Axonal regeneration in the rat spinal cord produced by an antibody against myelin-associated neurite growth inhibitors." Nature 343(6255): 269-72.

Selvaggi, T. A., R. E. Walker, et al. (1997). "Development of antibodies to fetal calf serum with arthus-like reactions in human immunodeficiency virus-infected patients given syngeneic lymphocyte infusions." Blood 89(3): 776-9.

Shields, S. A., W. F. Blakemore, et al. (2000). "Schwann cell remyelination is restricted to astrocyte-deficient areas after transplantation into demyelinated adult rat brain." J Neurosci Res 60(5): 571-8. 
Sigman, H. H., M. H. Poleski, et al. (1991). "Effects of pirenzepine on acute mucosal erosions, gastric acid and mucosal blood flow in the spinal rat stomach." Digestion 49(4): 185-91.

Smith, G. M., J. Hale, et al. (1996). "Astrocytes infected with replication-defective adenovirus containing a secreted form of CNTF or NT3 show enhanced support of neuronal populations in vitro." Exp Neurol 139(1): 156-66.

Snider, W. D. (1994). "Functions of the neurotrophins during nervous system development: what the knockouts are teaching us." Cell 77(5): 627-38.

Sterne, G. D., R. A. Brown, et al. (1997). "Neurotrophin-3 delivered locally via fibronectin mats enhances peripheral nerve regeneration." Eur J Neurosci 9(7): 1388-96.

Steuer, H., R. Fadale, et al. (1999). "Biohybride nerve guide for regeneration: degradable polylactide fibers coated with rat Schwann cells." Neurosci Lett 277(3): 165-8.

Stokols, S. and M. H. Tuszynski (2004). "The fabrication and characterization of linearly oriented nerve guidance scaffolds for spinal cord injury." Biomaterials 25(27): 5839-46.

Strohmaier, C., B. D. Carter, et al. (1996). "A splice variant of the neurotrophin receptor trkB with increased specificity for brain-derived neurotrophic factor." EMBO J 15(13): 3332-7.

Sykova, E., P. Jendelova, et al. (2006). "Bone marrow stem cells and polymer hydrogels-two strategies for spinal cord injury repair." Cell Mol Neurobiol 26(7-8): 111329.

Takami, T., M. Oudega, et al. (2002). "Schwann cell but not olfactory ensheathing glia transplants improve hindlimb locomotor performance in the moderately contused adult rat thoracic spinal cord." J Neurosci 22(15): 6670-81.

Tan, S. A. and P. Aebischer (1996). "The problems of delivering neuroactive molecules to the CNS." Ciba Found Symp 196: 211-36; discussion 236-9. 
Tator, C. H. (1998). "Biology of neurological recovery and functional restoration after spinal cord injury." Neurosurgery 42(4): 696-707; discussion 707-8.

Taylor, L., L. Jones, et al. (2006). "Neurotrophin-3 gradients established by lentiviral gene delivery promote short-distance axonal bridging beyond cellular grafts in the injured spinal cord." J Neurosci 26(38): 9713-21.

Teng, Y. D., E. B. Lavik, et al. (2002). "Functional recovery following traumatic spinal cord injury mediated by a unique polymer scaffold seeded with neural stem cells." Proc Natl Acad Sci U S A 99(5): 3024-9.

Terada, N., L. M. Bjursten, et al. (1997). "Bioartificial nerve grafts based on absorbable guiding filament structures--early observations." Scand J Plast Reconstr Surg Hand Surg 31(1): 1-6.

Tessier-Lavigne, M. (1994). "Axon guidance by diffusible repellants and attractants." Curr Opin Genet Dev 4(4): 596-601.

Tessier-Lavigne, M. and C. S. Goodman (1996). "The molecular biology of axon guidance." Science 274(5290): 1123-33.

Titsworth, W. L., S. M. Onifer, et al. (2007). "Focal phospholipases A2 group III injections induce cervical white matter injury and functional deficits with delayed recovery concomitant with Schwann cell remyelination." Exp Neurol 207(1): 15062.

Tobias, C. A., J. S. Shumsky, et al. (2003). "Delayed grafting of BDNF and NT-3 producing fibroblasts into the injured spinal cord stimulates sprouting, partially rescues axotomized red nucleus neurons from loss and atrophy, and provides limited regeneration." Exp Neurol 184(1): 97-113.

Tomita, M., R. L. Khan, et al. (2004). "The potential pathogenetic link between peripheral immune activation and the central innate immune response in neuropsychiatric systemic lupus erythematosus." Med Hypotheses 62(3): 325-35. 
Tsoulfas, P., D. Soppet, et al. (1993). "The rat trkC locus encodes multiple neurogenic receptors that exhibit differential response to neurotrophin-3 in PC12 cells." Neuron 10(5): 975-90.

Tuschong, L., S. L. Soenen, et al. (2002). "Immune response to fetal calf serum by two adenosine deaminase-deficient patients after T cell gene therapy." Hum Gene Ther 13(13): 1605-10.

Tuszynski, M. H. and A. Blesch (2004). "Nerve growth factor: from animal models of cholinergic neuronal degeneration to gene therapy in Alzheimer's disease." Prog Brain Res 146: 441-9.

Tuszynski, M. H., K. Gabriel, et al. (1996). "Nerve growth factor delivery by gene transfer induces differential outgrowth of sensory, motor, and noradrenergic neurites after adult spinal cord injury." Exp Neurol 137(1): 157-73.

Tuszynski, M. H. and F. H. Gage (1995). "Bridging grafts and transient nerve growth factor infusions promote long-term central nervous system neuronal rescue and partial functional recovery." Proc Natl Acad Sci U S A 92(10): 4621-5.

Tuszynski, M. H., R. Grill, et al. (2003). "NT-3 gene delivery elicits growth of chronically injured corticospinal axons and modestly improves functional deficits after chronic scar resection." Exp Neurol 181(1): 47-56.

Tuszynski, M. H., D. A. Peterson, et al. (1994). "Fibroblasts genetically modified to produce nerve growth factor induce robust neuritic ingrowth after grafting to the spinal cord." Exp Neurol 126(1): 1-14.

Tuszynski, M. H., N. Weidner, et al. (1998). "Grafts of genetically modified Schwann cells to the spinal cord: survival, axon growth, and myelination." Cell Transplant 7(2): 187-96.

Urfer, R., P. Tsoulfas, et al. (1994). "The binding epitopes of neurotrophin-3 to its receptors trkC and gp75 and the design of a multifunctional human neurotrophin." Embo J 13(24): 5896-909. 
Wang, C. X., C. Reece, et al. (2002). "Expression of tumor necrosis factor alpha and its mRNA in the spinal cord following a weight-drop injury." Neuroreport 13(11): $1391-3$.

Watson, D. J., G. P. Kobinger, et al. (2002). "Targeted transduction patterns in the mouse brain by lentivirus vectors pseudotyped with VSV, Ebola, Mokola, LCMV, or MuLV envelope proteins." Mol Ther 5 (5 Pt 1): 528-37.

Weaver, L. C., D. R. Marsh, et al. (2006). "Autonomic dysreflexia after spinal cord injury: central mechanisms and strategies for prevention." Prog Brain Res 152: $245-63$.

Weiss, P. (1945). "Experiments on cell and axon orientation in vitro: The role of colloidal exudates in tissue organization." Journal of Experimental Zoology 100(3): 353386.

Wen, X. and P. A. Tresco (2006). "Effect of filament diameter and extracellular matrix molecule precoating on neurite outgrowth and Schwann cell behavior on multifilament entubulation bridging device in vitro." J Biomed Mater Res A 76(3): 626-37.

Whittemore, S. R. and L. A. White (1993). "Target regulation of neuronal differentiation in a temperature-sensitive cell line derived from medullary raphe." Brain Res 615(1): 27-40.

Woerly, S., V. D. Doan, et al. (2004). "Prevention of gliotic scar formation by NeuroGel allows partial endogenous repair of transected cat spinal cord." J Neurosci Res 75(2): 262-72.

Woolsey, D., Minckler, J., Rezende, N. (1944). Human Spinal Cord Transplant. experimental medicine and surgery.

Xu, X. M., A. Chen, et al. (1997). "Bridging Schwann cell transplants promote axonal regeneration from both the rostral and caudal stumps of transected adult rat spinal cord." J Neurocytol 26(1): 1-16. 
Xu, X. M., V. Guenard, et al. (1995). "A combination of BDNF and NT-3 promotes supraspinal axonal regeneration into Schwann cell grafts in adult rat thoracic spinal cord." Exp Neurol 134(2): 261-72.

Xu, X. M., V. Guenard, et al. (1995). "Axonal regeneration into Schwann cell-seeded guidance channels grafted into transected adult rat spinal cord." J Comp Neurol 351(1): 145-60.

Xu, X. M., S.-X. Zhang, et al. (1999). "Regrowth of axons into the distal spinal cord through a Schwann-cell-seeded mini-channel implanted into hemisected adult rat spinal cord." Eur J Neurosci 11(5): 1723-1740.

Xu, X. M., S. X. Zhang, et al. (1999). "Regrowth of axons into the distal spinal cord through a Schwann-cell-seeded mini-channel implanted into hemisected adult rat spinal cord." Eur J Neurosci 11(5): 1723-40.

Yamauchi, J., J. R. Chan, et al. (2003). "Neurotrophin 3 activation of TrkC induces Schwann cell migration through the c-Jun N-terminal kinase pathway." Proc Natl Acad Sci U S A 100(24): 14421-6.

Yamauchi, J., J. R. Chan, et al. (2004). "Neurotrophins regulate Schwann cell migration by activating divergent signaling pathways dependent on Rho GTPases." Proc Natl Acad Sci U S A 101(23): 8774-9.

Ye, J. H. and J. D. Houle (1997). "Treatment of the chronically injured spinal cord with neurotrophic factors can promote axonal regeneration from supraspinal neurons." Exp Neurol 143(1): 70-81.

Yick, L. W., P. T. Cheung, et al. (2003). "Axonal regeneration of Clarke's neurons beyond the spinal cord injury scar after treatment with chondroitinase ABC." Exp Neurol 182(1): 160-8.

Yick, L. W., W. Wu, et al. (2000). "Chondroitinase ABC promotes axonal regeneration of Clarke's neurons after spinal cord injury." Neuroreport 11(5): 1063-7. 
Zeng, Y. S., Y. Ding, et al. (2005). "Co-transplantation of schwann cells promotes the survival and differentiation of neural stem cells transplanted into the injured spinal cord." Dev Neurosci 27(1): 20-6.

Zhang, G., L. Q. Jin, et al. (2005). "Live imaging of regenerating lamprey spinal axons." Neurorehabil Neural Repair 19(1): 46-57.

Zhang, N., H. Yan, et al. (2005). "Tissue-engineering approaches for axonal guidance." Brain Res Brain Res Rev 49(1): 48-64.

Zhang, Z. and L. Guth (1997). "Experimental spinal cord injury: Wallerian degeneration in the dorsal column is followed by revascularization, glial proliferation, and nerve regeneration." Exp Neurol 147(1): 159-71.

Zhang, Z., C. J. Krebs, et al. (1997). "Experimental analysis of progressive necrosis after spinal cord trauma in the rat: etiological role of the inflammatory response." Exp Neurol 143(1): 141-52.

Zhang, Z., R. Yoo, et al. (2005). "Neurite outgrowth on well-characterized surfaces: preparation and characterization of chemically and spatially controlled fibronectin and RGD substrates with good bioactivity." Biomaterials 26(1): 47-61.

Zhao, C., P. M. Strappe, et al. (2003). "Lentiviral vectors for gene delivery to normal and demyelinated white matter." Glia 42(1): 59-67.

Zhou, L. and H. D. Shine (2003). "Neurotrophic factors expressed in both cortex and spinal cord induce axonal plasticity after spinal cord injury." J Neurosci Res 74(2): 221-6.

Zsengeller, Z. K., G. P. Boivin, et al. (1997). "Anti-T cell receptor antibody prolongs transgene expression and reduces lung inflammation after adenovirus-mediated gene transfer." Hum Gene Ther 8(8): 935-41. 


\section{APPENDDIX}

\section{LIST OF ABBREVIATIONS}

\begin{tabular}{|c|c|}
\hline ANOVA & analysis of variance \\
\hline APC & Adenopolyposis coli, oligodendrocyte antigen \\
\hline BDNF & brain derived neurotrophic factor \\
\hline CNS & central nervous system \\
\hline CNFT & Ciliary Neurotrophic factor \\
\hline CSF & cerebrospinal fluid \\
\hline CSPG & chondroitin sulfate proteoglycan \\
\hline CST & corticospinal tract \\
\hline $\mathrm{DC}$ & dorsal columns \\
\hline GFAP & glial fibrillary acidic protein \\
\hline IP & intraperitoneal \\
\hline NeuN & neuronal antigen \\
\hline $\mathrm{NF}-\mathrm{H}$ & neurofilament $(210 \mathrm{kDa})$ \\
\hline $\mathrm{NGF}$ & nerve growth factor \\
\hline $\mathrm{NT}-3$ & neurotrophin 3 \\
\hline NT-4 & neurotrophin 4 \\
\hline PB & phosphate buffer \\
\hline
\end{tabular}


PBS phosphate buffered saline

SC Schwann Cell

SCI spinal cord injury

SMI31 neurofilament antigen

TBS tris buffered saline

TNF tumor necrosis factor

$\beta$ III tubulin neuronal antigen 


\title{
CURRICULUM VITAE
}

\section{Ahmed Abdellatif, MD, MSc, PhD}

\author{
Education [1984-1991] \\ - $\quad$ Faculty of Medicine, Alexandria, Egypt. \\ MD \\ [1993-1997] \\ - $\quad$ Faculty of Medicine, Alexandria, Egypt. \\ Master's degree in anatomy and embryology \\ $[2000-2007]$ \\ - Anatomical Sciences \& Neurobiology, University of Louisville, \\ School of Medicine, Louisville, KY \\ Master's degree in Anatomical Sciences and Neurobiology 2004 \\ PhD in Anatomical Sciences and Neurobiology 2007
}

Clinical

[1991-1993]

Experience - Clinical internship in Alexandria University Hospitals,

Alexandria, Egypt

- General practice in rural areas of Behira, Egypt. 
- Resident in orthopedics at Damanhor Teaching hospital, Damanhor, Egypt.

[1993-2000]

- $\quad$ Private practice (surgery) in Alexandria, Egypt.

[19aching-2000]

Experience - Al-Azhar University, Faculty of Medicine, Asiut, Egypt.

- [1993-1997] Assistant Lecturer in Gross \& Neuroanatomy.

- [1997-2000] Lecturer in Gross and neuroanatomy.

[2000- current]

- University of Louisville, School of Medicine, Louisville.

- Teaching assistant medical neuroanatomy.

- Teaching assistant Dental gross anatomy summer course.

[11/2007]

- $\quad$ Assistant professor Biology

School of Natural and Health Sciences, Barry University,

Miami Shores, Fl.

[12/2007-current]

- $\quad$ Associate professor Biology

School of Natural and Health Sciences, Barry University, Miami Shores, Fl. 
Research [2001-2007]

Graduate Research assistant, Department of neurological surgery, Kentucky spinal cord injury research center, University of Louisville, School of Medicine.

Publications Ahmed A. Abdellatif, J.L. Pelt, R.L. Benton, RM Howard, P. Tsoulfas, P. Ping, X.M. Xu, S.R. Whittemore. Gene delivery to the spinal cord: comparison between lentiviral, adenoviral, and retroviral vector delivery systems. J Neurosci Res. 2006 Aug 15;84(3):553-67

Abdellatif $\boldsymbol{A} \boldsymbol{A}$, Pelt JL, Howard RM, Tsoulfas P, Ping P, Xu XM, Whittemore SR. Gene therapy for spinal cord injury: Comparison between lentiviral, adenoviral, and retroviral vector delivery systems. J Neurotrauma. NNS abstracts 2003

Membership Member of the society for neurosciences.

Member of the American Association of Anatomists

Member of the American Association of neural transplantation 